\title{
JOURNAL OF EUROMARKETING
}

\section{EDITOR-IN-CHIEF}

\author{
Pennsylvania State University at Harrisburg
}

\section{ASSOCIATE EDITOR}

AJAY K. MANRAI

University of Delaware
TECHNOLOGY AND E-COMMERCE EDITOR

KIP BECKER

Boston University

\section{BOOK REVIEW EDITOR}

ALI KARA

Pennsylvania State University at York

\section{EDITORIAL REVIEW BOARD MEMBERS}

\section{J. SCOTT ARMSTRONG}

University of Pennsylvania

SØREN ASKEGAARD

The University of Southern Denmark, Denmark

GEORGE BALABANIS

City University, United Kingdom

J. ENRIQUE BIGNE ALCANIZ

University of Valencia, Spain

DAVID J. CARSON

University of Ulster at Jordanstown, Northern Ireland

F. JAVIER RONDAN CATALUNA

University of Seville, Spain

CHISLAINE CESTRE

University of Lausanne, Switzerland

LEO PAUL DANA

University of Canterbury, New Zealand

SRINIVAS DURVASULA

Marquette University

YVONNE VAN EVERDINGEN

RSM Erasmus University, Netherlands

PERVEZ N. GHAURI

King's College, United Kingdom

KJELL GRONHAUG

Norwegian School of Economics and Business Administration, Norway

KLAUS GRUNERT

Aarhus University, Denmark

KARIN HOLSTIUS

Turku School of Economics and Business Administration, Finland

HARTMUT H. HOLZMUELLER

University of Dortmund, Germany

\author{
FREDERIC JALLAT \\ Paris Graduate School of Business (ESCP-EAP), France \\ MILAN JURSE \\ University of Maribor, Slovenia \\ JORMA LARIMO \\ University of Vaasa, Finland \\ TOMMI LAUKKANEN \\ University of Joensuu, Finland \\ STEVEN LYSONSKI \\ Marquette University \\ RITA MARTENSON \\ University of Gothenburg, Sweden \\ LUIZ MOUTINHO \\ University of Glasgow, United Kingdom \\ NOEL MURRAY \\ Chapman University \\ NEIL HERNDON \\ South China University of Technology, China \\ DAVID MCHARDY REID \\ Seattle University \\ DOMINIQUE ROUZIES \\ Groupe HEC, France \\ ARNOLD SCHUH \\ Vienna University of Economics and Business Administration, \\ Austria \\ BRUNO SERGI \\ University of Messina, Italy \\ D. DEO SHARMA \\ Stockholm School of Economics, Sweden \\ KENNETH SIMMONDS \\ London Business School, United Kingdom \\ NITISH SINGH \\ Saint Louis University
}

Indexed and/or Abstracted in: EBSCOhost Products; Emerald Management Reviews; Gale Cengage; Business ASAP, Cabell's Directory

Journal of Euromarketing (ISSN: 1049-6483) is published quarterly by IMDA Press, 1201 Stonegate Road, Hummelstown, PA 17036, USA.

US Postmaster: Please send address changes to Journal of Euromarketing, c/o IMDA Press, 1201 Stonegate Road, Hummelstown, PA 17036, USA.

Annual Subscription, Volume 20, 2011

Print ISSN: 1049-6483, Online ISSN: 1528-6967

Institutional subscribers: $\$ 600$, Personal subscribers: $\$ 125$. Institutional and individual subscriptions include access to the online version of the journal.

Production and Advertising Office: 1201 Stonegate Road, Hummelstown, PA 17036, USA. Tel: 717-566-3054, Fax: 717-566-1191. Production Editor: Ms. O. H. Burnett.

Subscription Office: IMDA Press, 1201 Stonegate Road, Hummelstown, PA 17036, USA. Tel: 717-566-3054, Fax: 717-566-1191.

For a complete guide to IMDA Press' journal and book publishing programs, visit our Web site: www.imda.cc

Copyright @ 2010 IMDA Press. All rights reserved. No part of this publication may be reproduced, stored, transmitted, or disseminated in any form or by any means without prior permission from IMDA Press. IMDA Press grants authorization for individuals to photocopy copyright material for private research use on the sole basis that requests for such use are referred directly to the requester's local Reproduction Rights Organization (RRO), such as the Copyright Clearance Center (www.copyright.com) in the USA or the Copyright Licensing Agency (www.cla.co.uk) in the United Kingdom This authorization does not extend to any other kind of copying by any means, in any form, and for any purpose other than private research use. The publisher assumes no responsibility for any statements of fact or opinion expressed in the published papers. The appearance of advertising in this journal does not constitute an endorsement or approval by the publisher, the editor-in-chief, or the editorial board of the quality or value of the product/service advertised or of the claims made for it by its manufacturer.

Permissions: For further information, please visit http://journals.sfu.ca/je/index.php/euromarketing/index

June 2011 


\section{JOURNAL OF EUROMARKETING}

Volume 20, Number 1\&2, 2011

\section{CONTENTS}

EDITORIAL

Erdener Kaynak

\section{ARTICLES}

The Effectiveness of Humor in Advertising: A Cross-cultural Study in

Germany and Russia

Stefan Muller, Stefab Hoffmann, Uta Schwartz, and Katja Gelbrich

Foreign Direct Investment in Emerging East European Markets: A Call for

Research in a Complex, Dynamic and Continually Evolving Domain

Marina Dabic, R. Glenn Richey, and Frank G. Adams

Small to Medium Enterprises in the Danish Conference Sector and a 360-degree

Approach to Managing Customer Relationships

Trevor Hartland, Britt Damkjaer, Christopher Miller, and Brychan Thomas

Diffusion and Consumer Use of the Internet: A Cross-National Investigation

David B. Kuhlmeier

How Global are Global Brands? An Empirical Brand Awareness and Image Analysis

Thomas Cleff, Cesar Javier Sepulveda Martinez, and Nadine Walter

Profiles and Preferences of Online Millennial Shoppers in Bulgaria and Croatia

Patricia R. Loubeau, Elitsa Alexander, and Georgi Kalchev

Uses and Gratifications of the Internet in Emerging Markets: The Case of Serbia

And Ukraine

Gladys Torres Baumgarten and William L. James

\section{BOOK REVIEW}

Next Generation Business Strategic for the Base of the Pyramid: New 


\section{EDITORIAL}

In this new volume, I am very pleased to present to you a total of seven manuscripts on different aspects of European marketing from a cross-national and cross-cultural perspectives. A wide variety of papers are presented by authors of European origin as well as those from outside of Europe who have a keen interest in European marketing issues. There is one unifying theme ingrained in all of the articles- that is increasing importance of Europe in a globalizing world. Some authors term this as a Europe factor. All of the predictions for the future is that new Europe will gain increased prominence through inter and intra trade in major industries.

Although humor is extensively used as an advertising device in many countries, the question of whether humor is evaluated differently across cultures has not been answered appropriately yet. While some authors argue that humor is a "cultural universal", others suggest that humor has universal (e.g., sense of humor) as well as cultural-specific (e.g., expression and perception of different humor types) characteristics. Yet, the discussion lacks empirical evidence.

To date, the effectiveness of humor has not been analyzed in a cross-cultural setting. To fill this void, Muller et al integrate the type of humor in the well-established attitude toward the ad-model of humor. The authors propose that the core model (perceived level of humor $\rightarrow$ attitude toward the ad $\rightarrow$ attitude toward the brand) is culturally invariant while the extended part of the model (type of humor $\rightarrow$ perceived level of humor) is assumed to be culturally variant.
To test their research questions, the authors conducted an experiment with three fictitious print ads (aggressive humor, nonsense humor, no humor). 257 Russian and German respondents are surveyed. They choose Russia and Germany to test the suggested model as these two countries differ significantly with respect to the two GLOBE-dimensions perfor-mance orientation and in-group collectivism, which are assumed to interact with type of humor on perceived level of humor.

The study results show that culture (in-group collectivism, performance orientation) moderates the relation between humor type (aggressive, nonsense) and perceived level of humor while the influence of perceived level of humor on attitudes toward the ad and the brand is culturally stable.

The research by Dabic et al. examines the effects of foreign direct investment (FDI) in emerging European economies and poses a new call for research. Although the question of FDI effects has received extensive attention in the current literature, changing conditions in Europe make this area of study ripe for additional investigation. To make that case, this research compared a previously planned (command) economy of Croatia with a traditionally free-market economy -Turkey) and discovered three important outcomes.

The goals and expected outcomes of established firms in the European FDI market are subject to significant variance. Firms must find ways to exploit global cycles of economic instability, political volatility, and stagnation while 
defining strategic goals and expectations for an FDI.

The changes in economic conditions in emerging European economies, particularly formerly planned economy nations, require additional research. Firms need more infor-mation to help pinpoint when and where to enter the best global locations not only for the benefit of stakeholders, but for the long-term benefit of economic transactions in general.

Perhaps most importantly, from a public policy standpoint, governments should think deeper about the fit of an FDI to their economic environment. Generally, more FDI is better, but while "low-performing economies" need FDI to initiate the restructuring that improves their competitiveness, not all emerging markets need the same FDI. If new entry cuts existing local employment-the foreign investment could have a negative implication. Governance of who, when, and where is vitally important to FDI and host country success.

Many corporate enterprises use customer relationship management (CRM) techniques to manage customer information in order to attain competitive advantage. The purpose of the study by Hartland et al. was to understand how small to medium enterprises (SMEs) in the Danish conference sector manage and build customer relationships and to investigate the extent to which they were prepared to adopt a 360-degree view when pursuing a customer relationship management approach.

The study investigated four SMEs operating in the conference sector in Denmark using a triangulated case study methodology as advocated by Yin (2009). This partly contri-buted to the validity of the findings but was also reinforced by using a qualitative approach undertaken in a rigorous way in order to generate themes, identify issues and explore discourses. The justification of using the conference sector as an exemplar, and the rationale for the study being based on the selected four firms, was according to the fact that the sector was appropriate because of the nature of the inter-firm relationships.
As argued by CRM advocates (CRMGURU, 2004) issues such as education and knowledge relating to the competitive advantages CRM and a 360-degree approach could provide for SMEs were strong factors and a possible reason why SMEs had been slow in achieving a 360-degree approach.

The literature pointed towards very limited evidence to claim any indications about SMEs being fully prepared to adopt a 360-degree view approach. The empirical findings illustrated more conviction indicating the view that SMEs in the Danish conference sector were in the process of adopting a CRM approach and focusing increasingly on establishing a 360-degree view for each customer. Analysis of the findings showed that SMEs were still very slow in the development process due to educational, financial and organizational barriers/challenges, and although using multiple channels and possible touch points to approach individual customers, they appeared to be not fully prepared to adopt a 360-degree view at this present time.

The benefit of a 360-degree view is unique customer information collected through a number of integrated channels and converted into valuable insights based on thorough analysis of past customer purchases across all channels. In terms of originality/value the paper indicates that although SME's in the sector focus increasingly on building and managing individual customer relationships, they appear not to be fully prepared to achieve a 360-degree view.

As an international marketing tool, the Internet presents a powerful means by which to efficiently and effectively reach customers worldwide. Consequently, there is a need to understand what factors may differ across cultures in how potential customers may adopt technology. It has already been established that culture does influence a user's perception of IT innovations (e.g., Chiu, Fang, \& Tseng, 2010; Jarvenpaa, Tractinsky, Saarinen, \& Vitale, 1999; Robichaux, \& Cooper, 1998; Straub, Keil, \& Brenner, 1997) and that the acceptance rate of such technologies can vary 
across national settings (e.g., Thornton \& Marche, 2003). The adoption of the Internet, as a particular type of IT, to make purchases is also likely to vary according to various factors (McCoy, Galletta, \& King, 2007; Singh, Fassott, Chao, \& Hoffmann, 2006), including culture (Van Slyke, Lou, Belanger, \& Sridhar, 2010). The Internet's dynamic nature and tendency to be influenced by such factors as culture, perception of risk, and experience warrant additional research into consumers' online purchase intentions.

Not only is Internet technology itself challenging because of its complex and dynamic nature, but the acceptance and presence of Internet technology in a particular country may differ as a result of cultural influences. One method of explaining as to how technologies are adopted that is often cited is the Technology Acceptance Model (TAM) first proposed by Davis (1989). The TAM implies that the perceived usefulness and perceived ease of use of a technology will influence attitudes towards its use. Since the TAM may not apply to all international settings, McCoy, Galletta, and King (2007) warn that caution and rigorous testing should be exercised when applying it in multi-cultural contexts. Equally relevant to how the acceptance and adoption of a technology is influenced by its diffusion as an innovation is the work of Rogers (1983). According to Rogers, the rate of adoption of an innovation was based on the user's perception of the innovation's attributes, i.e. "in the eye of the beholder" (1983, p. 212). Rogers (1983) then posited five attributes or characteristics of an innovation that appeal to the perception of the user to make it distinct from previous technologies: relative advantage, compatibility, complexity, trialability, and observability.

A survey questionnaire was constructed by David B. Kuhlmeier to collect primary data from consumers in the USA and France regarding their use of the Internet, perceptions of risk, and online purchase intentions. Based on 344 usable responses (193 in France and 151 in the USA), findings revealed that how often one uses the Internet is negatively and significantly related to Perceived Risk in the French sample, but not in the U.S. sample. Results also suggested that how long one has been using the Internet is negatively and significantly related to perceived risk in the U.S. sample, but not in the French sample. Finally, perceived risk of Internet-based purchases is significantly and negatively associated purchase intention in both the French and U.S. samples.

Notably, findings as to what influences perceived risk of the Internet are different between the two countries. The fact that length of use in France has an influence on risk is discussed in relation to France's previous adoption of the Minitel system and how it might influence its adoption of the Internet. These findings suggest that antecedents and use of the Internet to make purchases vary cross nationally. They also suggest that managers need to adapt their online strategies according to each international market.

Although many global companies design a global marketing mix for their products and services, consumers' perception of a brand can be quite different in international markets.

The first purpose of the research by Cleff et al was to analyse whether brand awareness and brand image for the same brand differ between international markets. Therefore the iPod brand has been analysed in Mexico and in Germany through a sample of a total of 722 students in both countries during May and June 2009. According to the results, awareness and image of the iPod were different in the two countries: Brand recall of the iPod is higher among Mexicans (78\%) than in Germans (62\%). Also, the brand iPod is more highly regarded in Mexico than in Germany and in most attributes Mexicans have a better brand image of iPod than Germans (regarding brand attitude, functional and emotional brand associations, brand personality). The second purpose of this research was to examine which influencing factors drive these brand image differences. It was discovered that 
satisfaction, usage rate and purchase influence (recommendation and ownership) are the most important factors with an impact on brand image perception. The findings suggest that due to the significant brand image differences driven by various influencing factors, a standardized global marketing mix might not do the brand differences justice.

One of the challenges created by global ecommerce is how to understand markets and groups of potential customers on the Internet. Misunderstanding consumer preferences can cause a successful strategy in one country to fail elsewhere. In this light, there may be a need for micro marketing to countries as niche markets. Although there have been a number of studies done on Internet usage and e-shopping, no such study has been undertaken in Eastern Europe and especially in Bulgaria and Croatia. The research by Loubeau et al. has been undertaken with this perspective. Central and Eastern Europe (CEE) in general and Bulgaria and Croatia specifically are an important context to investigate in light of recent social, political and cultural changes. These countries have a more recent engagement with global consumerism and a more recent exposure to internet shopping opportunities. As transitional economies, adoption of e-commerce services for them is a significant element of economic development.

Bulgarian and Croatian youth provides enormous online buying promise, with the most regular online buyers in these two countries being millennials (those born between 1977 and 1990). Based on data acquired from 527 surveys distributed among college students, this study empirically assessed the factors affecting the online purchase among Bulgarian and Croatian millennials. The results obtained indicated a significant difference in the online shopping behavior between the Eastern-European region of Bulgaria and Croatia and the rest of the world.

While convenience is reported as the most common reason for online shopping worldwide, the primary reason Bulgarian and Croatian mil- lennials shop online is the pursuit of better prices. If we compare Bulgarian and Croatian prices to Western-European and US prices we note an interesting trend. While the majority of consumer prices tend to be significantly higher in Western Europe and US compared to Bulgaria and Croatia, there is one exception, i.e. prices of brand name products. This finding indicates that there seems to be a promising niche market for selling brand name products to Bulgarian and Croatian youth online. This finding should be of value to retailers interested in buying behaviors and attitudes of emerging e-commerce markets towards products and services.

In Croatia and Bulgaria "apparel and accessories" is among the most purchased categories online. Bulgarian millennials are buying primarily apparel and accessories online while looking for better prices. This may be a logical response to the higher disparity between Bulgarian and Western-European brand-name-apparel prices. Another reason may be the limited opportunities for purchasing a variety of brand names locally. The managerial imply-cations of this finding would be to develop marketing strategies and solutions for this promising emergent niche market.

While security concerns are reported as a major online shopping barrier globally, EasternEuropean millennials are more concerned with the inability to see, feel or touch the item online, rather than security. One possible explanation is the typical youth optimism and feeling of invincibility. This finding can be explained by the Bulgarian cash on delivery (COD) method which does not require providing personal information like a credit card number. Online payment methods (e.g. credit card payment systems, digital wallet and stored value payment systems), while growing in importance, are still not very prevalent in Eastern Europe. This study reveals the need for public-policy initiatives to educate the Eastern-European youth about online security and the risks of non-secure online transactions. Such efforts should go hand in hand with a broader public policy aimed at 
improving the digital payment infrastructure to ensure further economic development.

"Audio-video" is among the least purchased categories online in Croatia and Bulgaria, which deviates significantly from the high popularity of this category on a global scale. This may be due to the fact that most audio-video is illegally acquired in Bulgaria and Croatia. Upon the recommendation of the International Intellectual Property Alliance (IIPA), Bulgaria was added to the Special 301 Watch List in 2003. Bulgaria's overall enforcement system against piracy, especially optical media piracy, continues to be ineffective. The findings of this study reveal the need of improving the overall public policy against illegal audio-video downloads in Eastern Europe.

Generation Y consumers are an influential online shopping segment. Understanding the similarities and differences among millennials in different regions is crucial for both marketing theory and practice. The results of this study are likely to have wider implications for both the research and practice of implementing ecommerce in the context of developing countries.

Consumers use the Internet for many purposes but social gratification is a growing motivation as exemplified by the growth of social media. While the increasing usage of the internet for social gratification is better documented in developed economies (e.g. email, facebook, twitter) the study by Baumgarten and James focuses on the differences between heavy and light users in two European emerging markets, Ukraine and Serbia. A sample of 798 respondents was obtained via interviews in Kiev and Belgrade. All respondents were computer users but only 578 were Internet users. Based on the number of hours per week spent on the internet in social gratification activities the upper and lower thirds were identified as heavy and light users. Analyses of differences between these two groups tested research propositions with respect to demographic and psychographic segmen-tation variables. Males, especially those with higher education are heavy users, suggesting that these consumers represent a segment rich for targeting via social media. Other findings were idiosyncratic to one country or another indicating a crucial role for cultural differences in these emerging markets. It is interesting that opinion leadership and attitudes towards risk in Internet shopping did not differentiate between light and heavy social gratification as motivations for Internet usage. Ukrainians low in Consumer Ethnocentrism were heavily motivated by social gratification suggesting that social media might be particularly useful for multinationals attempting to penetrate the Ukrainian market.

Enjoy reading the journal!

$$
\begin{aligned}
& \text { Erdener Kaynak } \\
& \text { Editor-in-Chief }
\end{aligned}
$$

\section{REFERENCES}

Chiu, T; Fang, S., and Tseng, C. (2010). Early versus potential adopters: Exploring the antecedents of use intention in the context of retail service innovations. International Journal of Retail and Distribution Management, 38(6), 443-451.

CRMGURU (2004), Understanding SMEs, Roundtable discussion, February 12

Jarvenpaa, S. L., Tractinsky, N., Saarinen, L., and Vitale, M. (1999). Consumer trust in an internet store: A cross-cultural validation. Journal of Computer-mediated Communications, 5(2), (December)

McCoy, S., Galletta, D., and King, W. (2007). Applying TAM across cultures: The need for caution. European Journal of Information Systems, 16(1), 81-90.

Robichaux, B. and Cooper, R. (1998). GSSparticipation: A cultural examination. Information and Management, 33, 287-300.

Rogers, E. M. (1983). Diffusion of Innovations. The Free Press, New York, NY.

Singh, N., Fassott, G., Chao, M., and Hoffmann, J. (2006). Understanding international web 
site usage: A cross-national study of German, Brazilian, and Taiwanese online consumers. International Marketing Review, 23(1), 83-98.

Straub, D., Keil, M., and Brenner, W. (1997). Testing the technology acceptance model across cultures: A three country study. Information and Management, 33, 1-11.

Thornton, J., and Marche, S. (2003). Sorting through the dot bomb rubble: How did the high-profile e-retailers fail? International Journal of Information Management, 23(2), 121-138.

Van Slyke, C., Lou, H., Belanger, F., and Sridhar, V. (2010). The influence of culture on consumer-oriented electronic commerce adoption. Journal of Electronic Commerce Research, 11(1), 30-40 


\title{
ARTICLES
}

\section{The Effectiveness of Humor in Advertising Cross-cultural Study in Germany and Russia}

\author{
Stefan Muller \\ Stefan Hoffmann \\ Uta Schwarz \\ Katja Gelbrich
}

\begin{abstract}
To date, the effectiveness of humor has not been analyzed appropriately in a crosscultural setting. Therefore, the paper examines whether the impact of humor type on perceived level of humor, attitude toward the ad, and attitude toward the brand depends on culture. An experiment with fictive print ads is conducted. 257 Russian and German respondents are surveyed. The results show that culture (in-group collectivism, performance orientation) moderates the relation between humor type (aggressive, nonsense) and perceived level of humor while the influence of perceived level of humor on attitudes toward the ad and the brand is culturally stable.
\end{abstract}

KEYWORDS. Humor, advertising effectiveness, cross-cultural comparison

\section{INTRODUCTION}

Cross-cultural comparisons have become a standard in international marketing research (e.g., Nakata \& Hung, 2005; Taras, Rowney, \& Steel, 2009; Yaprak, 2008). Among others, the influence of culture on advertising efficacy has widely been examined (e.g., Biswas, Hussain, \& O'Donnell, 2009; Okazaki \& Mueller, 2007; Sun, \& Wang, 2010; Zou, 2005). Within the debate about whether models of consumer behav- ior are culturally stable or culture-bound (e.g., Aaker \& Maheswaran, 1997; Durvasula, Andrews, Lysonski, \& Netemeyer, 1993), scholars examine if models of advertising efficacy can be generalized from one cultural setting to another (Okazaki, Taylor, \& Doh, 2007). We build on this research by analyzing the cross-cultural effects of humorous advertisements. Although humorous advertising is used extensively in many countries (e.g., Toncar, 2001), scholars have not yet answered the question of whether

Stefan Muller, Ph.D., Stefan Hoffmann, Ph.D., Uta Schwartz are affiliated with Department of Management and Economics, Chair of Marketing, Dresden University of Technology, 01062 Dresden, Germany. Katja Gelbrick, Ph.D., Faculty of Economic Sciences, Department of Marketing, 98693 Ilmenau, Germany

Address correspondence to Uta Schwartz, Chair of Marketing, Faculty of Business and Economics, Technical University of Dresden, 01062 Dresden, Germany. E-mail: uta.schwarz@tu-dresden.de 
humor is evaluated differently across cultures. Some argue that humor can be used as a tool of communication throughout the world (e.g., Nevo, Nevo, \& Yin, 2001). Others suggest that only the sense of humor is panhuman, whereas the expression and perception of different humor types are culture-bound (Eisend, 2009; Ziv, 1988). Yet, the discussion lacks empirical evidence.

The vast majority of cross-cultural studies on humorous advertisements are descriptive, applying content analysis to examine whether the frequencies of humor use and/or different humor types vary across cultures (Alden, Hoyer, \& Lee, 1993; Biswas, Olsen, \& Carlet, 1992; McCullough \& Taylor, 1993; Koudelova \& Whitelock 2001; Hatzithomas, Boutsouki, \& Zotos, 2009; Toncar, 2001; Weinberger \& Spotts, 1989). These studies typically compare relatively similar cultures (e.g., US vs. UK). Few scholars draw on Hofstede's (2001) cultural dimensions to select national cultures (Alden, Hoyer, \& Lee, 1993; Koudelova \& Whitelock, 2001) or offer ex-post explanations of crosscultural differences (Toncar, 2001). Unger (1995) is the only one to analyze the effectiveness of humor in advertising across cultures, applying countries as a proxy-variable for different cultural settings. Recently, Lee and Lim (2008) measured culture on an individual level and examined the moderating impact of cultural orientation within an intra-cultural study.

With respect to Finnish and American respondents, Unger (1995) shows that perceived humor enhances attitudes toward the ad (Aad), which, in turn, improves attitudes toward the brand (Abr). Her findings suggest that this model of humor in persuasion is cross-culturally invariant. However, the study is based on convenience samples of two Western cultures, which are both industrialized and individualistic. Moreover, the type of humor is not considered. This drawback is crucial, because the type of humor may affect the level of perceived humor, depending on the recipients' cultural back- ground (Eisend, 2009). For example, Western people usually appreciate aggressive humor, whereas in relationship-oriented cultures, such as Confucian countries, defensive types of humor seem to be most appropriate (Nevo, Nevo, \& Yin, 2001). Hence, although humor is universal, certain types of humor may not be perceived as humorous in certain cultures.

Lee and Lim (2008) show that the effectiveness of humorous ads depends on how the humorous process (with or without incongruity resolution; with or without arousal safety) interacts with the respondent's cultural orientation (uncertainty avoidance and individualism). For two reasons, they could not answer the question of how culture interacts with these processes. First, the study consists of several isolated analyses. Neither different humorous processes nor cultural orientations are compared simultaneously. Second, the study actually is an intracultural comparison: all respondents are Chinese and, thus, only the individual cultural orientation within one cultural setting is considered.

To sum up, no cross-cultural study on the effectiveness of humor in advertising draws on cultural theories to systematically select prototypes of national cultures. Moreover, no study incorporates the relationship between type of humor and perceived level of humor, which may be contingent on culture, into the Aad-model of humor (Zhang, 1996a). We fill this void by integrating type of humor into this model. Using culture as a moderator variable, we propose and test, that only the core model 'perceived level of humor $\rightarrow$ attitude toward the ad $\rightarrow$ attitude toward the brand' is culturally invariant (figure 1). The extended part of the model (i.e., 'type of humor $\rightarrow$ perceived level of humor'), however, is assumed to be culturally variant. We draw on House, Javidian, Hanges, and Dorfman's (2002) GLOBE-framework, which seems to be more useful for cross-cultural research than other approaches because of its theoretical foundation and actuality (Okazaki \& Mueller, 2007). 
Figure 1: Extended Culture-Contingent Aad-Model Of Humor In Persuasion

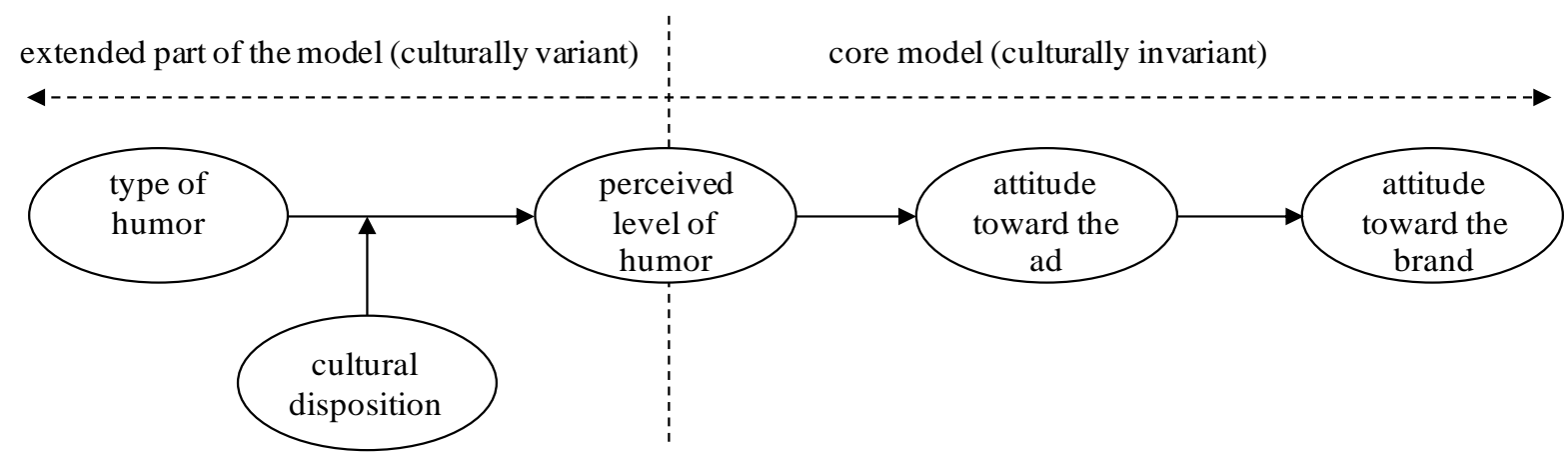

\section{CONCEPTUAL BACKGROUND AND HYPOTHESES}

\section{Culturally Invariant Part of the Model}

People across the world are humorous and laugh at funny situations (Nevo, Nevo, \& Yin, 2001). Smiling and laughter are physiological manifestations of humor observed in any culture (Ziv, 1988). These bodily expressions have a releasing effect triggering positive emotions (Adelmann \& Zajonc, 1989).

To explain the effectiveness of humorous advertising, most scholars draw on the Aadmodel (e.g., Zhang, 1996a), which builds on the assumption that humorous ads trigger releasing laughter and positive emotions (e.g., Gelb \& Pickett, 1983). These emotions, in turn, foster a positive Aad (Zhang \& Zinkhan, 2006; Zhang, 1996b). Due to conditioning processes, attitude toward the ad (Aad) serves as a mediator of attitude toward the product/brand (Abr) and of purchase intention (MacKenzie, Lutz, \& Belch, 1986). Hence, we argue cultural invariance for the core model

H1. The core model of humor in persuasion ('perceived level of humor $\rightarrow$ Aad $\rightarrow$ Abr') is culturally invariant.

\section{Culturally Variant Part of the Model}

While the sequencing "perceived level of humor $\rightarrow$ Aad $\rightarrow$ Abr" is well established, this model does not explain why an ad is perceived as funny. This drawback requires an extension of the model because intentionally humorous advertising messages will only have the desired persuasive effect, if they are actually perceived as humorous. Hence, we incorporate type of humor as an antecedent to perceived level of humor into the Aad-model of humor in persuasion as displayed in figure 1. Freud (1963) distinguished two types of humor: tendentious wit (aggressive and sexual humor) and nontendentious wit (nonsense humor). His wide-spread approach has been applied and enhanced by numerous authors (Goldstein \& McGhee, 1973; Speck, 1990; McCullough \& Taylor, 1993). Accordingly, we also draw on aggressive humor (as a form of tendentious wit) and nonsense humor (nontendentious wit) in the extended part of our model. Aggressive humor involves disparagement in order to enhance the self at the expense of others. The characters shown in ads are criticized, and, thus, the recipient feels superior. As criticism is expressed in a playful and ironic manner, recipients experience malicious joy ( $\mathrm{La}$ Fave, 1972). Nonsense humor is based on incongruity-resolution. It contains incongruent messages, which appear to have not the expected meaning (McCullough \& Taylor, 1993). To decode the ambivalent message, the recipient has to engage in cognitive activity. After having recognized the cause of incongruity, tension is drained by a releasing laughter (Suls, 1972).

For two reasons, we assume that what is considered funny or amusing differs from culture to culture. First, certain types of humor may 
be appropriate for certain situations or people within one culture, whereas they are taboos in other cultures. Humorous disparagement of people in a higher position is well-accepted in Western societies, but not in Confucian societies, where face giving and face taking are cultural standards. Second, members of different cultures may prefer certain types of humor. Italians, for instance, prefer jokes with sexual associations, while Germans derive more pleasure from humor based on incongruity-resolution (Ruch \& Forabosco, 1996). Therefore, we suppose that the impact of the type of humor on the perceived humorousness of print ads is moderated by culture.

$\mathrm{H} 2$. The influence of the type of humor on the perceived level of humor is moderated by culture.

To test our assumption, we draw on the GLOBE dimensions 'in-group collectivism' and 'performance orientation' (House, Hanges, Javidian, Dorfman, \& Gupta, 2004) because they are supposed to moderate the impact of type of humor on perceived level of humor. Ingroup-collectivism captures the type of relationship between individuals within a society (e.g., the degree to which people are affiliated with their families and focus on relationships with others, rather than on their own individual needs). In collectivistic cultures, such as Eastern European countries, individual needs are subordinate to group needs. In individualistic cultures, such as Western countries, people are more concerned with their individual well-being (Gelfand, Bhawuk, Nishii, \& Bechtold, 2004). Furthermore, to solve problems or unknown situations they are used to take personal engagement. In order to resolve the incongruity in nonsense ads, recipients need to consider the ambiguous situation and to search for explanations. Members of individualistic cultures are more willing and able to decode contradictory messages and they feel more joy by resolving incongruity, whilst their collectivistic counterparts tend to accept ambiguity. Therefore we assume the following effect for nonsense-humor ads:

$\mathrm{H} 2 \mathrm{a}$. Nonsense humor in advertising is perceived as more humorous in individualistic than in collectivistic cultures.

Performance orientation reflects the extent to which a society encourages competition and power (Javidan, 2004). In cultures with a low performance orientation, it is accepted that people differ in their ability to contribute to social welfare. Unprivileged members of a society can count on empathy and support. Performance orientation is likely to affect perceptions of aggressive humor in advertising because this type of humor relies on criticizing or denigrating others (e.g., politicians, blondes) in an ironic and sneering manner (Martin, 2007). We expect recipients in cultures with a low performance orientation to refrain from such criticism, whereas it may be more desirable in performance orientated cultures:

$\mathrm{H} 2 \mathrm{~b}$. Aggressive humor in advertising is perceived as more humorous in cultures with a high performance orientation than in cultures with a low performance orientation.

The core model suggests that the perceived level of humor affects Aad and Abr (see H1). We assume that the interaction effect between type of humor and culture (see $\mathrm{H} 2 \mathrm{a}$ and $\mathrm{H} 2 \mathrm{~b}$ ) spills over to Aad and Abr (MacKenzie et al., 1986):

$\mathrm{H} 3 \mathrm{a} / \mathrm{b}$. The interaction effect between type of humor and culture spills over from perceived level of humor to Aad (a) and Abr (b).

\section{METHOD}

\section{Choice of Cultures and Sampling Method}

We choose Russia and Germany for several reasons to test the suggested moderated model of the effectiveness of humor in cross-cultural 
advertising. First, Russia displays the greatest cultural distance of all GLOBE-countries to Germany (5.46) according to the formula by Kogut and Singh (1988). Second, their national cultures differ significantly with respect to the two GLOBE-dimensions (table 1), which are assumed to interact with type of humor on perceived level of humor. We base on the scores for practices ("as it is"), instead of the scores for values ("as it should be") because practice scores are less prone to social desirability (Javidian, 2004). Russia (5.83) scores higher on in-group-collectivism than Germany (4.16). The mean of all countries is $M=5.12(S D=.71)$. Similarly, Russia (3.53) scores lower than Germany (4.42) on performance orientation $(M=4.08 ; S D=.38)$. Third, Russia and Germany are widely disregarded by cross-cultural advertising research. Fourth, they represent markets with a substantial population and purchasing power.

To assure demographic equivalence of the two cultural subsamples (e.g., age and education), we collected data from business students (Calder, Philipps, \& Tybout, 1981). Of course, our intention to draw homogeneous subsamples restricts external validity, which should be assessed in further research. Subjects were invited to participate in an online survey outside of class. Altogether, 98 Russian and 159 German students completed the questionnaire, which constitutes a response rate of $75 \%$ for Russia and $60 \%$ for Germany. $71.4 \%$ of the Russian subjects and $57.9 \%$ of the German subjects are female.

\section{Treatment}

We employed a $2 \times 3$ mixed factorial design with culture (Russia, Germany) as the betweensubjects variable, and type of advertising (aggressive humor, nonsense humor, no humor) as the within-subjects variable. We exposed each respondent to three print ads, which promote a fictitious chewing gum brand. In contrast to Unger (1995) and Lee and Lim (2008), who applied real ads, we developed the ads from scratch in order to keep influencing factors (i.e., advertised product, tonality etc.) constant across the three treatments. Using fictitious brands also prevents answer bias that is caused by individual brand awareness and preferences. The ads were developed in a series of qualitative pretests, with 21 Russian students and 23 German students, so as to ensure that the ads conveyed the intended type of humor. In the main study, each respondent was exposed to the ads in randomized order. Almost all elements of the ads are identical (e.g., typeface, layout, background). However, the characters represented by the advertisement models are different. The focal theme of the aggressive humor ad is a poorly groomed man. This advertising character obviously completely neglects his appearance, except for his teeth - he has a big smile on his face, and displays his spotless white teeth. It is as if he wishes to demonstrate the perfect condition of his teeth, he proudly presents a package

TABLE 1: Cultural Orientations of Germany and Russia

\begin{tabular}{lccc}
\hline & $\begin{array}{c}\text { Germany } \\
\text { M }\end{array}$ & $\begin{array}{c}\text { Russia } \\
\text { M }\end{array}$ & $\begin{array}{c}\text { Whole Sample } \\
\text { M (SD) }\end{array}$ \\
\hline $\begin{array}{l}\text { In-group collectivism } \\
\begin{array}{l}\text { The degree to which people focus on their relationships } \\
\text { with others rather than on their individual needs. }\end{array}\end{array}$ & 4.16 & 5.83 & $5.12(.71)$ \\
$\begin{array}{l}\text { Performance Orientation } \\
\text { The degree to which a society appreciates competition and } \\
\text { power. }\end{array}$ & 4.42 & 3.53 & $4.08(.38)$ \\
\hline
\end{tabular}

Notes. Cultural values measured on seven-point rating scales 
of chewing gum. The slogan "The one and only for dental hygiene" communicates the extraordinary strong cleaning power of the advertised chewing gum. The nonsense humor ad depicts a couple kissing each other. The slogan "Exchange and collect" has no obvious relation to the visual part of the ad. However, recipients could resolve this incongruity by realizing that the couple is probably exchanging a chewing gum when kissing. A non-humorous ad served as a control condition. It depicts a woman who smiles, exposing her well-brushed teeth.

Manipulation check included aggressiveness $(1=$ non-aggressive, $7=$ very aggressive $)$ and nonsense $(1=$ makes perfect sense, 7 = complete nonsense). An RM-ANOVA showed that the respondents perceive the aggressive humor ad as significantly more aggressive than the nonsense ad and the non-humorous ad $\quad\left(M_{\text {aggressive }}=4.99\right.$ vs. $\quad M_{\text {nonsense }}=3.43$ vs. $\left.M_{\text {no humor }}=3.12, F(2,251)=133.33, p<.001\right)$. Similarly, the nonsense ad was more intensively perceived as being nonsense than the aggressive ad and the non-humorous ad $\left(M_{\text {nonsense }}=4.35 \mathrm{vs}\right.$. $M_{\text {aggressive }}=3.54 \quad$ vs. $\quad M_{\text {no humor }}=3.26, \quad F(2$, $251)=30.98, p<.001)$.

\section{Measures}

Perceived level of humor was measured by four statements adapted and extended from Zhang and Zinkhan (2006) and from Cline, Altsech, \& Kellaris (2003). Following Unger (1995), Aad and Abr were measured by three and statements, respectively. Respondents evaluated these statements for each ad on sevenpoint rating scales $(1=$ disagree, $7=$ agree $)$. Back translation ensured the cross-cultural equivalence of the measurement instruments (Brislin, 1970). All measures, factor loadings and the correlation-matrix between the constructs are displayed in the Appendix.

\section{Confound Check}

To rule out group effects, we tested whether the two cultural samples differ with respect to sense of humor. T-tests indicated no significant difference with regard to two items measured on seven-point rating scales: "I have a great sense of humor" $\quad\left(M_{\text {Russia }}=4.51 ; \quad M_{\text {Germany }}=4.65\right.$; $t(255)=.91, \mathrm{~ns})$ and "Compared to others, I am more humorous" $\left(M_{\text {Russia }}=4.49 ; \quad M_{\text {Germa- }}\right.$ $\mathrm{ny}=4.35 ; t(255)=.89, \mathrm{~ns})$.

To control for confounding effects, we used ANOVA to check whether sex or sex $\mathrm{x}$ culture influence the dependent model variables (perceived level of humor, Aad, Abr) for any of the three ads. Neither of the results was significant.

\section{Course of Analysis}

The core model (H1) was tested using partial least squares (PLS) path modeling (Hair, Ringle, \& Sarstedt, 2011; Wold, 1982) and the software SmartPLS 2.0 (Ringle, Wende, \& Will, 2005). It has been recently demonstrated that this approach can feasibly be used in international marketing research (Henseler, Ringle, \& Sinkovics 2009). Moreover, we rely on the partial least squares procedure for estimating latent variables as we have to divide the sample of 257 respondents in two subgroups (Russia: $\mathrm{n}=98$; Germany: $n=159)$. Compared to covariancebased structural equation models, PLS is more robust for small sample sizes. Since PLS does not allow for statistical inference tests for the estimated path coefficients, we performed nonparametric bootstrapping procedure (Davison \& Hinkley, 1997; Efron \& Tibshirani, 1993) with 500 subsamples each. PLS estimates a path model on bases of each sample providing the means, standard errors, and confidence intervals for the estimates of all parameters. This information can be used for statistical inferences (e.g., t-tests; Chin 1998; Hair, Ringle, \& Sarstedt, 2011). Furthermore, this procedure is that it is easy to implement and no assumptions about the distribution of the population is required.

To test the core model's invariance across cultures, we used culture (Russia vs. Germany) as a moderating variable. We applied a special t-test for analyzing moderator effects within the PLS-approach, as suggested by Chin (2000). For 
this purpose, we first ran bootstrap re-samplings for the various groups. Then, t-values were calculated indicating the difference of the paths within the two samples, divided by a corrected term of a pooled estimator of variance.

In order to examine if culture moderates the relationship between type of humor and perceived level of humor (H2), we conducted an ANOVA with type of humor (aggressive humor, nonsense humor, no humor) and the interaction of humor and culture on perceived level of humor. Significant interactions would indicate cross-cultural variance of the extended model. Finally, we ran mediation analysis to test if the effect on perceived humor is transferred to Aad and $\mathrm{Abr}(\mathrm{H} 3)$.

\section{RESULTS}

\section{Culturally Invariant Part of the Model}

The PLS analysis shows that the empirical data fit the model. Factor loadings exceed the .7 threshold (see Appendix); Cronbach's Alpha $(\alpha)$ and composite reliability (CR) exceed the required levels of $\alpha \geq .7$ and $C R \geq .6$ (table 2). The average variance extracted (AVE) is greater than .5 (Bagozzi \& Yi, 1988). Using the test by
Fornell and Larcker (1981), we also find support of discriminant validity.

The bootstrapping procedure indicates that all path coefficients of the structural model significantly differ from zero in all subsamples $(\mathrm{t}(255)>1.98, \mathrm{p}<.05)$. All $\mathrm{R}$ squares of Aad and $\mathrm{Abr}$ are above $\mathrm{R}^{2}=.40$, with a maximum of $\mathrm{R}^{2}=.66$ for Abr for the aggressive humor ad in the German sample (figure 2). The lowest value is found for Aad for the nonsense humor ad in the German sample $\left(\mathrm{R}^{2}=.40\right)$. Moreover, the $\mathrm{Q}^{2}$ values associated with the Stone-GeisserCriterion are consistently higher than zero (Russia, aggressive humor: $\mathrm{Aad}=.61, \mathrm{Abr}=.57$; Russia, nonsense humor: $\mathrm{Aad}=.77$, Abr $=.71$; Germany, aggressive humor: Aad $=.73$, Abr $=$ .48 , Germany, nonsense humor: Aad $=.75$, Abr $=.70$ ), indicating that the model has predictive relevance (Chin, 1998).

According to Chin's (2000) formula, all tvalues of the group difference between the two cultures are far below the threshold of $t(255)=1.98$. Thus, moderator analysis yields insignificant $t$-values for the path from perceived level of humor to Aad, both for aggressive humor $(t(255)=.95$, ns $)$ and nonsense humor $(t(255)=.76, \mathrm{~ns})$. T-values for the path

TABLE 2: Local Fit Measures of the Measurement Model

\begin{tabular}{|c|c|c|c|c|c|c|c|c|}
\hline & \multicolumn{4}{|c|}{ Russia } & \multicolumn{4}{|c|}{ Germany } \\
\hline & $\alpha$ & CR & AVE & $\mathrm{FL}$ & $\alpha$ & CR & AVE & $\mathrm{FL}$ \\
\hline \multicolumn{9}{|l|}{ Aggressive humor } \\
\hline Perceived level of humor & .92 & .94 & .80 & $>.8$ & .93 & .97 & .88 & $>.9$ \\
\hline Aad & .89 & .93 & .82 & $>.8$ & .94 & .96 & .89 & $>.9$ \\
\hline Abr & .89 & .92 & .75 & $>.7$ & .96 & .95 & .82 & $>.8$ \\
\hline \multicolumn{9}{|l|}{ Nonsense humor } \\
\hline Perceived level of humor & .89 & .92 & .75 & $>.7$ & .95 & .96 & .86 & $>.9$ \\
\hline Aad & .95 & .97 & .91 & $>.9$ & .95 & .96 & .90 & $>.9$ \\
\hline Abr & .92 & .94 & .81 & $>.7$ & .91 & .94 & .79 & $>.7$ \\
\hline
\end{tabular}

Notes. $\alpha=$ Cronbach's alpha, CR=Composite reliability, AVE=Average variance explained, FL=Factor loading 
FIGURE 2: Results of a PLS Estimation for the Core Aad-Model of Humor in Persuasion

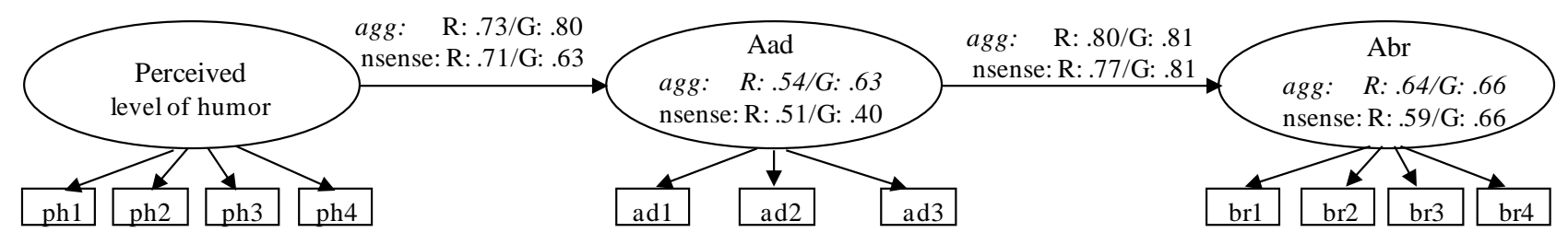

Notes: $\operatorname{agg}=$ aggressive humorad; nsense $=$ nonsense humorad; $\mathrm{R}=\mathrm{Russia} ; \mathrm{G}=$ Germany. $\mathrm{R}^{2}$ is displayed within the latent variables.

from Aad to Abr are also insignificant for aggressive humor $(t(255)=.15, \mathrm{~ns})$ and for nonsense humor, respectively $(t(255)=.56, \mathrm{~ns})$. Supporting $\mathrm{H} 1$, there is no significant difference in the core Aad-model of humor in advertising between the Russian and the German sample.

\section{Culturally Variant Part of the Model}

An RM-ANOVA indicates a significant effect of type of humor on perceived level of humor $\left(F(2,510)=69.84, p<.001 ; \eta^{2}=.22\right)$ as well as a significant interaction between type of humor and culture on perceived level of humor $(F(2$, $\left.510)=19.65, p<.001 ; \eta^{2}=.07\right)$, which supports H2. There is no significant main effect of culture on perceived level of humor ( $F(1$, $\left.510)=.68, p=.411 ; \eta^{2}=.003\right)$. Follow-up-ttests confirm that the perceived level of humor differs significantly between Russian and Ger- man participants for each type of humor (aggressive humor: $t(255)=-3.33, p<.001$; nonsense: $t(255)=-1.75, \quad p<.05 ; \quad$ no humor: $t(255)=-5.68, \quad p<.001$, one-tailed). Figure 3 indicates that German respondents perceive both the aggressive humor ad and the nonsense humor ad as more humorous than Russian respondents. Germany scores lower than Russia on in-group collectivism, but higher on performance orientation. This supports $\mathrm{H} 2 \mathrm{a}$ : nonsense humor in advertising is perceived as more humorous in individualistic (Germany) than in collectivistic cultures (Russia). It also supports $\mathrm{H} 2 \mathrm{~b}$ : aggressive humor in advertising is perceived as less humorous in cultures with a low performance orientation (Russia) than in cultures with a high performance orientation (Germany).

\section{FIGURE 3: Interaction Between Type of Humor and Culture on Perceived Level of Humor}

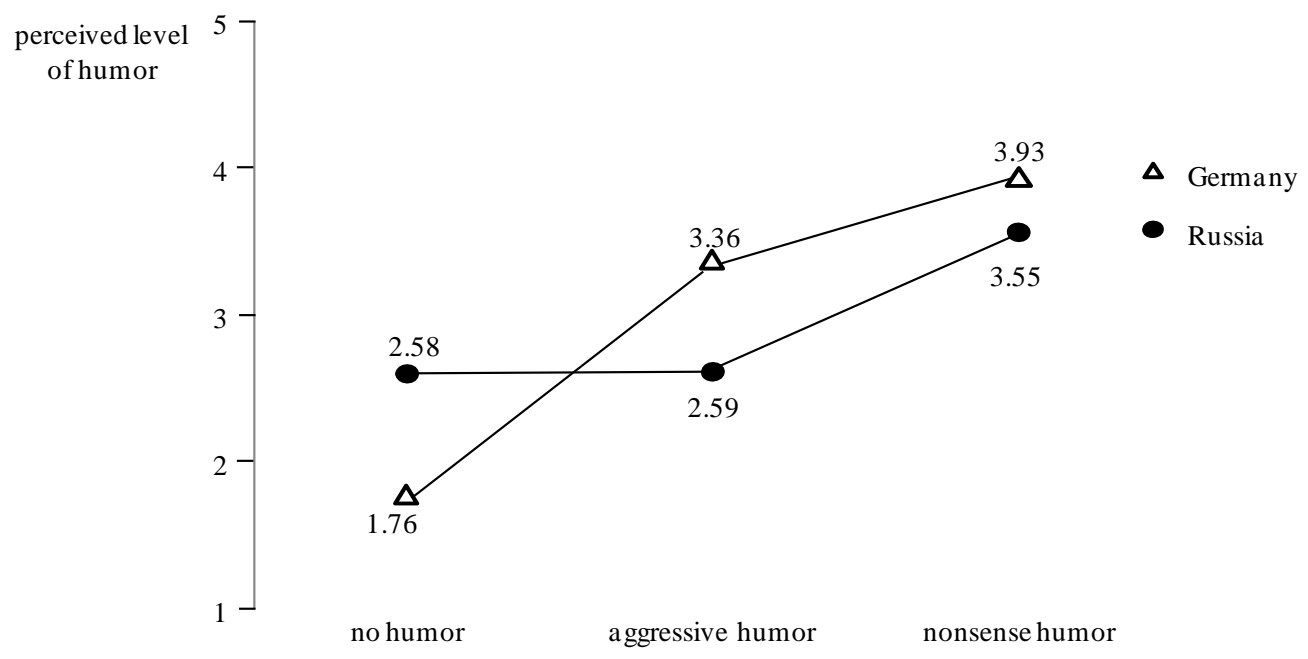

Notes: seven-point rating scales $(1=$ disagree, 7 = agree $)$ 
Although not specifically hypothesized, further culture-specific follow-up-t-tests are needed to examine which type of humor is most appropriate for each culture. Within the German sample, t-tests for dependent samples (two-tailed) indicate significant pairwise differences between all three types of humor (no humor vs. aggressive humor: $t(158)=-10.06, p<.001$; no humor vs. nonsense humor: $t(158)=-13.82$, $p<.001$; aggressive humor vs. nonsense humor: $t(158)=-3.03, p<.01)$. Within the Russian sample, t-tests reveal significant differences between no humor vs. nonsense humor $(t(97)=-5.78, p<.001)$ and aggressive humor vs. nonsense humor $(t(97)=-4.28, p<.001)$. No difference is found between no humor and aggressive humor $(t(97)=-.04, \mathrm{~ns})$.

\section{Mediation Effect of Perceived Level of Humor}

To test H3 (perceived level of humor mediates the relationship between type of humor and Aad and Abr), we compared two runs of an RMANOVA (table 2). In the first run, we specified type of humor as the independent variable and Aad as the dependent variable. In the second run, the influence of perceived level of humor was partialled out of the dependent variables by a preceding OLS regression. As table 2 shows, there is a significant influence of type of humor on $\operatorname{Aad}\left(p<.001 ; \eta^{2}=.280\right)$. In the second analysis, this effect disappears $\left(n s ; \eta^{2}=.001\right)$. Thus, the effect of type of humor on Aad is fully mediated by perceived level of humor. We repeated the procedure with Abr as the dependent variable. Again, as indicated by a significant influence of type of humor on Abr $(p<.001$; $\eta^{2}=.229$ ), a full mediation is confirmed. This effect disappears when the effect of perceived level of humor is partialled out $\left(\mathrm{ns} ; \eta^{2}=.000\right)$.

To test if the interaction between type of humor and culture is transferred from perceived level of humor to Aad (H3a) and Abr (H3b), we repeated both analyses with the interaction of type of humor and culture as the independent variable. Table 3 shows that the effect on Aad is partly mediated by perceived level of humor, decreasing the effect from $\eta^{2}=.053(p<.001)$ to $\eta^{2}=.014(p<.05)$. The effect on Abr is fully mediated by perceived level of humor, decreasing the effect from $\eta^{2}=.028(p<.001)$ to nonsignificance $\left(\mathrm{ns} ; \eta^{2}=.008\right)$. Hence, H3 is supported.

\section{DISCUSSION}

Our study confirms the core model suggesting a cross-culturally stable sequence of humor effects. Ads that are perceived as humorous strengthen Aad and Abr in both samples (H1). Additionally, the study confirms that the level of perceived humor depends on the interplay between the type of humor shown in the ad and the recipients' cultural embedding (H2). Finally, these effects spill over to Aad and Abr (H3). Thus, to explain how humorous advertising works across cultures, we need both the culturally invariant core-model and its extension by a culturally variant component.

Beyond testing our hypothesis, this study confirms that humorous ads are more efficient than non-humorous ads. This is true for nonsense humor in both countries analyzed. Ads

TABLE 3: Mediation Effect of Perceived Level of Humor

\begin{tabular}{llccccccc}
\hline & & \multicolumn{3}{c}{ Aad } & \multicolumn{3}{c}{ Abr } \\
\cline { 3 - 7 } & & $\mathrm{F}$ & $\mathrm{p}$ & partial $\eta^{2}$ & $\mathrm{~F}$ & $\mathrm{p}$ & partial $\eta^{2}$ \\
\hline \multirow{2}{*}{ Type of humor } & ANOVA & 99.07 & .000 & .280 & 75.80 & .000 & .229 \\
& ANCOVA & .20 & .821 & .001 & .11 & .895 & .000 \\
Type of humor $\boldsymbol{x}$ culture & ANOVA & 14.16 & .000 & .053 & 7.347 & .000 & .028 \\
& ANCOVA & 3.50 & .031 & .014 & 1.97 & .141 & .008 \\
\hline
\end{tabular}

Notes. ${ }^{*}$ The influence of the perceived level of humor is partialled out. 
applying aggressive humor are superior to nonhumorous ads only in Germany, but not in Russia. Nonsense humor is the more effective of the two types of humor considered, both in Russia and Germany. Thus, practitioners, who generally prefer to standardize advertisement campaigns throughout Eastern and Western countries (Schuh, 2000), might run the same campaign with nonsense humorous ads in both cultural areas. Conversely, caution is indicated when implementing aggressive humor: in Russia, ads of this type are not more effective than non-humorous ads. As suggested in $\mathrm{H} 2 \mathrm{~b}$, due to low performance orientation, the disparagement of the ad model is not perceived as funny. Additionally, the high level of human orientation in Russia (Bakacsi et al., 2002) might imply that the Russian participants are less amused by the disparagement. Hence, the use of aggressive ads is only advisable for Western markets like Germany.

Furthermore, our study shows that the effectiveness of non-humorous ads is significantly lower in Germany than in Russia. The reason is that, consumers have been intensively exposed to advertisements for decades in industrialized countries like Germany. These consumers have learned that advertising is a fictional game, designed primarily to entertain rather than to inform. Subsequently, German recipients expect exciting ads, whereas they consider informative, non-humorous ads as boring. Thus, the use of humorous ads is generally more advisable in saturated advertising markets. In transitional countries, such as Russia, consumers expect product information (Hoffmann \& Wittig, 2007).

Like every study, this study has also some limitations calling for further research. First, further research should consider additional types of humor. Warm humor, for instance, may be most appropriate in cultures with high levels of in-group collectivism because members of these cultures are particularly friendly, generous, and altruistic. Second, real brands should be examined to determine whether prior Abr moderates the effectiveness of humorous ads across cultures. Third, more cross-cultural studies are needed to investigate whether the effectiveness of aggressive and nonsense humor depends on the cultural profile of a country. Fourth, Russia is a society in transition, where consumers are likely to change values (Bakacsi, Sándor, András, \& Viktor, 2002; Jung et al., 2009), consumption attitudes and behaviors (Money \& Colton, 2000). Therefore, a replication study in a couple of years should test the stability of our results. Fifth, although student samples may provide a strong test of theory in cross-cultural research, ecological validity and generalizability of the results are restricted. Hence, further research should also use non-student populations. Finally, we consider Germany as an example of an individualistic culture with a high level of performance orientation and Russia as an example of a collectivistic that scores low on the dimension of performance orientation. Thus, more cross-cultural studies are needed to investigate whether the effectiveness of aggressive and nonsense humor depend on the cultural profile of a country.

\section{REFERENCES}

Aaker, J. L., \& Maheswaran, D. (1997). The effect of cultural orientation on persuasion. Journal of Consumer Research, 24(3), 315328.

Adelmann, P. K., \& Zajonc, R. B. (1989). Facial feedback and the experience of emotion. Annual Review of Psychology, 40(1), 249-280.

Alden, D. L., Hoyer, W. D., \& Lee, C. (1993). Identifying global and culture specific dimensions of humor in advertising. A multinational analysis. Journal of Marketing, 57(2), 64-76.

Bagozzi, R. P., \& Yi, Y. (1988). On the evaluation of structural equation models. Journal of the Academy of Marketing Science, 16(1), 74-94.

Bakacsi, G., Sándor, T., András, K., \& Viktor, I. (2002). Eastern European cluster: tradition 
and transition. Journal of World Business, 37(1), 69-80.

Biswas, S., Hussain, M., \& O’Donnell, K. (2009). Celebrity Endorsement in Advertisements and Consumer Perceptions: A Cross-Cultural Study. Journal of Global Marketing, 22(2), 121-137.

Biswas, A., Olsen, J. E., \& Carlet, V. (1992). A Comparison Of Print Advertisments From The United States And France. Journal of Advertising, 21(4), 73-81.

Brislin R. W. (1970). Back-Translation For Cross-Cultural Research. Journal of CrossCultural Psychology, 1, 185-216.

Calder, B., Phillips, L. W., \& Tybout, A. M. (1981). Designing Research For Application. Journal of Consumer Research, 8, 197-207.

Chin, W. W. (1998). The Partial Least Squares Approach to Structural Equation Modeling. in Marcoulides, G. A. (Ed.): Modern methods for business research (pp. 295-358). Mahwah: Lawrence Erlbaum.

Chin, W. W. (2000). Frequently asked questions - PLS and PLS Graph. available at http://disc-ntcba.uh.edu/chin/plsfaq/plsfaq.htm.

Cline, T. W., Altsech, M. B., \& Kellaris, J. J. (2003). When Does Humor Enhance or Inhibit Ad Responses? The Moderating Role of the Need for Humor. Journal of Advertising, 32(3), 31-45.

Davison, A. C., \& Hinkley, D. V. (1997). Bootstrap Methods and Their Application. Cambridge: Cambridge University Press.

Durvasula, S., Andrews, J. C., Lysonski, S., \& Netemeyer, R. G. (1993). Assessing the Cross-National Applicability of Consumer Behavior Models: A Model of Attitude Toward Advertising in General. Journal of Consumer Research, 19(4), 626-636.

Efron, B., \& Tibshirani, R. J. (1993). An Introduction to the Bootstrap. New York: Chapman Hall.

Eisend, M. (2009). A Meta-Analysis of Humor in Advertising. Journal of the Academy of Marketing Sciences, 37(2), 191-203.
Fornell, C., \& Larcker, D. F. (1981). Evaluating Structural Equation Models with Unobservable Variables and Measurement Error. Journal of Marketing Research, 18(1), 39-50.

Freud, S. (1963). Jokes and Their Relation to the Unconscious. New York: Norton. (originally published in German 1905).

Gelb, B. D., \& Pickett, C. M. (1983). AttitudeToward-The-Ad. Links to Humor and to Advertising Effectiveness, Journal of Advertising, 12(2), 34-42.

Gelfand, M. J., Bhawuk, D. P. S., Nishii, L. H., \& Bechtold, D. J. (2004). Individualism and Collectivism. In House, R. J., Hanges, P. J., Javidan, M., Dorfman, P. W., \& V. Gupta (Eds.), Culture, Leadership, and Organizations: The GLOBE Study of 62 Societies (pp. 437-512). Thousand Oaks: Sage.

Hair, J. F., Ringle, C. M., \& Sarstedt, M. (2011). PLS-SEM: Indeed a Silver Bullet. Journal of Marketing Theory and Practice, 19(2), 139151.

Hatzithomas, L., Boutsouki, C., \& Yorgos, Z. (2009). The Effects of Culture and Product Type on the use of Humor in Greek TV Advertising: An Application of Speck's Humorous Message Taxonomy. Journal of Current Issues and Research in Advertising, 31(1), 43-61.

Henseler, J., Ringle, C. M. and Sinkovics, R. R. (2009). The use of partial least squares path modeling in international marketing. In Sinkovics, R. R., \& P. N. Ghauri (Eds.), New Challenges to International Marketing. Advances in International Marketing (pp. 277319). Bingley: Emerald.

Hoffmann, S., \& Wittig, K. (2007). Adaptation of Advertisement Campaigns to Foreign Markets. A Content Analysis. Journal of European Economy, 6(2), 128-150.

Hofstede, G. (2001). Culture'S Consequences. Comparing Values, Behaviors, Institutions and Organisations Across Nations ( $2^{\text {nd }}$ ed.). Thousand Oaks: Sage. 
House, R. J. and Javidan, M. (2004). Overview of GLOBE. In House, R. J., Hanges, P. J., Javidan, M., Dorfman, P. W., \& V. Gupta (Eds.). The GLOBE Study of 62 Societies (pp. 9-28). Thousend Oaks: Sage.

House, R. J., Hanges, P. J., Javidan, M., Dorfman, P. W., \& Gupta, V. (2004). The GLOBE study of 62 societies. Thousand Oaks: Sage.

House, R. J., Javidan, M., Hanges, P., \& Dorfman, P. (2002). Understanding Cultures and Implicit Leadership Theories Across the Globe: An Introduction to Project GLOBE. Journal of World Business, 37(1), 3-10.

Javidian, M. (2004). Performance Orientation. In House, R. J., Hanges, P.J., Javidan, M., Dorfman, P.W., \& V. Gupta (Eds.). The GLOBE Study of 62 Societies (pp. 239-281). Thousand Oaks: Sage.

Kogut, B., \& Singh, H. (1988). The Effect of National Culture on the Choice of Entry Mode. Journal of International Business Studies, 19(3), 411-432.

Koudelova, R., \& Whitelock, J. (2001). A Cross-Cultural Analysis of Television Advertising in the UK and the Czech Republic. International Marketing Review, 18(3), 286300.

La Fave, L. (1972). Humor Judgments as a Function of Reference Groups and Identification Classes. In Goldstein, J. H., \& P. E. McGhee (Eds.). Theoretical Perspectives and Empirical Issues (pp. 195-210). New York: Academic Press.

Lee, Y. H., \& Lim, E. A. C. (2008). What's Funny and What's not. The Moderating Role of Cultural Orientation In Ad Humor. Journal of Advertising, 37(2), 71-84.

Fang, L., Cheng, H., \& Li, J. (2009). Consumer Responses to Sex Appeal Advertising: A Cross-Cultural Study. International Marketing Review, 26(4/5), 501-520.

MacKenzie, S. B., Lutz, R. J., \& Belch, G. E. (1986). The Role of Attitude Toward the Ad as a Mediator of Advertising Effectiveness: A Test of Competing Explanations. Journal of Marketing Research, 23(2), 130-143.
Martin, R. A. (2007). The psychology of humor. An integrative approach, Burlington: Elsevier.

McCullough, L. S., \& Taylor, R. (1993). Humor in American, British and German ads. Industrial Marketing Management, 22(1), 17-28.

Miller, J. G. (1984). Culture and Development of Everyday Social Explanation. Journal of Personality and Social Psychology, 46(5), 961-978.

Money, R. B., \& Colton, D. (2000). The Response of the 'New Consumer' to Promotion in the Transition Economies of the Former Soviet Bloc. Journal of World Business, 35(2), 189-205.

Nakata, C., \& Hung, Y. (2005). Progress and Promise: The Last Decade of International Marketing Research. Journal of Business Research, 58(7), 611-618.

Nevo, O., Nevo, B., \& Yin, J. L. S. (2001). Singaporean Humor. A Cross-Cultural CrossGender Comparison. Journal of General Psychology, 128(2), 143-157.

Okazaki, S., \& Mueller, B. (2007). CrossCultural Advertising Research: Where We Have Been and Where We Need to Go. International Marketing Review, 24(5), 499518.

Okazaki, S., Taylor, C. R., \& Doh, J. P. (2007). Market Convergence and Advertising Standardization in the European Union. Journal of World Business, 42(4), 384-400.

Ringle, C. M., Wende, S., \& Will, A. (2005). SmartPLS $2.0 \quad$ (beta). available at http://www.smartpls.de.

Ruch, W. (1996). A Cross-Cultural Study of Humor Appreciation: Italy and Germany. Humor, 9(1), 1-18.

Schuh, A. (2000). Global Standardization as a Success Formula for Marketing in Central Eastern Europe. Journal of World Business, 35(2), 133-148.

Speck, P. S. (1990). The Humorous Message Taxonomy. A Framework for the Study of Humorous Ads. Current Issues and Research in Advertising, 13(1), 1-44. 
Suls, J. M. (1972). Cognitive Processes in $\mathrm{Hu}-$ mor Appreciation. In Goldstein, J.H., \& P. E. McGhee (Eds.). Handbook of humor research (pp. 39-57), New York: Springer.

Sun, S., Wang, Y. (2010). Familiarity, Beliefs, Attitudes, and Consumer Responses Toward Online Advertising in China and the United States. Journal of Global Marketing, 23(2), 127-138.

Taras, V., Rowney, J., \& Steel, P. (2009). Half a Century of Measuring Culture: Review of Approaches, Challenges, and Limitations Based on the Analysis of 121 Instruments for Quantifying Culture. Journal of International Management, 15(4), 357-373.

Toncar, M. F. (2001). The Use of Humor In Television Advertising. Revisiting the USUK Comparison. International Journal of Advertising, 20(4), 521-39.

Unger, L. S. (1995). Observations: A CrossCultural Study on the Affect-Based Model in Advertising. Journal of Advertising Research, 35(1), 66-71.

Weinberger, M. G., \& Gulas, C. S. (1992). The Impact of Humor in Advertising. A review. Journal of Advertising, 21(4), 35-59.

Weinberger, M. G., \& Spotts, H. E. (1989). Humor in US vs. UK TV Commercials. A
Comparison. Journal of Advertising, 18(2), $39-42$.

Wold, H. (1982). Soft Modeling: The Basic Design and Some Extensions. In Jöreskog, K. G., \& Wold, H.(Eds.). Systems Under Direct Observations: Causality, Structure, Prediction (pp. 1-54), Amsterdam: North-Holland.

Yaprak, A. (2008). Culture Study in International Marketing: A Critical Review and Suggestions for Future Research. International Marketing Review, 25(2), 215-229.

Zhang, Y. (1996a). The Effect of Humor in Advertising: An Individual Difference Perspective. Psychology \& Marketing, 13(6), 531545.

Zhang, Y. (1996b). Responses to Humorous Advertising. the Moderating Effect of Need for Cognition. Journal of Advertising, 25(1), $15-32$.

Zhang, Y., \& Zinkhan, G. M. (2006). Responses to Humorous Ads. Does Audience Involvement Matter?. Journal of Advertising, 35(4), 113-27.

Ziv, A. (1988). National styles of humor. New York: Greenwood.

Zou, S. (2005). Contributions to International Advertising Research: An Assessment of the Literature Between 1990 and 2002. Journal of Advertising, 34(1), 99-110. 
APPENDIX 1: Measures of the Dependent Variables

\begin{tabular}{|c|c|c|c|c|c|c|c|c|}
\hline & \multicolumn{4}{|c|}{ nonsense humor } & \multicolumn{4}{|c|}{ aggressive humor } \\
\hline & \multicolumn{2}{|c|}{ Germany } & \multicolumn{2}{|c|}{ Russia } & \multicolumn{2}{|c|}{ Germany } & \multicolumn{2}{|c|}{ Russia } \\
\hline & $\mathrm{FL}$ & $\mathrm{R}$ & $\mathrm{FL}$ & $\mathrm{R}$ & $\mathrm{FL}$ & $\mathrm{R}$ & $\mathrm{FL}$ & $\mathrm{R}$ \\
\hline \multicolumn{9}{|l|}{ Perceived level of humor } \\
\hline The ad is humorous. (ph1) & .93 & \multirow{5}{*}{$.77-.85$} & .88 & \multirow{5}{*}{$.52-.78$} & .93 & \multirow{5}{*}{$.80-.95$} & .86 & \multirow{5}{*}{$.60-.91$} \\
\hline I was amused. (ph2) & .93 & & .93 & & .95 & & .93 & \\
\hline The ad is funny. (ph3) & .92 & & .78 & & .93 & & .93 & \\
\hline $\begin{array}{l}\text { I had to laugh when considering the } \\
\text { ad. (ph4) }\end{array}$ & .93 & & .86 & & .95 & & .95 & \\
\hline $\begin{array}{l}\text { Attitude toward the ad } \\
\text { I like the ad. (ad1) }\end{array}$ & 96 & & 95 & & .94 & & .94 & \\
\hline $\begin{array}{l}\text { I would enjoy seeing the ad again. } \\
\text { (ad2) }\end{array}$ & .93 & \multirow[t]{2}{*}{$.83-.90$} & .96 & \multirow[t]{2}{*}{$.85-89$} & .94 & \multirow[t]{2}{*}{$.82-.84$} & .94 & \multirow[t]{2}{*}{$.65-.87$} \\
\hline $\begin{array}{l}\text { The ad is likeable. (ad3) } \\
\text { Attitude toward the brand }\end{array}$ & .96 & & .94 & & .94 & & .83 & \\
\hline The brand is trustworthy. (br1) & .76 & \multirow{4}{*}{$.59-.86$} & .80 & \multirow{4}{*}{$.64-84$} & .86 & \multirow{4}{*}{$.70-.83$} & .77 & \multirow{4}{*}{$.59-.87$} \\
\hline The brand suits me. (br2) & .92 & & .93 & & .90 & & .85 & \\
\hline The brand is congenial. (br3) & .94 & & .94 & & .95 & & .94 & \\
\hline The brand appeals to me. (br4) & .93 & & .93 & & .91 & & .90 & \\
\hline
\end{tabular}

Notes. The figures indicate factor loadings and inter-item correlations

APPENDIX 2: Descriptive Statistics and Correlation Matrix

\begin{tabular}{|c|c|c|c|c|c|c|c|c|}
\hline & \multicolumn{4}{|c|}{ Russia } & \multicolumn{4}{|c|}{ Germany } \\
\hline & \multirow[t]{2}{*}{$\mathrm{M}(S D)$} & \multicolumn{3}{|c|}{$\mathrm{R}$} & \multirow[t]{2}{*}{$\mathrm{M}(S D)$} & \multicolumn{3}{|c|}{$R$} \\
\hline & & $\begin{array}{l}\text { Perceived } \\
\text { level } \\
\text { of humor }\end{array}$ & Aad & Abr & & $\begin{array}{c}\text { Perceived } \\
\text { level } \\
\text { of humor }\end{array}$ & Aad & Abr \\
\hline \multicolumn{9}{|l|}{ Aggressive } \\
\hline $\begin{array}{l}\text { Perceived } \\
\text { level of humor }\end{array}$ & 2.59 (1.67) & - & & & $3.36(1.87)$ & - & & \\
\hline Aad & $1.96(1.26)$ & .73 & - & & 2.64 (1.62) & .80 & - & \\
\hline $\mathrm{Abr}$ & $1.66(1.02)$ & .60 & .78 & - & $2.06(1.16)$ & .59 & .81 & - \\
\hline \multicolumn{9}{|l|}{$\begin{array}{l}\text { Nonsense } \\
\text { humor }\end{array}$} \\
\hline $\begin{array}{l}\text { Perceived } \\
\text { level of humor }\end{array}$ & 3.55 (1.61) & - & & & 3.93 (1.77) & - & & \\
\hline Aad & 3.81 (1.94) & .71 & - & & $4.50(1.61)$ & .63 & - & \\
\hline Abr & $2.90(1.61)$ & .68 & .76 & - & 3.55 (1.49) & .53 & .81 & - \\
\hline
\end{tabular}




\title{
Foreign Direct Investment in Emerging East European Markets: A Call for Research in a Complex, Dynamic and Continually Evolv- ing Domain
}

\author{
Marina Dabic \\ R. Glenn Richey, Jr. \\ Frank G. Adams
}

\begin{abstract}
Foreign direct investment is a domain of International Business research with a rich body of literature. Research has long looked at the environment, including foreign direct investment funding, technology and knowledge, as a determinant of business strategy. Tremendous and continual changes, including increasing globalization, the rise of economic unions, and overall market instability is creating an environment where researchers and practitioners need to revisit the industrial economic impacts on foreign direct investments and the impact of those investments on said economies. Moreover, with the saturation of "more developed" markets, many business are looking to emerging markets as the best venues for continued growth and potential profit expansion, introducing still further changes into the foreign direct investment landscape. This study suggests several areas for future research in foreign direct investment, by a brief comparison of the impact foreign direct investment has had on two important and very different emerging economies - Croatia and Turkey. The analysis draws the attention of scholars to the importance of continuing to study the impact that such investments have on these and similar developing or "redeveloping" economies.
\end{abstract}

KEYWORDS. Foreign Direct Investment, Global Marketing, Resource Development, EU, Turkey, Croatia, Industrial Economics

\section{INTRODUCTION}

All business ventures require resources to successfully compete in their chosen market (Barney, 1991; Morgan and Hunt, 1995), and understanding the growing influence of global factors on commercial exchange is one of the most important issues in marketing (Harvey, et al 2008). Foreign Direct Investment (FDI) has been cited in the literature as resource that profoundly influences the market environment, associated with displacement and disruption of firms in developing economies, but also as a source of new firm opportunity in developing economies as a result of industry growth (Burke et al., 2008).

In the last two decades, the rate of world trade growth has exceeded world income

Marina Dabic, Ph.D. is affiliated with Faculty of Economics and Business, University of Zagreb, J.F. Kennedy Square 6, Zagreb, Croatia. R. Glenn Richey, Jr. Ph.D. and Frank G. Adams are affiliated with Management and Marketing Department, The University of Alabama, 361 Stadium Drive, Tuscaloosa, AL 35487, USA.

Address correspondence to Marina Dabic, Professor of International Business and Entrepreneurship, Faculty of Economics and Business, University of Zagreb, Zagreb, Croatia. E-mail: mdabic@efzg.hr 
growth, and FDI has grown nearly twice as fast as the world income (OECD, 2002; UCTAD $2003,2004)^{1}$. New OECD members from the formerly planned economies of Central and Eastern Europe saw some of the world's most rapid growth in inward FDI. The contribution of FDI as a share of gross domestic product (GDP) in the new OECD members grew from close to zero in 1990 to about 47\% in 2006, approximately twice as much as the world average in that year (UNCTAD, 2007) . Thus, developing a better understanding the role FDI plays in shaping the growth of global trade is a matter of great importance to both scholars and practitioners (Markusen and Venables 1999).

FDI has been found to influence a variety of outcomes. Alfaro, et al. (2004), find that FDI provides lower costs to the investing country and creates more investment by parties in the recipient nation. At the same time, FDI contributes to technological development even more than domestic investment (Borensztein, et al. 1998). Contradictorily, FDI has been cited as detrimental to local performance in same industry, but creates local market resources that benefit domestic industry (Javorick 2004; Markusen and Venables 1999). However, there are findings that question the value of such local market resources (Görg and Greenway 2004). Further, variance in research findings (Kaminski, 2001; Bornstein et al. 1998; Tuselmann, 1999; Kuznecovs and Maslows, 2004; Barry, 2002, Brenton et al 1999), suggest that FDI is a highly dynamic phenomena.

This research is intended explore the question of whether findings in FDI can be considered as established, or whether they require periodic reexamination, and, if so, what questions need to be addressed by future research. This study approaches this question by briefly examining literature of the FDI domain, and then comparing the effects of FDI on two European economies: Croatia, a formally planned economy, and Turkey, a traditionally free market economy. Based on these analyses, future research areas for the FDI domain are suggested.

\section{CONCEPTUAL BACKGROUND}

As FDI continues to increase, it is important to note that the global distribution of investment varies among FDI recipient countries. Extant literature has unsuccessfully sought to explain this varying allocation of FDI into emerging/transitioning economies (Kaminski, 2001; Bornstein et al. 1998; Tuselmann, 1999; Kuznecovs and Maslows, 2004; Barry, 2002, Brenton et al 1999). Bennet and Green (1972), as an example, point out political instability as a determinant of FDI. Henisz' research (2000), one of the key motivators of this work, analyzed the importance of institutional economic environment for attractiveness of entry models and supporting a link between market entry mode choice and the degree of strategic uncertainty. Firms pursuing international business opportunities analyze a number of factors regarding the FDI location decision (Dunning, 1999, 2000; Porter, 2000, Makino, et al. 2004). Overall, Dunning $(1981 ; 2000 ; 2003)$, concluded that foreign countries that attract investments by multinational firms are typically defined by a large and growing market, a high gross domestic product (GDP), low factors of production costs, and relative political stability. Other authors have built upon Dunning's framework to empirically assess factors that influence FDI (Wasseem 2007) and the importance of country of origin (Wang, et al 2009). In addition to differences in economies that receive FDI, scholars have identified differences in the type of effects that FDI produces.

Bitzer and Görg (2005) provide an updated literature review with particular emphasis on the influence of inward and outward influence of FDI. They employ a large panel analysis of countries to explain that spillovers in one country can enable more general conclusions for the OECD as a group and open research for crosscountry variation. Bevan and Estrin (2000) found that FDI inflows to CEE are motivated by several factors including low unit labor costs; large market size; the credit rating of the FDI recipient country, and economic geography (ge- 
ographical proximity is associated with increased FDI).

At the same time, nations as diverse as the United States and the United Arab Emirates compete to attract foreign firm FDI inflows. While it seems plausible that FDI will be attracted to regions characterized by more favorable environmental factors (Kobrin 1976), legal systems (Perry, 2003), and governance infrastructures (Globeman and Shapiro1999, 2003, Daniel, 2002), all other things constant, most of the relevant literature has focused on economic determinants of FDI inflows. It is, of course, true that the international business literature has acknowledged the importance of countryspecific political risk (Kobrin, 1976, Ahmed et al.2002; Akhter and Lusch, 1988). As such, empirical analyses of FDI now routinely include variables to control for inter-country differences in the broad political environment so that volatility does not create study bias (Altomonte, 2000; Nicoletti et al. 2003; Bevan \& Estrin, 2000; Mody \& Srinivasan, 1998; Morisset, 2000; Stevens, 2000; Tuman \& Emmert, 1999), albeit with somewhat mixed results (Dawson, 1998). Nevertheless, a wide range of factors have been cited as antecedents of FDI effects, each with distinct limitations, suggesting a need for research models with more comprehensive controls.

Altomonte (2000), for example cited a need for greater resolution of industry-specific effects and the role of $R \& D$ versus other types of FDI. Nicoletti, et al. (2003) offers controls for macroeconomic factors, but not for variables of cultural distance. Bevan and Estrin, (2004) analyzed the determinants of FDI from Western countries, mainly in the European Union (EU), to Central and Eastern European nations, but did not consider how those factors influence cases where wealthier countries are the recipient of FDI flows. Demirbag et al., (2007) and Meyer (2001) used institutional and transaction costs perspectives in explaining foreign equity ventures' performance in an emerging market economy.
As these examples show, different authors focused their research to explore the most important influences to FDI, including macroeconomics performance (Kornecki; Rhoades 2007; Kornecki; 2008) country characteristics (Christman, et al. 1999); unit labor costs Johnson (2006), Bevan et al. (2004), Pusterla and Resmini (2005), Clausing and Dorobantu (2005), Disdier and Mayer (2004), gravity factors (Asiedu (2006), Ismail(2009)), market size (Ledyaeva, (2009), Birsan and Buiga (2008), sectorial patterns (Resmini, 2001.) competitive advantage (Zámborský, 2008) and proximity. This variety of determinants of FDI suggests the dynamics of FDI are broad and the effects are difficult to fully cover in any model. Thus, we suggest a re-visitation or even a revival of FDI research that includes more holistic models, better samples, and a focus on strategic impacts on the firm and the environments in emerging markets.

\section{AN ANALYSIS OF FDI EFFECTS IN TWO CASES}

The purpose of this comparative study is to demonstrate that the levels of FDI in Europe have changed over time and that those differences have varied with differences in the recipient nations of FDI. Inspired by the work of Kornecki (2008), the study estimates the effects of FDI on economic growth, in two specific European cases: a traditionally free-market economy (Turkey) and a formerly planned-economy (Croatia). We have conducted macroeconomics performance analysis on these two countries, and also on the initial European Union (EU) 15, new members EU 12 (states of the CEE region) for the period 1992-2009 on the relationship between foreign direct investment (FDI) and performance in CEE countries. Data for the analysis is drawn from the UNCTAD World Investment Report (2001; 2004; 2006; 2007; 2008), following Kornecki (2008).

EU(15) represents following 15 countries: Six founders: Belgium, France, Germany, Italy, 
Luxembourg and Netherlands, preceding Denmark, Ireland and the United Kingdom who joined in 1973. Greece became the 10th member of the EU prior to Spain and Portugal five years later. Furthermore in 1995 three more countries expanded the union, Austria, Finland and Sweden putting together the EU (15). As for the EU (12) countries: Czech Republic, Cyprus, Estonia, Latvia, Lithuania, Hungary, Malta, Poland, Slovenia and Slovakia joined in May 2004 and Bulgaria and Romania in January 2007. Countries considered as candidates are Croatia, Turkey and Former Republic of Macedonia (History of the European Union).

EU membership requires the adoption of EU legislation across the range of commercial and civil law, including trade rules, financial regulation, and competition policy so we analyzed macroeconomic factor through inward FDI Performance Index. Inward FDI Performance Index is the ratio of a country's share of global FDI inflows to its share in global GDP. If the Inward FDI Performance Index value is greater than one, the country received more FDI than its relative economic size. A value below one indicates that the country received less FDI than its relative economic size (UNCTAD, 2004 in Kornecki 2008).

\section{EQUATION 1:}

$$
\mathrm{INDi}=\frac{\mathrm{FDIi} / F D I w}{G D P i / G D P w}
$$

INDi = The Inward FDI Performance Index of the ith country

FDIi $=$ The FDI inflows in the ith country

FDIw $=$ World FDI inflows

GDPi $=$ GDP in the ith country

$\mathrm{GDPw}=$ World GDP

An inward FDI performance index was used to examine country-level secondary datasets. This comparison is one of the CEE countries inward FDI against the World Performance Index $(1992-2007)$. The indication is that the FDI performance of CEE transitioning economies was above the world average performance. We hope that this and the related information offer new theoretical insights and openings for empirical tests that analyze how performance is driven by industrial economic factors.

As demonstrated by Table 1, Croatia experienced sharper increases in inflows of FDI between 1992 and 2003, surpassing all other EU nations by 2001. This high increase in FDI was partially due to the intensive privatization process that was going on since the year 2000. However, by 2003, Croatia experienced a sharp drop in foreign direct investment. Turkey, on the other hand, received much lower levels of FDI between 1992 and 2000 and has been experiencing steadily increasing levels of FDI ever since. However, as of this study, the levels of foreign investment in Turkey are still roughly $1 / 2$ those of the top 15 EU recipients of FDI.

As demonstrated in Table 2 and 3, all nations in this study experienced a similar rate of increase in gross domestic product (GDP) between 1990 and 2007, a direct investment increase of approximately $20 \%$. Therefore, while mindful of the importance of growth and development, researchers need to examine a broader palette of components that constitute country success in FDI development. This suggests the influence and/or inclusion of all FDI on the productivity of all countries included in the study. As in the case of the amounts of FDI investment discussed in Table 1, GDP increases in Croatia were greater than those experienced in Turkey, suggesting that FDI levels helped drive broader economic conditions. The unstable growth rate in Turkey reflecting economical fluctuations might have been the cause of FDI inflow reserve even more. Borensztein et al. (1998) support that the contribution of FDI to in-country economic growth is evident only when there is an interaction between human capital, FDI, and performance.

As demonstrated in Table 4, from 1996, unemployment rates in Croatia sharply increased. A decrease did not begin until 2000. During the same period, unemployment decreased in 
TABLE 1: Inward FDI Performance Index

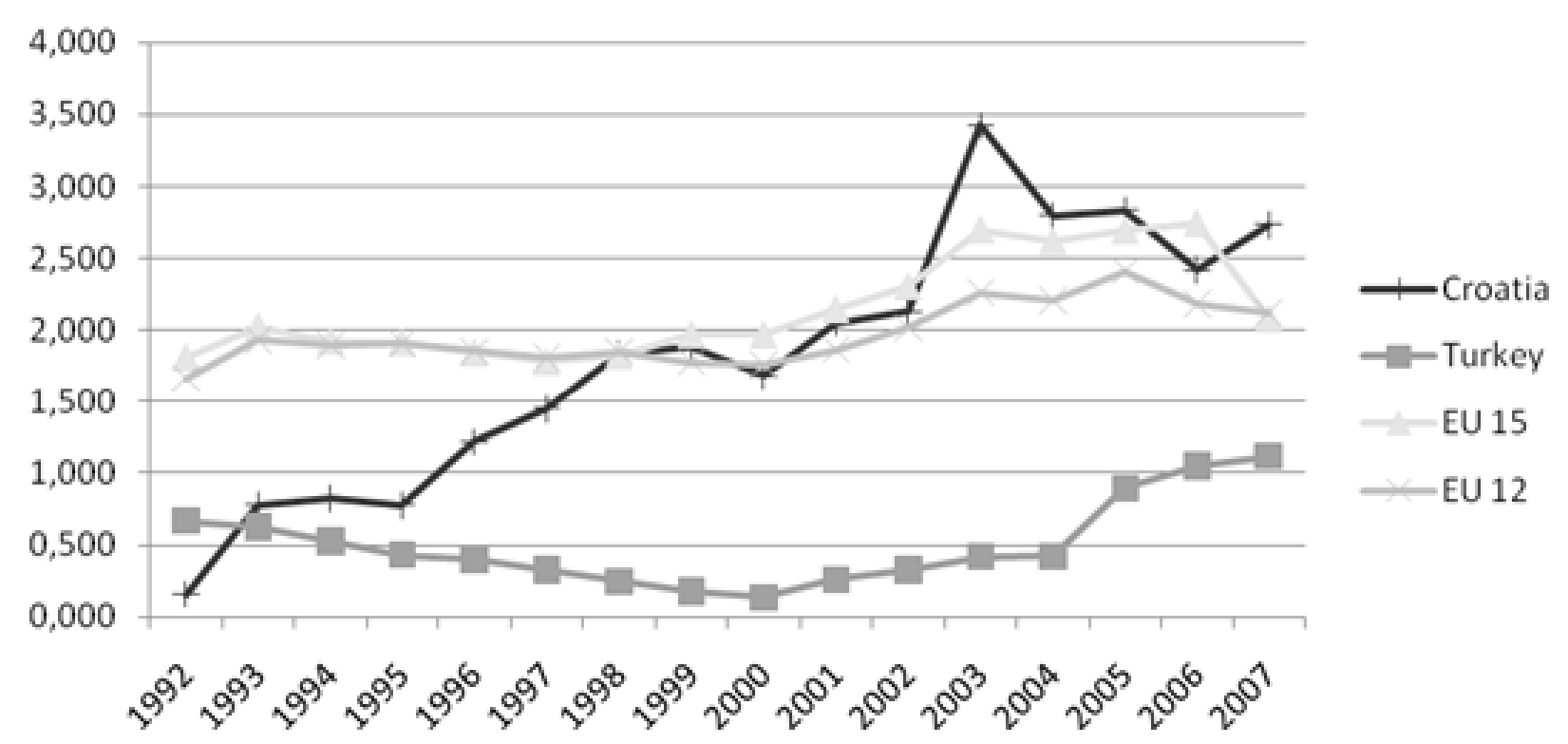

TABLE 2: GDP per Capita, US\$, at Prices and PPPs of 2005

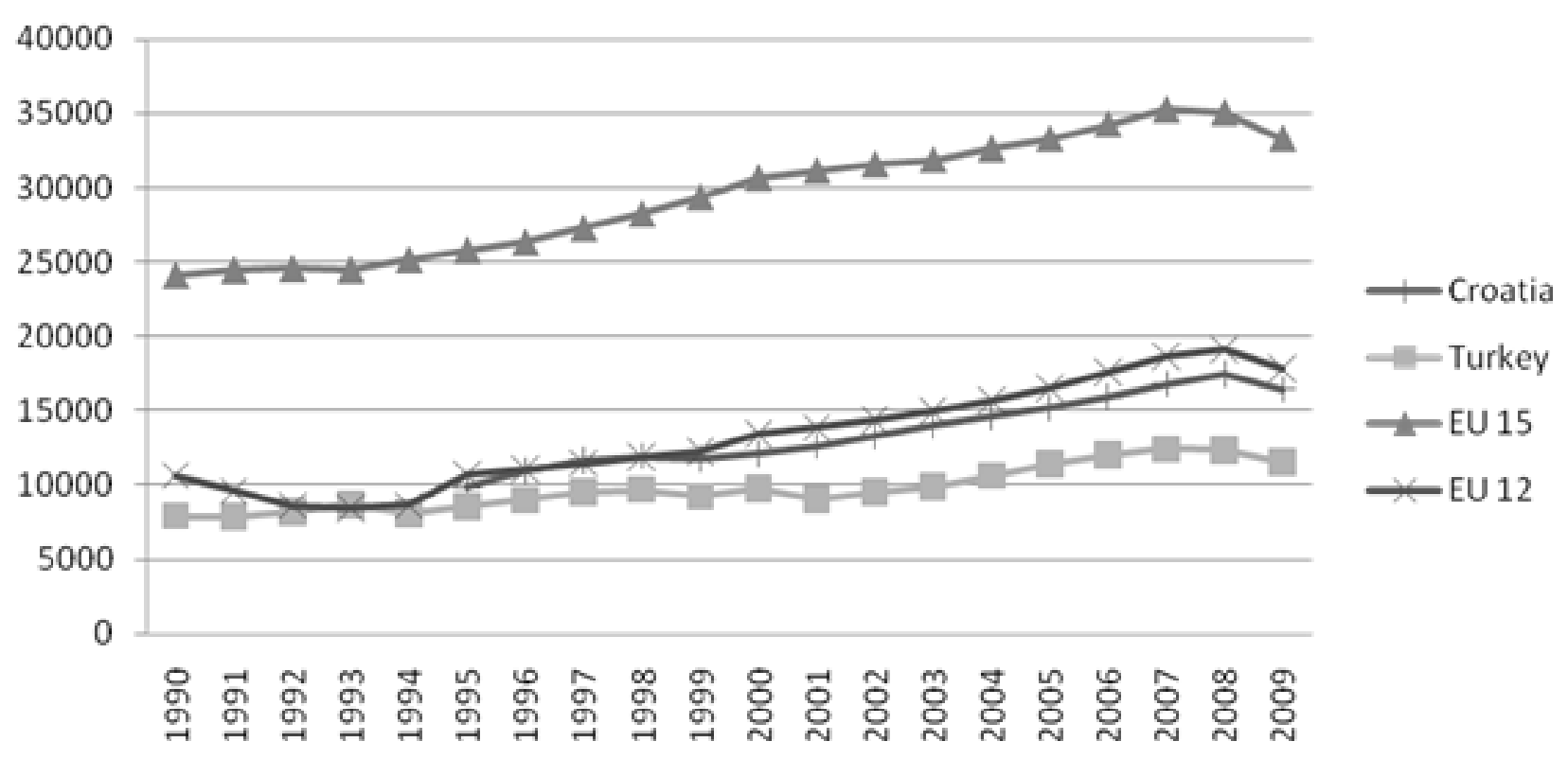

Source: (Unanimous) http://w3.unece.org/ 
TABLE 3: GDP at Prices and PPPs of 2005, Growth Rate
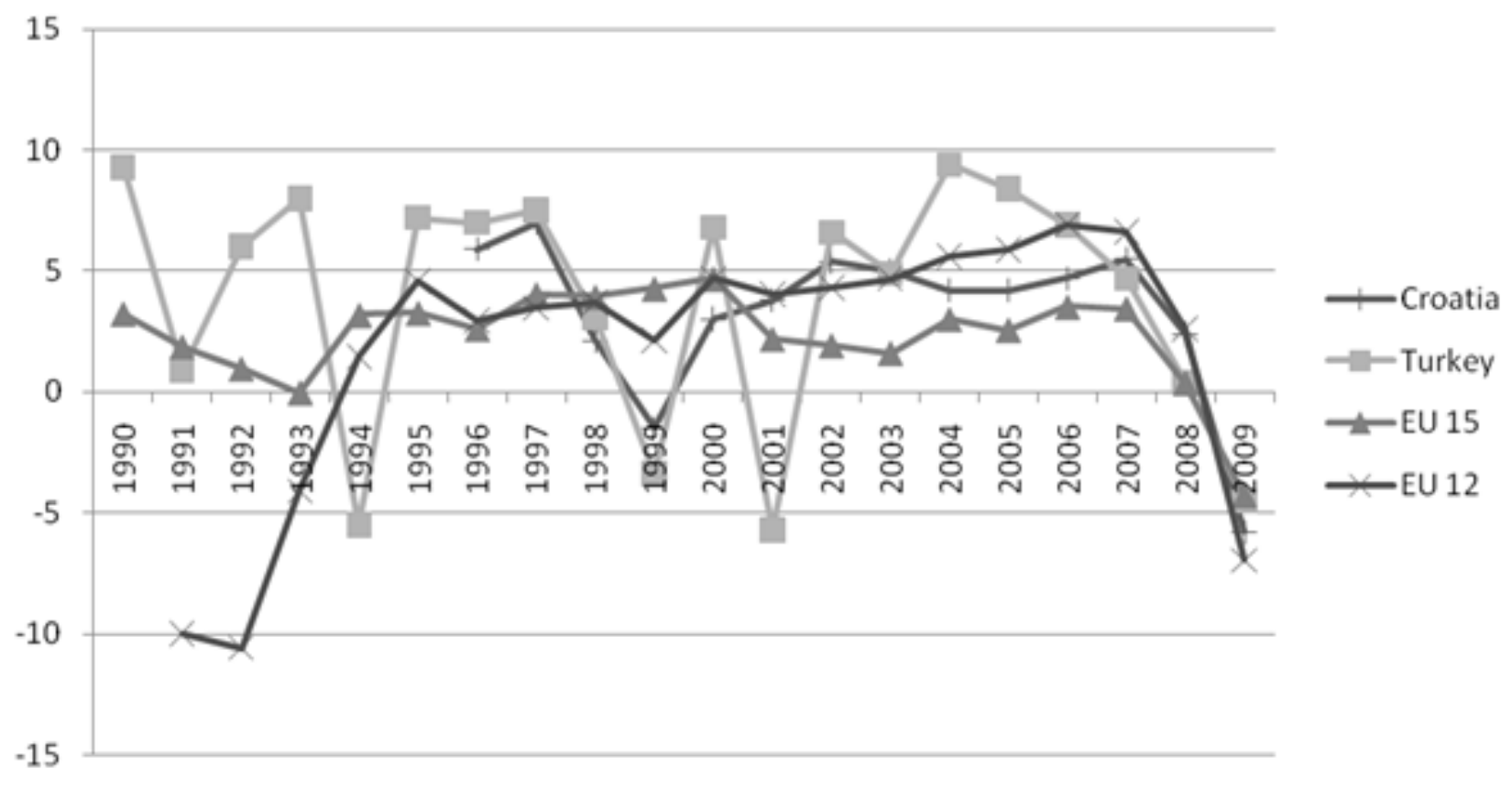

Source: (Unanimous) http://w3.unece.org/

TABLE 4: \% Unemployment Rate

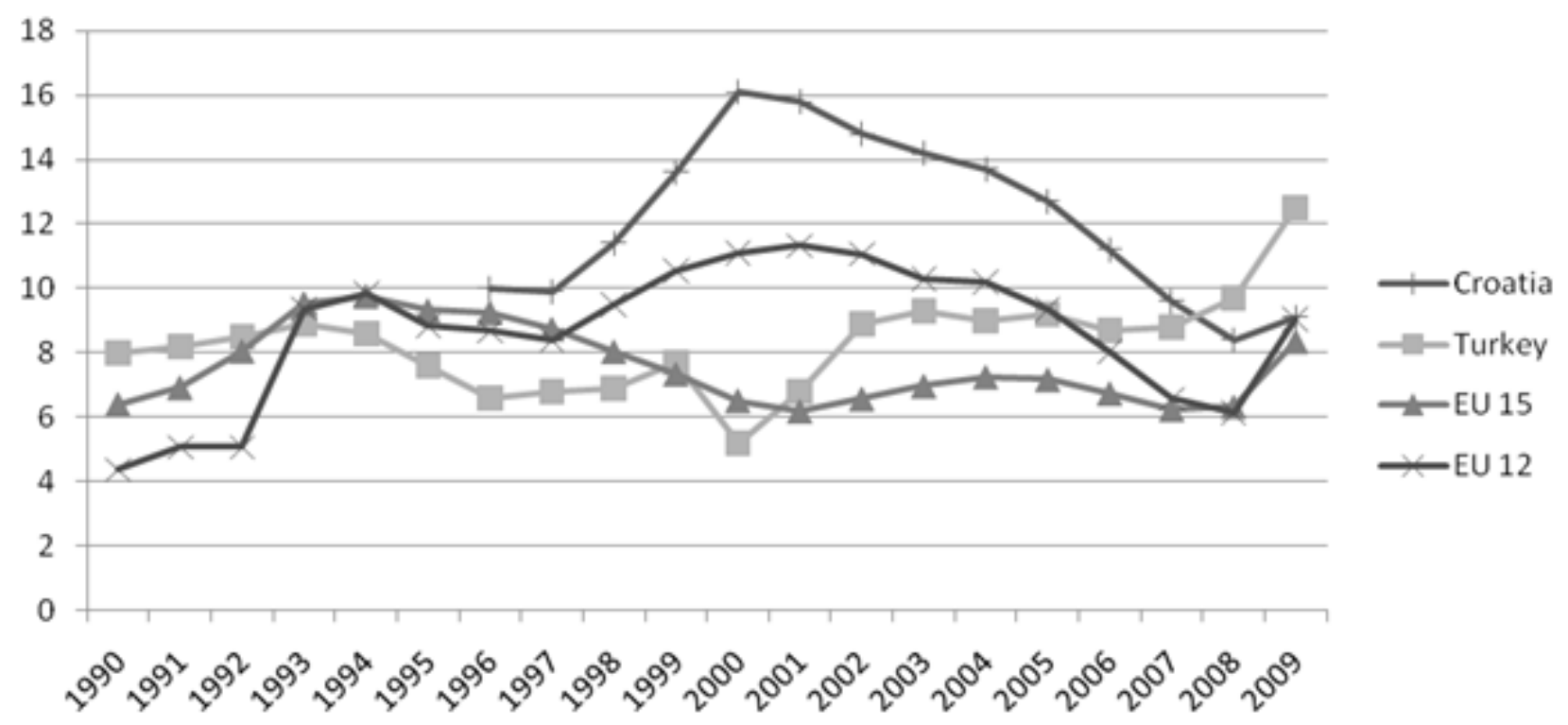

Source: (Unanimous) http://w3.unece.org/ 
Turkey and began to increase in 2000. When compared against the rate of FDI increases in these two countries, this suggests an inverse relationship between FDI and employment in the recipient nation. However, unemployment decreased in Croatia after 2000 while FDI continued to increase.

This suggests that early stages of FDI may displace existing industries or workers with facilities manned by imported, "expert" technicians, while at later stages, as FDI sponsored industries expand, they begin to train and employ local personnel. Additionally, this pattern may represent a diffusion of skills and resources from FDI into the local economy, opening new opportunities for local businesses to start and expand and employ local personnel.

Original values for the inflation were given in percentages, but since Croatia had a hyperinflation problem in the beginning of the 90's, a logarithmic scale was computed for the comparison.

As demonstrated in Table 5, prices for all markets studied have fallen since 1992. These rates of decline share an inverse relationship with the rates of increase with the rates of FDI investment. This is particularly evident in Croatia, which was recognized by the EU in 1992, providing its first access to FDI. However, it is particularly interesting to note that prices continue to decline even as FDI began to decline in Croatia, the EU 15 and 12 (see table 1). This suggests the resources built by FDI in a recipient nation may represent durable resource effects described by Penrose (1959) as "sticky."

Inward FDI stock presents the value of the capital increased by the retained profits that originates from the foreign investor measured as a percentage of GDP. Capital of the subsidiary corresponds to all the companies assets reduced by liabilities towards third parties including the parent. As demonstrated by Table 6, imported material follows the pattern of FDI. From the point at which FDI begins to increase (year 1992 for Croatia, the EU 12 and the EU15; year 2000 for Turkey), material imports as a percentage of GDP increases and generally decreases once FDI begins to fall off.

In order to further explore the influence of FDI on the economic growth using data of the four countries correlation matrix was calculated. Table 7 illustrates positive correlation between real GDP and inward FDI stock. Coefficients are highly significant and this relationship is proven reliable. Highest score was found in Croatian example $(0,912)$, preceding EU 12 $(0,871)$, EU $15(0,860)$ and Turkey $(0,602)$.

Table 5: Consumer Price Index Growth Rate; Logarithmic Scale

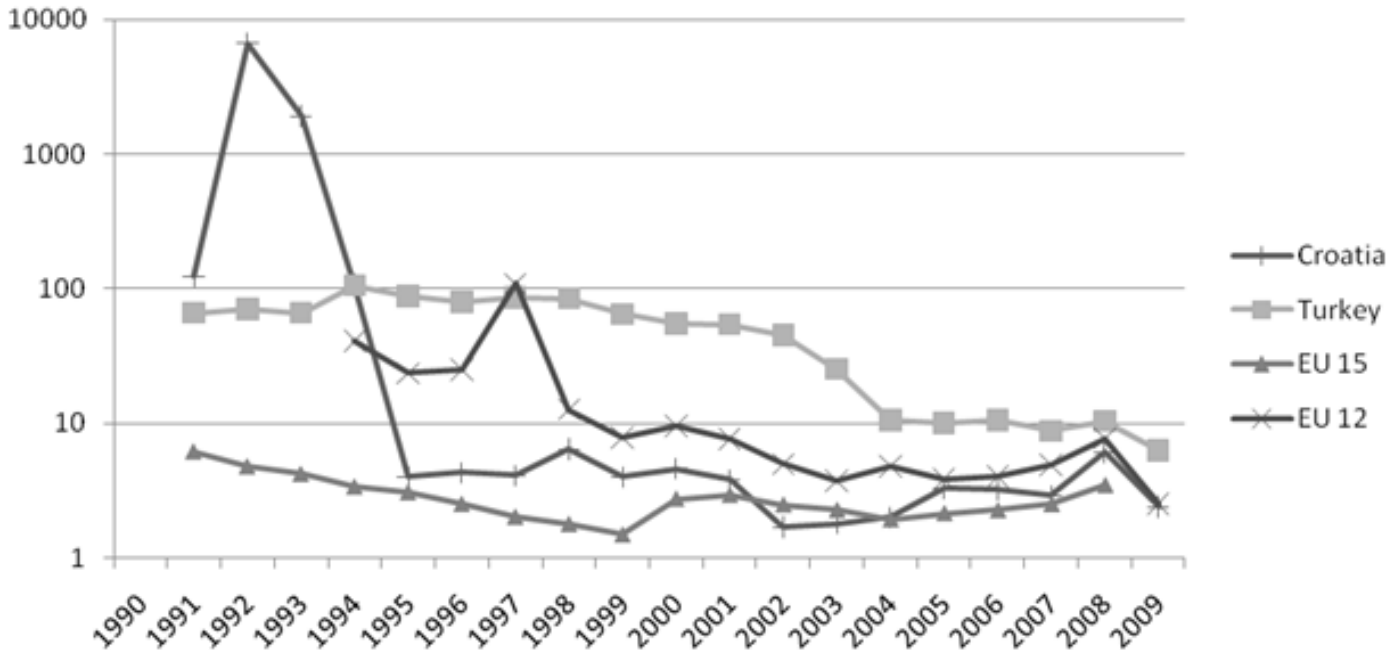

Source: (Unanimous) http://w3.unece.org/ 
TABLE 6: Inward FDI Stock; Percentage of Gross Domestic Product

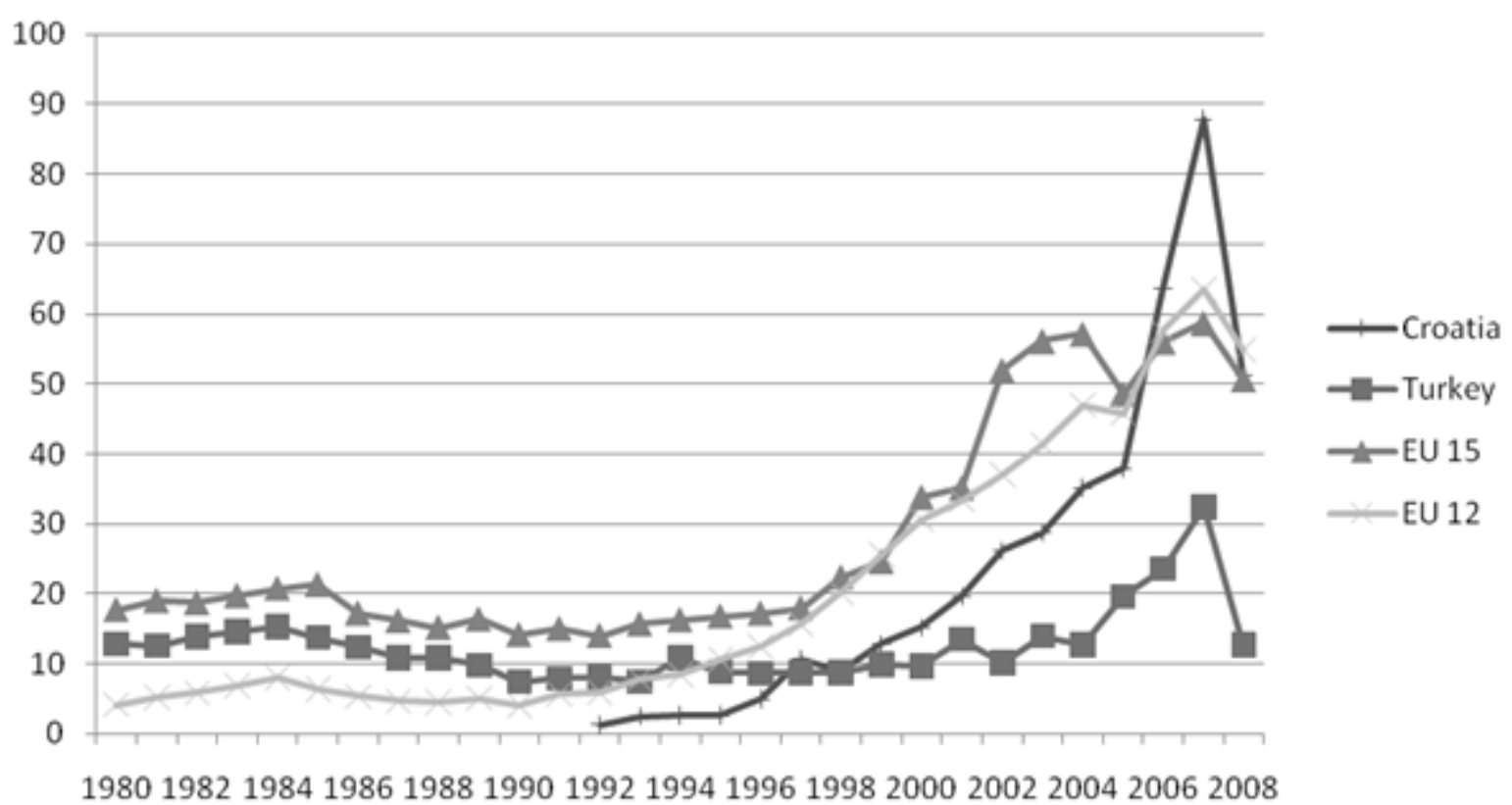

Source: (Unanimous) http://stats.unctad.org

CONCLUSION AND FUTURE RESEARCH

This study illustrates to both domestic and IB researchers the evolving dynamics of FDI in emerging markets. This research area is of growing importance in a globalizing world economy where firms are looking for move new markets. In a new global economy where Toyota is building cars in Istanbul, Turkey at their \#1 quality plant, and German ThyssenKrupp is soon to manufacture steel in Alabama, US; largely known as a mature service economy with high cost factors of production, the importance of obtaining FDI is growing in all economic

TABLE 7: GDP; Millions of US\$, at Prices and PPPs of 2005 and Inward FDI Stock Correlation 1990-2008

\begin{tabular}{lcccc}
\hline Country & Croatia & Turkey & EU 15 & EU 12 \\
\hline Correlation &, $912^{* *}$ &, $602^{* *}$ &, $860^{* *}$ &, $871^{* *}$ \\
R2 & 0,831 & 0,362 & 0,739 & 0,758 \\
p value & 0,000 & 0,000 & 0,000 & 0,000 \\
\hline
\end{tabular}

Source: http://stats.unctad.org, calculated by author markets. The reality is that the global economy is opening doors for new and perhaps guerilla strategy in FDI, employing unusual, low-cost and innovative approaches to attract the attention (Dahlén, et al. 2009) of global investors to opportunities in developing economies.

Past research in FDI, while important to our understanding of normative expectations, may not be completely relevant to current world economics. As the world changes, so should research and the predictions of empirical studies. In fact it may be possible that the empirical aspects of IB research will avoid normative Theory development due to the ever moving interactions of culture, polity, economic protectionism, and technology. As such, it is our suggestion that evolving contingencies and evolutions in global business are reducing the validity of past FDI studies and opening the door for new work in both emerging market analysis and developed market "re-involvement", such as the growth of state interest in Russian manufacturing after its efforts at privatization (Durand 2008) and the growth of Japanese participation in Pacific- 
Asian economies (Pempel 2001) after a long hiatus from those regions following World War II. Moreover, the discussion needs to be extended to both impacts on the firm (Barney 1986) and impacts on the home county environment (Harvey et al 2009).

\section{MANAGERIAL IMPLICATIONS}

The growth and restructuring of international entry strategy for global front-runners faces very complex questions. Where firms will place production and focus distribution is in flux to the point that extended market research is needed. Firms must find ways to exploit global cycles of economic instability, political volatility, and stagnation while defining strategic goals and expectations for an FDI.

Encouraging economic development and regional integration between CEE countries, not just with the EU, is one of the main aims in EU's accession policy. Could EU judgments have a decisive impact on the relative performance of the different CEE economies in the longer term via FDI? Should a top global company invest in Croatia or Turkey now or wait for EU involvement. It seems that to research opportunity is open in a practical sense. Firms need more information to help pinpoint when and where to enter the best global locations not only for the benefit of stakeholder, but for the long-term benefit of economic transactions in general.

From a public policy standpoint, governments should think deeper about the fit of an FDI to their economic environment. Speaking from a pure GDP stand point - more FDI is better for a target country. Low-performing economies need FDI to initiate the restructuring that can improve their competitiveness. Yet not all emerging markets need the same FDI. If new entry cuts existing local employment - the foreign investment could have a negative implication. Governance of who, when, and where is vitally important to FDI and host country success. As such, there may need to be a shift in strategies for pan-European markets (and beyond) and FDI inflows may drop off, holding back economic integration and progress in transitional economies as well. We should point out that current research opportunities are immediately important in the EU.

\section{LIMITATIONS AND FUTURE RESEARCH}

Our initial discussion was that the both firm and economic performance are important for FDI. This is a good starting point for increasing the economic activity in the host state. But we have concluded that the past macroeconomic indicators are not playing a decisive role in the localization of foreign investments. We must be very open that examinations of interaction effects have been under studied in FDI research. As the field of research has opened to new ideas, we now offer opportunities for important research across gaps in our existing knowledge. We end with a proposal of options as research "area" questions (RAQ). It is our hope that readers will leverage these questions as areas of future study.

\section{RESEARCH AREA QUESTIONS}

\section{$R A Q 1$}

What is the relationship between FDI and employment in the home country? Findings of this study suggest that FDI initially inversely correlates with recipient country employment, and yet later may positively correlates with the employment in recipient countries. Are these changes in correlation consistent in other FDI recipient countries and, if so, what influences drive such a relationship?

\section{$R A Q^{2}$}

Does FDI build resources that diffuse into the recipient country's economy? Findings of this study indicate a positive correlation between FDI inflows and recipient country GDP and an inverse correlation between FDI inflows 
and consumer prices in the recipient country in the early stages of FD investment. Yet, in later time periods, even when FDI inflows decrease, recipient country GDP continue to increase and consumer prices continue to decrease. Does this indicate resources established by FDI that are "repurposed" to drive other effects on the recipient economy?

\section{RAQ3}

What role does cultural distance between an acquiring firm and an acquired firm play in helping the acquired firm assimilate the acquiring firm's goals and in helping the acquiring firm extend its implicit contract beyond the acquired firm to the acquired firm's employees? Do the correlations observed hold in a larger sample? As noted by Franke and Richey (2010), the sample size of international studies is determined by the number of distinct cultures represented, not by the total number of respondents. What relationships are likely to emerge if larger numbers of cultures are included?

\section{RAQ4}

What role does global marketing capability play in helping acquiring firms better identify potential acquisitions in the global market that may more easily assimilate into the purchasing firm? Are firms that are better equipped to understand the needs and interests of potential employees in FDI recipient countries better able to adapt the means by which they integrate the employees of acquired firms into their operations?

\section{RAQ5}

What control factors are significant in examining relationships such as these? Conditions in the global business arena vary by individual currency, level of competition, degree of political risk, import/export barriers, degree of ethnocentrism toward foreign brands or offerings, and level of employee education and training, among others. Future research should consider such potential covariates.

\section{RAQ6}

What is the relationship between the factors that draw FDI to a given country and the outcomes that investing firms harvest? What influences allow investing firms to turn the potential customer demand and employee skill resources of a given market into a profitable return?

The FDI phenomenon is both dynamic and complex. As political, social and economic changes occur, variance in the effects anticipated from antecedents and moderators of FDI may also be expected. Further, refinements in standards of methodological practice in the International Business research domain may also change over time. Thus scholars should remain open to reexamination of accepted findings in the FDI literature, not only in Europe, but in the entire International Business academy.

\section{REFERENCES}

Ahmed, Z. U., Mohamad, O., Tan, B. \& Johnson, J.P. (2002). International risk perceptions and mode of entry: a case study of Malaysian multinational firms. Journal of Business Research, 55(10), 805-813

Akhter, H. \& Lusch, R.F(2000). Political risk and the evolution of control of foreign business: Equity, earnings, and market entry mix. Journal of Global Marketing, 1(3), 109-128

Alfaro L., Chanda, A., Kalemi-Ozcan, S. \& Sayek, S. (2004). FDI and economic growth: the role of local financial markets. Journal of International Economics, 64(1), 89-112.

Altomonte, C. (2000). Economic determinants and institutional frameworks: FDI in economies in transition. Transnational Corporations, 9(2), 75-106.

Barney, J.B. (1986). Strategic factor markets: expectations, luck and business strategy. Management Science 32(10), 1231-1241

Asiedu, E. (2006), Foreign direct investment in Africa: The role of natural resources, market size, government policy, institutions and po- 
litical instability. The World Economy,29, 63-77.

Barney, J. (1996). Firm resources and competitive advantage. Journal of Management, 17(1), 99-120.

Barry, F. (2002). EU accession and prospective FDI flows to CEE countries: A view from Ireland, (Dublin: University College Dublin), working paper, (August), mimeo.

Bennet, P. D., \& Green, R.T.. (1972). Political instability as a determinant of direct foreign investment in marketing. Journal of Marketing Research, 19(May), 182-86.

Bevan, A., Estrin, S., \& Meyer, K. (2004). Foreign investment location and institutional development in transition economies. International Business Review, 13(1), 43-64.

Bevan, A., \& Estrin, S. (2004). The determinants of foreign direct investment into European transition economies, Journal of Comparative Economics, 32(4), 775-787

Bevan, A. A., \& Estrin, S. (2000). Determinants of FDI in transition economies, Working Paper no. 342. Centre for New and Emerging Market, London Business School, London, England.

Birsan, M., \& Buiga, A. (2008). FDI determinants: case of Romania. Transition Studies Review, 15(4), 726-736

Bitzer, J., \& Gorg, H. (2005). The impact of FDI on industry performance. Research Paper, University of Nottingham, Nottingham, England

Borensztein, E., De Gregorio, J. \& Lee, J.W. (1998). How does foreign direct investment affect economic growth? Journal of International Economics, 45(1), 115-135.

Brenton, P., Di Mauro F. \& Lucke, M. (1999). Economic integration and FDI: An empirical analysis of foreign investment in the EU and in central and eastern Europe. Empirica, 26(2), 95-121.

Burke, A., Görg, H., \& Hanley, A. (2008). The impact of foreign direct investment on new firm survival in the UK: evidence for static versus dynamic industries. Small Business Economics, 31(4), 395-407.

Clausing, K.A., and Dorobantu, C.L., (2005). Re-entering Europe: does European Union candidacy boost foreign direct investment? Economics of Transition, 13(1), 77-103.

Chowdhury, A., \& Mavrotas, G. (2006). FDI and growth: What causes what? The World Economy, 29(1), 9-19.

Christmann, P., Day, D., \& Yip, G.S. (1999). The relative influence of country conditions, industry structure, and business strategy on multinational corporation subsidiary performance. Journal of International Management, 5(2), 241-265.

Consumer Price Index growth rate; logarithmic scale, http://w3.unece.org/, 20.August 2010

Dahlén, M., Granlund, A., \& Grenros, M. (2009). The consumer-perceived value of non-traditional media: effects of brand reputation, appropriateness and expense, Journal of Consumer Marketing, 26(3), 155-163.

Dawson, J.W. (1998). Institutions, investment and growth: new cross-country and panel data evidence. Economic Inquiry, 36(4), 603-619.

Demirbag, M, Tatoglu, E., and Glaister, K.W. ( 2007 ). Factors influencing perceptions of performance: The case of western FDI in an emerging market, International Business Review, 16(3), 310-336

Disdier, A.C., \& Mayer, T. (2004). How different is Eastern Europe? Structures and determinants of location choices by French firms in Eastern and Western Europe. Journal of Comparative Economics, 32(2), 280-296.

Dunning, J. H. (1981). International Production and the Multinational Enterprise. London: Allen and Unwin.

Dunning, J.H. (1999). Location and the multinational enterprise: A neglected factor. Journal of International Business Studies, 29(1), 4566.

Dunning, J.H. (2000). The eclectic-paradigm as an envelope for economic and business theo- 
ries of MNE activity. International Business Review, 9(1), 163-90.

Dunning, J. H. (2003). An evolving paradigm of the economic determinants of international business activity, managing multinationals in a knowledge economy: Economics, culture and human resources. In J.L.C.U. Cheng and M.A. Hitt (Eds.), Advances in International Management, (pp. 3-27). Bradford: Emerald Publishing Group.

Durand, C. (2008). Between developmentalism and instrumentalization: The comeback of the producing state in Russia. Journal of Innovation Economics, 2(2), 196-210.

FDI Intelligence from the Financial Times Ltd, www.fdimarkets.com ; access $10^{\text {th }}$ July 2010.

Franke, G., Richey, G. (2010). Improving generalizations from multi-country comparisons in international business research. Journal of International Business Studies, Advance online publication 20 May 2010; doi: 10.1057/jibs.2010.21

GDP per Capita, US\$, at prices and PPPs of 2005, http://w3.unece.org/, 20.August 2010.

GDP at Prices and PPPs of 2005, Growth Rate, http://w3.unece.org/, 20.August 2010.

Globerman, S. \& Shapiro, D. (1999). The impact of government policies on foreign direct investment: the Canadian experience. Journal of International Business Studies, 30(3), 513-532.

Globerman, S., \& Shapiro, D. (2003). Governcence infrastructure and US foreign investment. Journal of International Business Studies, 34(1), 19-39.

Görg, H., \& Greenway, D. (2004). Much ado about nothing? Do domestic firms really benefit from foreign direct investment? World Bank Research Observer, 19(2), 171197.

Harvey, M.G., Kiessling, T.S., \& Richey, Jr, R.G. (2008). Global social time perspectives in marketing: A strategic reference point theory application. International Marketing Review, 25(2), 146-165.
Henisz, W.J. (2000). The institutional environment for multinational investment. Journal of Law, Economics and Organization, 16(2), 334-364.

Inward FDI Performance Index - Results for 2005-2007. Retrieved from http://www.unctad.org/Templates/WebFlyer .asp?intItemID=2471\&lang=1， 20.August 2010.

Inward FDI stock; percentage of gross domestic product, http://stats.unctad.org, 20.August 2010

Ismail N. W. (2009). The determinant of foreign direct investment in ASEAN: A semigravity approach, pp. 710-722.

Javorick, B.S. (2004). Does foreign direct investment increase the productivity of domestic firms? In search of spillovers through backward linkages. American Economic Review, 94(3), 605-627.

Kaminski, B. (2001). How accession to the European Union has affected external trade and foreign direct investment in Central European economies. World Bank Policy Research Working Paper No. 2578, Washington D.C.: World Bank.

Kobrin, S.J. (1976). Environmental determinants of foreign direct manufacturing investments: An ex-post empirical analysis. Journal of International Business Studies, 7(2), 29-42.

Kornecki L., \& Rhoades, D. (2007). How FDI facilitates the globalization process and stimulates economic growth in CEE. Journal of International Business Research, 6(1), 113-126.

Kornecki L. (2008). Foreign direct investment and macroeconomic changes in CEE integrating in to the global market. Journal of International Business and Cultural Studies. http://www.aabri.com/manuscripts/09222.pd $\mathrm{f}$

Kuznecovs O., \& Maslovs, A. (2004). Relative FDI attractiveness of eight EU accession states, SSE Riga Working Papers 2004: $50(60)$. 
http://www2.sseriga.edu.lv/library/working_ papers/FT_2004_5.pdf, accessed 27.12.2007

Ledyaeva, S. (2009). Foreign direct investment determinants in post-crisis Russia: Empirical evidence. The EU and Emerging Markets, 12(2), 95-108.

Markusen, J.R., \& Venables. A.J. (1999). Foreign direct investment as a catalyst for industrial development. European Economic Review, 43(2), 335-356.

Makino, S., Isobe, T., \& Chan, C.M. (2004). Does country matter? Strategic Management Journal, 25(10), 1027-1043.

Meyer, M. (2001). Institutions, transaction costs and entry mode choice in Eastern Europe. Journal of International Business Studies, 32(2), 357-367.

Mody, A., \& Srinivasan, K. (1998). Japanese and US firms as foreign investors: Do they march to the same tune? Canadian Journal of Economics, 31(4), 778-800.

Morgan, R., \& Hunt, S.B. (1995). The comparative advantage theory of competition. Journal of Marketing, 59(2), 1-15.

Morisset, J. (2000). FDI in Africa: policies also matter. Transnational Corporations, 9(2), 107-126.

Nicoletti, G., Golub, S., Hajkova, D., Mirza D., \& Yoo, K.Y. (2003). Policies and international integration: Influences on trade and foreign direct investment, OECD Economics Department Working Papers, No. 359, OECD Publishing. doi: 10.1787/062321126487

Northrup, D. (2005). Globalisation and the great convergence, rethinking world history in the long term. Journal of World History, 16(3), 249-267.

O’Rourke, K., \& Williamson, H. (2004). Once more: when did globalization begin? European Review of Economic History, 8(1), 109-117.

O'Rourke, K., \& Williamson, H. (2004a). From Malthus to Ohlin: Trade, industrialization and distribution since 1500. Retrieved from.
http://www.tcd.ie/iiis/HNAG/Papers/jiefinal. pdf on June 12, 2010.

OECD, (2002). Foreign Direct Investment and Development: Where Do We Stand?, Paris

Pempel, T.J. (2001). International finance and Asian regionalism. The Pacific Review, 13(1), 57-72.

Penrose, E.T., (1959). The theory of the growth of the firm, Oxford: Basil Blackwell.

Perry, A. (2003). Finding and facing facts about legal systems and FDI in South Asia. Legal Studies, 23(4), 649-689.

Porter, M. (2000). Location, competition, and economic development: Local clusters in a global economy. Economic Development Quarterly, 14(1), 15-35.

Rumy, H. (1996). The limitations of low labour costs as an inducement to foreign direct investment: An example from the motor industry. European Business Review, 96(4), 26-29.

Pusterla, F., \& Resmini, L. (2005). Where do firms locate in transition countries? An empirical investigation. ISLA Universita " $\mathrm{L}$. Bocconi", Milan.

Kaminski, B., (2001). How accession to the European Union has affected external trade and foreign direct investment in central European economies, World Bank Policy Research Working Paper No. 2578, Washington, D.C., World Bank.

Real GDP \& Inward FDI stock 1990-2008, Retrieved from http://stats.unctad.org, on 21th August 2010.

Resmini, L. ( 2001). The determinants of foreign direct investment into the CEECs: New evidence from sectoral patterns. Economics of Transition, 8(3), 665-689.

Stevens, G.V.G. (2000). Politics, economics and investment: Explaining plant and equipment spending by US direct investors in Argentina, Brazil and Mexico. Journal of International Money and Finance, 19(2), 115-135.

The history of the European Union, Retrieved from 
http://europa.eu/abc/history/index_en.htm, on $21^{\text {st }}$ August 2010.

Tian, X. (2007). Accounting for sources of FDI technology spillovers: Evidence from China. Journal of International Business Studies, 38(1), 147-159.

Tuman, J., \& Emmert, C. (1999). Explaining Japanese foreign direct investment in Latin America. Social Science Quarterly, 80(3), 539-555.

Tuselmann, H.J. (1999). German direct foreign investment in Central and Eastern Europe: relocation of German industry? European Business Review, 99(6), 359-367.

UNCTAD, (2001). World Investment report: Promoting Linkages, United Nations, New York and Geneva.

UNCTAD, (2004). World Investment Report, Linking, The shift towards services. Retrieved from www.unctad.org/en/docs/wir2004_en.pdf

UNCTAD, (2006). World Investment Report. FDI Developing and Transition Economies: Implication for Development. Geneva, Switzerland.

UNCTAD, (2007). World Investment Report 2007: Transnational Corporations, Extractive Industries and Development, United Nations.

UNCTAD, (2008). World Investment Report 2008: International corporation and infrastructure challenge UNECE, statistical databases. Retrieved from: http://w3.unece.org/,18 ${ }^{\text {th }}$ August 2010. http://www.unctad.org/Templates/WebFlyer .asp?intItemID $=2471 \&$ lang $=1$

Zámborský, P. ( 2008 ). Foreign Direct Investment, Performance and Competitive Ad- vantage, A Dissertation. Massachusetts, USA.

Wang, C., Clegg, J., \& Kafouros, M. (2009). Country-of-origin effects of foreign direct investment: an industry level analysis. Management International Review, 49(2), 179199.

Wasseem, M. (2007). The location determinants of FDI in the GCC countries. Journal of Multinational Financial Management, 17(4), 336-348.

World Investment Report, (2007). Transnational Corporations, Extractive Industries and Development.

\section{NOTES}

1.Foreign direct investment (FDI) is defined as an investment involving a long-term relationship and reflecting a lasting interest and control by a resident entity in one economy (foreign direct investor or parent enterprise) in an enterprise resident in an economy other than that of the foreign direct investor (FDI enterprise or affiliate enterprise or foreign affiliate).

Source: World Investment Report 2007: Transnational Corporations, Extractive Industries and Development p. 245. http://www.unctad.org/en/docs/wir2007p4_en.p df

2.FDI implies that the investor exerts a significant degree of influence on the management of the enterprise resident in the other economy. Such investment involves both the initial transaction between the two entities and all subsequent transactions between them and among foreign affiliates, both incorporated and unincorporated. FDI may be undertaken by individuals as well as business entities. Ibid 


\title{
Small to Medium Enterprises in the Danish Conference Sector and a 360-Degree Approach to Managing Customer Relationships
}

\author{
Trevor Hartland \\ Britt Damkjaer \\ Christopher Miller \\ Brychan Thomas
}

\begin{abstract}
Many corporate enterprises use Customer Relationship Management (CRM) techniques to manage customer information in order to attain competitive advantage. The purpose of this study was to understand how small to medium enterprises (SME's) in the Danish conference sector manage and build customer relationships and to investigate the extent to which they were prepared to adopt a 360degree view when pursuing a customer relationship management approach. A qualitative, explorative triangulated case study method was conducted to explore this in more depth. The findings revealed that SME's in the sector essentially manage customer relations using a database system without having a completely integrated CRM system. The main barriers/challenges were technology and internal education.
\end{abstract}

KEYWORDS. SME's, 360 degree approach, customer relationships, conference sector

\section{INTRODUCTION}

Managing customer relationships is often the 'lifeblood' of all organisations regardless of the business sector or size in which they operate. Burns (1995) suggested that business development could only occur by improving knowledge of the customers' needs, and servicing those needs better than competitors. Much the same argument exists today but with a more holistic view point; that no enterprise can succeed in distinguishing itself through operational excellence, customer intimacy or product innovation without understanding the needs and desires of its customers (Hood, 2003).

It was considered that to gain knowledge regarding customers' needs and desires, contact between the company and its customers was necessary so as to initiate a dialogue and effectively obtain unique information about each individual customer (Galbreath and Rogers, 1999). Innovative database platforms and multi-channel delivery vehicles with advanced analytics were considered the way forward (Schoenbachler, 2002). Others emphasised the importance of the customer's channel preference and choice in the process of understanding the customer (Langford

Trevor Hartland, Christopher Miller, Ph.D., and Brychan Thomas, Ph.D. are affiliated with Glomorgan Business School, University of Glamorgan, Pontypridd, CF37 1DL, United Kingdom. Britt Damkjaer is CRM Manager at Oticon A/S. Denmark

Address correspondence to Brychan Thomas, Reader in Innovation Policy, Glamorgan Business School, University of Glamorgan, Pontypridd CF37 1DL, United Kingdom. E-mail: bcthomas@glam.ac.uk 
and Cosenza, 2000). Relationships with customers have been debated ever since, based on marketing strategies designed to approach customers through, for instance, relationship marketing, CRM, e-CRM, and more recently, the 360degree view, all of which reflect the relationship evolution as discussed in this paper.

The Internet has provided 'instant' access to multiple sources of information allowing for numerous options to improve marketing and sales approaches towards customers. However, Mitussis et al. (2006) observe that a holistic view of the customer is often ignored and instead, they are seen through a 'single lens'. Whichever channel is used, however, the debate has more recently focused on the goal to reach diverse customers through different touch points, while ensuring a single view of the customer is maintained (Rogers and Zeuner, 2004). This involves managing the manner in which each customer interacts across channels and/or product/ service lines, while at the same time, recognising that various elements such as technology, information resources and processes are involved (Haydock, 2000).

While many authors have contributed to the debate on the 360-degree concept, it has led to variation in terminology, including "customer experience management", describing the relationship being built (Stone, 2003). Others have called it a multi-channel contact strategy approach (Fanelli, 2004; Schoenbachler, 2002; Simons et al, 2002; Hood, 2003; Haydock, 2000). It involved aspects such as contact strategy, multi-channel marketing, customer contact strategy, integrated or multi-levelled marketing (Peppers and Rogers, 2003, Hood, 2003; Hill, 2001; Macintosh, 2002; Burns, 1995; Schoenbachler, 2002). The central theme, however, was the same: managing customer relationships.

Early debate regarding the 360-degree approach embraced areas such as sales, direct and interactive marketing, customer service, distribution channel management and communications with customers whether from a marketing, sales or customer strategy context (Hood, 2003; Stone, 2003a,b\&c). In this paper, the term 360-degree view focuses on the approach of multiple communication channels used to build relationships to enable SME's to achieve a 360-degree approach. Leo et al. (2005) described this as a process of knowledge generation whereby customer information such as needs and preferences may be captured both directly and indirectly, through two-way communication in an interactive feedback system.

On the surface, the recipe for success appears straightforward: interact with customers, collect valuable data, compile 360-degree views of individual customers and utilise the information to build profitable relationships over time (Peppers and Rogers, 2003). Only 10-15 percent of SME's, however, use a formal CRM package (CRMGURU, 2004) and only 29 percent of midsize companies use customer focused strategies and technologies to provide visibility into sales cycles and sales activities (Rogers and Zeuner, 2004).Therefore, as Robinson (2004) points out, since corporate enterprises use CRM systems as a way to handle and leverage customer information to gain a competitive advantage, why then are so few SME's investing in CRM and not changing their focus to a 360-degree approach when it too could give them significant competitive advantage?

Since so few SME's were currently embracing the CRM process (CRMGURU, 2004) it was assumed that they were not likely to be considering how to manage and build relationships with the entire available network. Yet, although it is acknowledged that SME's were likely to have differing needs from large corporations, particularly when it came to the frequency and nature of contact with their customers, it is argued nevertheless that the benefits would still apply. Therefore, the central theme of this paper considers the nature of two-party (dyadic) relationships between the customer and enterprises.

The conference sector was chosen within the service industry, where customer orientation, tailoring products to consumer's needs and building relationships are pre-requisites to survival in a 
highly competitive market. Indications of this explorative research could then serve other SME's who are also heavily dependent on leveraging the customer experience.

The European Union (EU) 2007 reports that $99.8 \%$ of businesses are SME's. These organisations play a major role in both national economic growth and job creation (EU, 2007). The Small Business Act for Europe (SBA, 2007) claims that "a vibrant SME sector is crucial for the economic health of Europe". Larger organisations also recognise the economic impact of SME's. As Acs et al. (2001) state, SME's are becoming increasingly important pillars of the economies of major trading partners. The increasing value for the national economy is illustrated in the Global Entrepreneurship Monitor (GEM) reports 2005 and 2006 respectively (Brooksbank and Jones-Evans, 2005; Bosma and Harding, 2006). Both indicate a constant growth in the number of small or new businesses. In order to investigate how SME's in the Danish conference sector manage and build customer relationships, and the extent to which they are prepared to adopt a 360-degree view when pursuing a customer relationships management approach, the paper presents a literature review followed by the methodology involving an explorative case study method, findings and conclusions.

\section{LITERATURE REVIEW}

Peppers and Rogers (2003) propose that establishing a 360-degree view of an individual customer means recognising the customer at any time across product purchase and service lines. They argue that sales managers and agents could utilise insights contained within these 360-degree views to acquire and retain customers for SME's and keep the "earning relationship" through channels and touch points such as account management, call centres, marketing, channel management, finance, order management, support, product warranty, external data, e-commerce and Web applications.
Customer access to multiple channels when they contact the enterprise, while building a single customer relationship is the essence of a 360degree view (Hood, 2003; Gummesson, 2004; Stone, 2003a\&b; Peppers and Rogers, 2003). It is acknowledged, however, that SME's may not have as many separate channels and touch points as stated above, although they still need to define, target and manage customers before, during and after the sale throughout a customer's lifecycle. Limited literature relating to SMEs' channels in the new 360-degree environment has made it difficult to specify which channels are grouped compared to individual touch points. Yet, it is assumed that it requires handling relationships through customer contact points not only for marketing, sales and service functions, but also finance and production departments as well as other touch points to recognise customer's needs and requirements.

Once a company is ready to pursue a customer relationship strategy, CRM and the 360-degree view is equally applicable to effectively ensure that the right environment is established to build and retain such relationships. Galbreath and Rogers (1999) argue that CRM is about the transformation of the entire enterprise and how it views and conducts business with its customers. It generally combines various elements of technology, information resources and processes in order to create a 360-degree view of its customers. CRM is simply the ability to treat individual customers differently, which involves creating a seamless experience between the customer and all areas of the organisation. Establishing a cross-functional team with a cohesive mission that encompasses all the customer touch points to embrace a 360-degree view is one such example. Peppers and Rogers (2003) posit that the prerequisite for a 360-degree approach is a one-toone focus with each individual customer. Embracing a CRM strategy equally means embracing a 360-degree approach to view individual customer profiles.

There are, however, differing views as to how far advanced SME's are in the process of 
managing customers and creating an environment which integrates marketing, sales, service, back-office and supply functions in order to achieve a 360-degree view of their customers. Although few SME's have formal methods in place to understand their customers, investing in CRM and a change of focus to a 360-degree approach could give a competitive edge, while investing in CRM-enabling applications can give SME's significant competitive advantages (Robinson, 2004).

For some SME's, CRM and a 360-degree view are relatively new business and management concepts. They are still doing 'business as usual' since they are uncertain as to what they will achieve. Either business relationships are not formalised or captured, or they operate under the misconception that "CRM is for large companies, not for them" (Robinson, 2004).

Surveys have differed in their findings as to how much SME's use a formal CRM package. Industry organisation, CRMGURU found that only 10-15 percent of SME's use a formal CRM package (Robinson, 2004), whereas organisations such as Gartner and The Customer Marketing Institute, found that 48-50 percent were using CRM software or a sales force automation package system (IOMA's Report on Customer Relationship Management, 2004). Gartner's study also found that, close to 80 percent of companies (large and small firms) did not have a CRM strategy involving customers as a "company asset".

Although CRM has been used to describe technological tools and applications for the front end of a business, Peppers and Rogers (2003) suggest that once a company is ready to pursue a customer relationship strategy designed for a more customer-oriented focus, the 360-degree view is applicable. It is a matter of changing the mindset to provide a 360-degree view of each individual customer. This notion is supported by the argument that a change to a customer focus is critical as well as understanding what sort of relationship the customer actually needs from a business. A customer orientation rather than product or sales orientation is often considered to be a precursor to CRM implementation.

A further argument is because SME's are less structured; they do not have systematic processes and are therefore not as well prepared to achieve CRM (CRMGURU, 2004). Instead, it is an intuitive process for SME's, since they talk to their customers they capture complaints and they understand that if they are in touch with their customers they therefore deliver value (Thomson, 2004).

Another consideration is that SME's do not see benefits and therefore ask: "what's in it for me"? According to Jay Curry, nobody has answered that for SME's and thus, it is mainly a matter of education (Curry, 2002).

A further view is that SME's have fewer barriers between the customer and the organisation because there is less of an infrastructure. However, a different type of CRM is required to be effective when you do not have a person responsible for sales and marketing. Instead, everyone tries to do their job and they need to keep the customer in mind (Kinikin, 2004).

If a unified view of the customer (i.e. 360degree view) can be achieved, the potential for synergies of sales opportunities and marketing communications is increased. With more effective targeting of individual customers involving enhanced cross and up-selling opportunities, enterprises can exploit one channel over another, and create multi-channel marketing campaigns dependent on customer demographics, economic models and organisational structures (Schoenbachler, 2002; Hood, 2003; Stone, 2003a\&B).

A synergistic strategy for physical and electronic channels implies that those channels have their own value and competitive strength (simons et al, 2002). Enterprises can achieve excellence in the vital customer touch points of marketing, sales and service when focusing on managing the customer contact points. This will deliver a high return on investment through satisfied customers, repeat business and enhanced profits. The downside of a focused channel view rather than a customer-centric view is less loyal customers that 
are difficult to retain, negative word of mouth referrals and increased support costs to manage an unmanageable situation (hood, 2003).

The benefit of a 360-degree view is unique customer information collected through a number of integrated channels and converted into valuable insights based on thorough analysis of past customer purchases across all channels. True customer preferences and higher-valued customers can then be segmented as much as individual customers can be offered customised products and services.

Synergy can be achieved through integration of the multi-channel environment and continued focus on the customer, rather than the channel, since success will depend on how well all channels are used to the best advantage. Many enterprises gain benefit, but many do not. "One size does not fit all", and enterprises and customers each have their own requirements and needtailored solutions (Hood, 2003). In order to achieve desired customer behaviour and test marketing activities designed to achieve this, CRM and a 360-degree view are important tools to manage the different ways in which an organisation "touches" a customer (Stone, 2003b).

Possible barriers facing SME's are a consequence of making SME's less advanced in the CRM process, while focusing on a 360-degree customer view. One barrier is the financial issue. The debate concerns SME's spending relatively more on implementing and profiting from CRM than their larger counterparts, because SME's cannot amortise the investment over as many people or undertake pilot projects before they start a rollout (CRMGURU, 2004). SME's are more likely to have less funds available and therefore implement CRM practice without changing company cultures (Hood, 2003). A possible barrier could also be that SME's are unable to see any immediate benefit, or even to perceive a benefit at all, given what is actually out there for them (Robinson, 2004).

Organisational issues also create an internal barrier for SME's when moving towards a CRM database system and a 360-degree customer view. Here, SME's have their own particular characteristics which affect the way in which they operate and which largely determine their preoccupations and concerns; organisational structures in small firms are less rigid, sophisticated and complex than in larger firms (Hill, 2001a\&b). Indeed as Robinson (2004) comments, many SME's are not ready for CRM and therefore need to develop their organisational capabilities in order to fully adopt it.

Customer information is key and although most SME's have a database, many do not have a consolidated view of whom their customers are (Burns, 1995). According to Robinson (2004), a learning curve investment will achieve positive CRM and a 360-degree approach: reshaping the customer process, selecting CRM systems, developing training programs and it is important that SME's pay attention if they wish to attain a competitive advantage.

\section{METHODOLOGY}

The study investigated four SME's operating in the conference sector in Denmark using a triangulated case study methodology as advocated by Yin (2009). This partly contributed to the validity of the findings but was also reinforced by using a qualitative approach undertaken in a rigorous way in order to generate themes, identify issues and explore discourses. The justification of using the conference sector as an exemplar, and the rationale for the study being based on the selected four firms, was according to the fact that the sector was appropriate because of the nature of the inter-firm relationships.

The research aim was to investigate how near SME's are to achieving a 360 degree approach to managing customer relationships. The purpose of this study was to understand how small to medium enterprises (SME's) in the Danish conference sector manage and build customer relationships and to investigate the extent to which they were prepared to adopt a 360-degree view when pursuing a customer relationship management approach. In relation to this the research followed a 
design with objectives/research questions according to the five central themes of:

(1) the customer management approach (Rogers, 2000a; Curry, 2002; IOMA, 2004; Leo et al, 2005) - what customer management approach is the SME using?

(2) transactional-oriented or relational-oriented customer approach - to what extent does the SME use a transactional-oriented or relationaloriented customer approach?

(3) personalized, digitalized or customized approach - which approach in terms of personalized, digitalized or customized, or a combination of these, is the SME using?

(4) whether SME's are ready with regard to 'new' behavior in their customer approach what is the SME's attitude towards change in their customer approach?

(5) SMEs and the 360-degree view approach how near are SME's to achieving a 360-degree approach?

These were the questions/themes that the interviews concentrated on in relation to the objectives through the focused interview and other material which provided the results. The data collection methods used included (i) the compilation of information concerning each firm from company reports and documents relating to customer relationships, (ii) observation of company activities involving the management of customer relationships and (iii) semi-structured interviews conducted with key executives in the sales and marketing departments. In-depth analysis of the interview transcripts enabled the researchers to establish what the firms believe CRM involves. In doing, this it was possible to triangulate the findings from the analysis of company information, observation of activities and the semistructured interviews. In relation to the data collected, all the information analysed was anonymized for each organisation. The SME's chosen for this study were private sector firms and have the following characteristics:

- They are cultural institutions using their facilities to offer conferences and events;
- They have scarce resources in relation to human and financial capacity for commercial activities;

- It is a niche market where production and consumption coincide, thus a high contractual commitment is necessary;

- The target group and segments of B-2-B customers are considerably fragmented.

- They all had web sites.

It was believed that the size of the organization was less important, but rather it was a matter of the strategy to approach customers which would empower the relationships.

The conference sector was chosen within the service industry where customer orientation is the focus, and it is essential to tailor products to consumers' needs in order to survive. The conference sector (hospitality industry) in Denmark has a number of SME's, more or less subsidised by the Government, which offer unique facilities in a cultural environment while offering conference facilities. The attention on customers is vital in a highly competitive market place with increasing product offerings due to low entrance barriers from other related industries e.g. caterers and restaurants requiring large facilities in historic old buildings or rejected warehouses.

The actual sizes of companies were in the range 10-50 employees. Company A provides a wide range of graphic display products and highly innovative and cost-effective display and merchandising solutions, tailor-made to the exact requirements of the customer. Company $\mathrm{B}$ runs an exhibition venue with 5,000 sq metres of space for many different types of events such as trade fairs, product presentations, dinners and parties from 300 to 3,400 seated guests as well as conferences with 300-1,200 participants. Company $\mathrm{C}$ runs a popular venue for cultural, corporate events and sport and with 22,000 sq metres of area and offers a range of conference facilities in addition to other facilities. Company D runs a design centre which involves innovative temporary exhibits on the main floor including local design with the rest of the focus on international design. 
In accordance with Yin (2009) the case study approach used for this work has:

1. Aimed to understand and explore how near SMEs are to achieving a 360-degree approach to managing customer relationships;

2. Not necessarily commenced with a set of preconceived questions and ideas with regard to the organisations which have been researched;

3. Employed multiple methods to collect the relevant information from the case study sources and the relevant literature.

The following findings provide the results of the four SME case studies investigated. The potential outcome of the analysis of the findings provides insights into how SMEs manage and build customer relationships and how near they are to achieving a 360-degree view approach.

\section{RESULTS}

\section{(1) Customer Management Approach}

Research Question - what customer management approach is the SME using?

It was difficult to identify one single customer management approach which all SMEs in the study currently used, but some elements were generally the same. The sales and marketing department were key channels, in which the SMEs grouped several touch points to ensure one contact person to manage a customer.

After interviewing the four SMEs in the Danish conference sector it was found that they all were using some kind of database system to manage customer data. None had a completely integrated or advanced CRM system within the organization, but more than one had a CRM system running, albeit at different stages as to the extent it provided synergy or synchronized data across different products when purchased by the same customer. "Management of information and data is registered in a database system - at the moment only data related to one activity can be registered, which means that if the same customer has purchased another product, I would not know unless I was informed directly personto-person" (company a).
Two other SMEs were focusing on two separate databases depending on pre-sales contacts or committed customers for product delivery in the sales and marketing department, yet they were still in the process of integrating a CRM system. "We don't have one "golden" CRM system. We have more units within the organisation, which do not have integrated information about the same customers who approach us through different channels" (company c). "Our mindset is very much like CRM - we think like CRM, but because it's very complicated to integrate different systems and the costs are huge it's difficult to achieve" (company d).

\section{(2) Transactional-oriented or Relational- oriented Customer Approach}

Research Question - to what extent does the SME use a transactional-oriented or relationaloriented customer approach?

Half of the SMEs made an effort towards establishing a personal relationship with the customer. From an academic point of view, relationship marketing is about creating and maintaining long-lasting relationships through interactive dialogue, product benefits, and high customer service orientation across the organisation (Egan, 2011; Little and Marandi, 2003; Christopher et al, 2002; Gronroos, 2000; Gummesson, 1999). Other SMEs showed that it perhaps was more a matter of quick exchange of business. Others have argued that relationship marketing is just a framework for exchange which managers had to consider when focusing on appropriate product/service, customer and organisational methods (Palmer, 1996; Rich, 2000; Rao and Chad, 2002).

A question was whether SME's had moved from a short-term transactional-oriented approach at all? Or have they moved towards a long-term relational-oriented approach? Kotler (1991) argued that businesses were moving away from a focus on exchange - a narrow sense of transaction-towards building value-added relationship and marketing networks. Rogers $(2000 \mathrm{a} \& \mathrm{~b})$ claimed that the revolution is about 
customer, relationships and technology. The interviews indicated that SMEs in transformation between eagerly conducting quick sales to increase revenue (i.e. transaction according to Kotler, 2002), as well as trying to make efforts to build long lasting relationships for future profits. All the SMEs interviewed were facing a transformation from being more or less productorientated/transactional to becoming more relational in the process of building and managing customer relationships. This was confirmed by the statement "we don't really have relationships to a lot of our customers because we still focus on the products and activities, and not on the customer itself' (company a). They continue that it is difficult to build relationships with a customer when they do not know the customer's business, and when each has its own database.

It could be argued that SMEs were in the transformation of becoming more relationaloriented towards customers, but it was the nature of the Internet, which embraced the quick exchange between the two parties, and due to convenience therefore accepted the transactionaloriented customer approach, as was the case for most enterprises in the 1970s and 80s.

It is the evolution from transaction marketing to relationship marketing, which results in research indicating the need for a more rigorous database and greater utilisation of current computerised tracking systems. All the SMEs interviewed had some kind of databases to accumulate customer data, suggesting that they had progressed with the relationship revolution. The question was rather; what approach did they conduct when looking into the channels and touch points they used for building relationships?

\section{(3) Personalised, Digitalised or Customised Ap- proach?}

Research Question - which approach in terms of personalised, digitalized or customized, or a combination of these, is the SME using?

During the 1980s and early 1990s relationship building and management was a leading approach in modern marketing practice (Jackson,
1985; Dwyer et al., 1987). Yet there was a difference between conducting a personalised, digitalised or customised approach.

Along with the relationship revolution, and one-to-one marketing, a personalised approach would better manage individual relationships to individual customers (Rich, 2000; Lackner, 1998). Alternatively, a digitalised approach embracing the Internet as the source of information, feedback, and data gathering would build strong relationships (Hanson, 2000; Stermer, 1999). With a combination of the two approaches, a customised approach, digital evolution continuously improved technical systems to support business performance, yet personal relations were equally important (Zineldin, 2000; Peppers \& Rogers, 2000a\&b; Hill 2001). It could be argued that SMEs pursued a one-to-one, personalised approach to better manage individual relationships to individual customers.

As Websites became cheaper and more advanced, relationships developed with improved online communication between companies and customers. SMEs conducted a digitalised approach, embracing the Internet more than just uploading company information onto a Website. According to Hanson (2000) it was a process developed in three stages: (i) publishing sites; (ii) databases and forms; (iii) personalisation.

As the one-to-one vehicle further developed the personalisation approach to a larger scale (i.e. mass customisation); and the impact of the Internet together with information technology has enabled automation of sales and marketing efforts i.e. CRM systems (Peppers and Rogers, 2003a\&b), a customised approach was a more accurate characteristic of SMEs' access to customers.

Assuming that the three customer approaches reflected the relationship evolution, every SME should have achieved an integrated CRM system, to manage each of their individual customers. Yet, this seemed not to be the case. The SMEs appeared close to pursuing a combined customer approach embracing all three approaches - a personalised, digitalized, and customized approach. 
(4) Whether SME's Are Ready With Regard to 'New' Behaviour in Their Customer Approach

Research Question - What is the SME's attitude towards change in their customer approach?

When exploring the status of how near SMEs were in the CRM process, it appeared that those SMEs interviewed were either not advanced with an integrated CRM system and used a simple database system instead; nor when having one, they used it as an advanced database system to manage customer data, leaving out the integration of knowledge sharing between departments, and counting on personal relationships established on an individual basis.

The SMEs seemed committed to CRM principles believing in its high relevance and benefits to current and future business. For all it was vital to register and manage information to know what customers want, when and how in order to create loyalty and retain customer portfolios. "It's very relevant for any company to have a CRM system, regardless of the size. It's vital to handle and register the information about your customers in order to work constructively" (company b). They were aware of how fragile their organisation would be once an employee moved to another firm having stored valuable customer profile information in their head. This was something that could be avoided if a central CRM system was used.

SMEs' attitude towards a change in their customer approach was obtained through statements of their strengths and weaknesses in building customer relationships. Their statements showed that their attitude supported the business philosophy of CRM and that they already thought CRM (company d). SMEs appeared to be ready to change their behaviour to improve their customer approach. However, their weaknesses showed that they still had some hurdles to overcome.

The central issue for all four SMEs was that their database systems, even the two more advanced ones, were not geared for a highly customer-centric approach. This was confirmed by the comment, "we don't really have relationships to a lot of our customers because we still focus on the products and activities, and not on the customer itself, thus we approach them as "debtors", not as customers" (company a). This illustrated that product-orientation was an obstacle to becoming fully customer-oriented, so data registration was based upon product activity on specific dates and not continuously developed and improved for customer profile purposes.

\section{(5) SMEs and the 360-degree view approach}

Research Question - How near are SME's to achieving a 360-degree view approach?

Giving customers access to use multiple channels when they contact a company, while building a single customer relationship is the essence of a 360-degree view (Hood, 2003; Stone, 2003a,b\&c; Peppers and Rogers, 2003). When exploring the results of the interviews, the SMEs appeared to be conducting a CRM philosophy without knowing it.

They grouped sales, marketing and sales channels as one unit, handled most of the contact points sales, marketing and Website, service, support, evaluation, and reclamation, while being a call centre. This suggested that they used multiple channels and possible touch points to approach customers. SMEs potentially concentrated their effort to the benefit of the customers. It was explained, "I think we have a 360-degree approach to our customers because there's no information lost. We are in control of who's account is responsible to each individual customer, and we have some really good tools to handle the relationships (CRM, website, newsletter), which support all our channels" (company b).

Establishing a cross-functional team with a cohesive mission that encompasses the entire customer touch points embraces a 360-degree view. The SMEs were already well ahead in their approach. For instance, company d explained that knowledge sharing was one of their biggest assets, and that everyone involved across departments knew about the final product when delivered to the customer. Regardless of which 
contact touch points the customer used, the people involved were informed.

The SMEs seemed very focused and dedicated to add value to their customers. They emphasised the importance of having one contact person in charge. This was confirmed, "We add value by giving the customers inspiration, and inputs to flexibly adjust the product to their needs" (company b), and supported by, "In order to keep this positioning, having a unique product offering, you need to keep being flexible and adjust your product to the customer's needs" (company d). However, statistics show SMEs are still in transition (IOMA's report on Customer Relationship Management, 2004) and debate is ongoing as to why more SMEs are not pursuing a customer relationship strategy where a 360-degree view is applicable.

The literature indicates that once SMEs were ready to pursue a customer relationship strategy, it could be identified as a one-to-one focus when building relationships to single customers (Peppers \& Rogers, 2003). Those SMEs interviewed all seemed to have problems with "handling the customers individually" once there were more than ten. This could arguably be one reason why they seemed slow in achieving a 360-degree view approach.

Throughout the literature there is agreement that financial, organisational or educational aspects could be potential barriers to develop the CRM and 360-degree view process. A possible barrier was that SMEs were unable to see an immediate benefit, or even to perceive a benefit, given what was actually available for them (Robinson, 2004). This did not reflect the views of the SMEs interviewed since they did see the benefit of having an integrated CRM system, but due to limited human and financial resources, and capacity at an operational level, found alternative ways of optimising a more or less advanced database system to handle customer contacts.

Organisational issues were mentioned as an internal barrier, where due to less rigid, sophisticated and complex organisational structures they were not ready for CRM and a 360-degree view
(Hill, 2001). This suggestion was fairly true "we don't have capacity enough to actually achieve the 360-degree customer profile to improve our relationship with each individual customer" (company c). The reason for this was likely to be because SMEs were usually in progressive development - like start-up companies, and CRM and 360-degree approaches had a low priority given the lack of time to structure or formalise overall procedures.

SMEs were theoretically better equipped for CRM, but in the real world it was not happening because they did not have the staff or the consultant power to progress into CRM as a business strategy (Curry, 2002). This was because they did not have a large number of employees structured into different skills and organisational functions. It was impossible to provide one holistic, cross-channel integrated CRM system to support the 360-degree view approach.

SMEs were already customer-centric but did not have the financial and human resources to provide customisation, personalised attention, and focus on after-sales support to customers. This organisational issue could arguably be a major barrier to explaining why SMEs potentially were slow in achieving a 360-degree view approach.

Alternatively, Curry (2002) suggested that it was a matter of education as to why SMEs did not achieve a 360-degree approach. And as Robinson (2004) argues, since a learning curve investment would achieve CRM and a 360-degree approach i.e. reshaping the customer process; selecting CRM systems and developing training programmes was a major barrier to SMEs. This was in fact true for those SMEs interviewed.

The overall results showed that the four organisations seemed to have something close to a 360 degree approach but they did not refer to it as that and simply "got on with it". This appears to be a fairly typical situation in SMEs since they simply do things without ascribing terms for what they do as entrepreneurs. Generally very few firms will have a fully developed CRM system and one would certainly expect less among 
smaller firms. Here it is important to observe that good CRM implementation actually gives a 360degree view of the customer.

For the SMEs a formal strategy, for example a CRM strategy, appears to be absent and is probably not relevant. Firms of this size are probably operations oriented so that they have a body of knowledge for CRM operation. It would appear best to evaluate them in terms of an operational perspective and not from a formal strategic one.

\section{CONCLUSIONS}

Through an understanding of how SMEs managed and built customer relationships, the objective of this research was to investigate how near SMEs in the Danish conference sector are to achieving a 360-degree view approach in order to manage customer relationships. The literature advocated that CRM and the 360-degree view were important tools to investigate the different ways in which an organisation "touches" a customer (Stone, 2003b). When analysing the attitude and mindset of the SMEs, they rather thought like CRM while building and managing relationships without reflecting upon the synonymous term CRM, 360-degree or another term of approach.

Business advocators for CRM suggested that it required a learning curve investment to achieve CRM and a 360-degree approach i.e. reshaping customer process, selecting CRM systems and developing training programmes, and that was something SMEs appeared not to pay enough attention to (CRMGURU, 2004). Academic research advocated that creating a continuous interactive dialogue with customers, exploiting the customer data available to them, and turning it into empowering knowledge, would ensure a unified view of a single customer relationship - a true 360-degree view approach (Hood, 2003; Gummesson, 2004; Gummesson, 2002; Stone, 2003a,b\&c; Peppers and Rogers, 2003). It was really a matter of giving customers access to use multiple channels when they contacted a compa- ny, while building a single customer relationship. Yet, how ready were SMEs really for such an approach to achieving this 360-degree view of each customer profile?

The findings showed that several SMEs expressed a lack of understanding, differing interests and no recognition by senior management or indeed the rest of the organisation. They had an underlying attitude and mindset of "What's in it for us", which subsequently indicated that most of them had not prioritised 360-degree and CRM high enough, and indicated potential obstacles to implement CRM. Yet, when examining the interview findings in more detail, it became evident that SMEs were in the process of building value-added relationships with their customers and pursuing a combined customer approach that embraced a certain level of personalised, digitalized and customised approach. This was partly through creating interactivity and dialogue with customers and partly by establishing customer relationships through personal relationships. Business focus was likely to transform into CRM with a hybrid of marketing relationship programmes that would range from relational to transactional to outsourcing market exchanges and customer interactions. When examining the generalizable results of the case studies, the SMEs appeared to be conducting much of a CRM philosophy already and it appears that this would hold true for other cases.

As argued by CRM advocates issues such as education and knowledge relating to the potential of CRM coupled with a 360-degree approach could provide SMEs with a potential competitive advantage (CRMGURU, 2004).

The literature indicates that SMEs are unprepared to adopt a 360-degree view approach. The empirical findings illustrated more conviction indicating the view that SMEs in the Danish conference sector were in the process of adopting a CRM approach and focusing increasingly on establishing a 360-degree view for each customer. Analysis of the findings showed that SMEs were still very slow in the development process due to educational, financial and organisational barri- 
ers/challenges, and although using multiple channels and possible touch points to approach individual customers, they appeared to be not fully prepared to adopt a 360-degree view at this present time. The benefit of a 360-degree view is unique customer information collected through a number of integrated channels and converted into valuable insights based on thorough analysis of past customer purchases across all channels. In terms of originality/value the paper indicates that although SME's in the sector focus increasingly on building and managing individual customer relationships, they appear not to be fully prepared to achieve a 360-degree view.

\section{REFERENCES}

Acs, Z., Morck, R., and Yeung, B. (2001). Entrepreneurship, globalisation and public policy. Journal of International Management, 7(3), 235-251.

Bosma, N., and Harding, R. (2006). Global Entrepreneurship Monitor, GEM 2006 results. London Business School and Babson College, (available on http://www.gemconsortium.org/, accessed on 10th March 2008).

Brooksbank, D., and Jones-Evans, D. (2005). Global Entrepreneurship Monitor - 2005 Wales Executive Summary Report, Welsh Assembly Government, (available on http://www.gemconsortium.org/, accessed 10th March 2008).

Burns, J. (1995). Illuminating Developing and implementing a customer strategy. Managing Service Quality, 5(4), 44-48.

Christopher, M., Payne, A., and Ballantyne, D. (2002). Relationship Marketing: Bringing Quality, Customer Service and Marketing Together, Butterworth, London.

CRMGURU.com (2004), Understanding SMEs, Roundtable discussion, $12^{\text {th }}$ February. Attending: Jay Curry, Paul Greenberg, Erin Kinikin, and Bob Thompson, resume edited by Thompson, $\mathrm{T}$.
Curry, J. (2002). Keys to CRM success for SmallMedium-size Enterprises. Retrieved from: CRMGURU.com, $14^{\text {th }}$ April, item no 424, http://crmguru.custhelp.com/cgi-

bin/crmguru.cfg/php/enduser/std_adp.php?p_ sid=*u8g_dmh\&p_lva=\&p_faqid=424\&p_cr eated $=1018773431$.

Dwyer, F.R., Schurr, P.H., and Oh, S. (1987). Developing buyer-seller relationships. Journal of Marketing, 51 (2), 11-27.

Egan, J. (2011). Exploring Relational Strategies in Marketing. 4 ed, Pearson Education.

EU (2007). European business - Facts and Figures - 2007 edition, European Commission (http://epp.eurostat.ec.europa.eu/portal/page? _pageid=1073,46587259\&_dad=portal\&_sch ema $=$ PORTAL\&p_product_code $=K S-B W-$ 07-001, accessed 10th March 2008).

Fanelli, M. (2004). Contact strategy. The hot new direct marketing term - explained, $A d$ Age.com,

http://www.adage.com/MarketingIntel/contac tmarketing.html

Galbreath, J., and Rogers, T. (1999). Customer relationship leadership: a leadership and motivation model for the twenty-first century business. The TQM Magazine, 11(3), 161171.

Gronroos, C. (2000). Service Management and Marketing. A customer Relationship Management Approach. 2 ed. John Wiley \& Sons.

Gummesson, E. (2004). Return on relationships (ROR): the value of relationship marketing and CRM in business-to-business contexts. Journal of Business \& Industrial Marketing,19(2), 136-148.

Gummesson, E. (2002). Relationship marketing and a new economy: it's time for deprogramming. Journal of Services Marketing, 16(7), 585-589.

Gummesson, E. (1999). Total Relationship Marketing. Rethinking Marketing Management: From 4Ps to 30Rs. Butterworth-Heinemann.

Hanson, W. (2000). Principles of Internet Marketing. South-Western College Publishing. 
Haydock, M. (2000). Direct Marketing News, 2000.

Hill, J. (2001a). A multidimensional study of the key determinants of effective SME marketing activity: Part 1. International Journal of Entrepreneurial Behaviour \& Research, 7(5), 171-204.

Hill, J. (2001b). CRM Success Through Integrating Customer Touch Points. Filter v.3.1, Agency.com.

Hood, R. (2003). One Customer, One Relationship, Multiple Marketing Channels. What's new in Marketing (WNIM) online, Issue 13.

IOMA, (2004). Report on Customer Relationship Management. IOMA.

Jackson, B.B. (1985). Build customer relationships that last. Harvard Business Review,63(November- December), 120-8.

Kinikin, E. (2004). Scorecard Summary: Siebel's CRM on Demand. Forrester Research, March 5.

Kotler, P., Jain, D., A, and Maesincee, S. (2002). Marketing Moves. Harvard Business SchoolPress/ McGraw-Hill.

Kotler, P. (1991). The New Marketing Paradigm. Marketing Science Institute Review, Spring(1), 4-5.

Lackner, D. (1998). One-to-one marketing: maximizing database marketing with customer intelligence. Telemarketing \& Call Center Solutions, 16(8), 68-71.

Langford, B., and Cosenza, R. (2000). Surviving the click versus brick wars by managing five customer contact points, Frontiers in Direct and Interactive Research Proceedings. New York, NY : John Wiley \& Sons, p28-31, 4p.

Leo, Y.M., Sin, A., Tse, C., and Yim, F. (2005). CRM: Conceptualization and scale development. European Journal of Marketing, 39(11/12), 12-28

Little, E., and Marandi, E. (2003). Relationship Marketing Management, Cengage Learning, Chicago.

Macintosh, G. (2002). Perceived risk and outcome differences in multi-level service rela- tionships. Journal of Services Marketing, 16(2), 143-157.

Mitussis, D., O'Malley, L., and Paterson, M. (2006). Mapping the re-engagement of CRM with relationship marketing. European Journal of Marketing, 40(5/6), 572-589.

Palmer, A.J. (1996). Relationship marketing: A universal paradigm or management fad? The Learning Organization, 3(3), 18-25.

Peppers, D., and Rogers, M. (2000a). Accuracy of Data. Retrieved from: 1tol.com, on $15^{\text {th }}$ December.

Peppers, D., and Rogers, M. (2000b). RealWorld Lessons in Customer Relationship Management, The One to One Manager.

Peppers, D., and Rogers, M. (2003). Solving the Data Dilemma: Maximising Data Quality to Build Profitable Customer Relationships, White paper, Peppers \& Rogers Group.

Rao, S., and Chad, P. (2002). Thinking about relationship marketing: Where are we now? Journal of Business \& Industrial Marketing, 17(7), 598-614.

Rich, M.K. (2000). The direction of marketing relationships. Journal of Business and Industrial Marketing, 15(2/3), 170-179.

Robinson, T. (2004). SMEs and CRM: An Odd Couple? CRMGURU.com, 12 February, Retrieved from: http://crmguru.custhelp.com/cgibin/crmguru.cfg/php/enduser/.

Rogers, M. (2000a). You say CRM, I say one-toone, 1tol.com, $3^{\text {rd }}$ August, Retrieved from: http://www.1to1.com/View.aspx?DocID=102 20.

Rogers, M. (2000b). A Collective One-to-One Experience, Inside 1to1, Issue January 20.

Rogers, M., and Zeuner, B. (2004). Let's Talk Process: Tactical Steps for Driving Higher Sales From Your CRM Initiative, web seminar by Saleslogix and Rogers \& Peppers Group, $16^{\text {th }}$ March, Retrieved from: http://highspeed.saleslogix.com/downloads/p eppers/march04/Webinar.pdf

SBA, (2007). Small Business Act for Europe, European Commission (EC) - Enterprise and 
Industry, Retrieved from: http://ec.europa.eu/enterprise/entrepreneurshi p/sba_en.htm\#_ftnref1, 10th March 2008).

Schoenbachler, D.D. (2002). Multi-channel shopping: understanding what drives channel choice. Journal of Consumer Marketing, 19(1), 42-53.

Simons, L., Steinfield, C., And Bouwman, H. (2002). Strategic Positioning of the Web in a multi-channel market approach. Internet $R e$ search: Electronic Networking Applications and Policy, 112(4), 339-347.

Stermer, J. (1999). Exchang Marketing Threat or Opportunity? AC Nielsen Online

Stone, M. (2003a). The new marketing? Or old lamps for new? What's new in Marketing online, WNIM.com, June, issue 18, http://www.wnim.com/archive/issue1803/ind ex.htm.

Stone, M. (2003b). CRM - The Value of Marketing and Customer Management, What's New
In Marketing online, WNIM.com, September, issue 21 , http://www.wnim.com/archive/issue2103/cr m.htm.

Stone, M. (2003c). CRM - The Value of Marketing and Customer Management, What's New In Marketing online, WNIM.com, October, issue 22 , http://www.wnim.com/archive/issue2203/cr m.htm.

Yin, R. (2009). Case study research: Design and Methods. Beverly Hills, CA: Sage Publishing.

Zineldin, M. (2000a). Total relationship management (TRM) and total quality management (TQM), Managerial Auditing Journal, $15^{\text {th }}$ January, 20-28.

Zineldin, M. (2000b). Beyond Relationship Marketing: technological marketing. Marketing Intelligence \& Planning, 18(1), 9-23. 


\title{
Diffusion and Consumer Use of the Internet: A Cross-National Investigation
}

\author{
David B. Kuhlmeier
}

\begin{abstract}
Researchers examined the diffusion and adoption of technologies in international settings. Cross-national consumer behavior regarding the intention to buy products and services online is investigated in an empirical study of 344 Internet users from France and the United States. Findings vary between the countries, but reveal negative associations between frequency and length of Internet use and perceived risk of purchasing online, and between perceived Internet risk and purchase intention. These findings are discussed in context of the technology acceptance and diffusion of innovation theories. Results are then discussed regarding their theoretical and practical implications.
\end{abstract}

KEYWORDS. Internet, e-commerce, international, diffusion, adoption, technology

\section{INTRODUCTION}

Firms that seek to market their goods and services on the Internet face numerous challenges, such as website functionality and appeal, development of security and trust, payment mechanisms, to name a few. As in domestic marketing, these challenges become more complex when a firm targets international consumers. As an international marketing tool, the Internet presents a powerful means by which to efficiently and effectively reach customers worldwide. Consequently, there is a need to understand what factors may differ across cultures in how potential customers may adopt technology like the Internet for purchasing goods and services.

It has already been established that culture influences a user's perception of IT innovations (e.g., Chiu, Fang, \& Tseng, 2010; Jarvenpaa, Tractinsky, Saarinen, \& Vitale, 1999; Ro- bichaux, \& Cooper, 1998; Straub, Keil, \& Brenner, 1997) and that the acceptance rate of such technologies can vary across national settings (e.g., Thornton \& Marche, 2003). The adoption of the Internet, as a particular type of IT, to make purchases is also likely to vary according to various factors (McCoy, Galletta, \& King, 2007; Singh, Fassott, Chao, \& Hoffmann, 2006), including culture (Van Slyke, Lou, Belanger, \& Sridhar, 2010). Such considerations, are among the factors which marketers must consider in determining how to successfully establish their presence online and to attract potential international customers to use their website.

Although much of both the academic and business world is abuzz of how the Internet has changed the economy and how business is conducted, comparatively little is yet known about what factors influence consumer online spending habits. It is safe to assume that the longer a con-

David B. Kuhlmeier, Ph.D. is affiliated with Langdale College of Business Administration, Valdosta State University, Valdosta, GA 31698, USA.

Address correspondence to David B. Kuhlmeier, Longdale College of Business Administration, Valdosta State University, Valdosta, GA 31698, USA. E-mail:dbkuhlmeier@valdosta.edu

The author gratefully acknowledges the valuable contribution from Gary Knight, Ph.D. of Florida State University in editing this paper and the financial support for this study provided by the Steele Foundation of the Langdale College of Business Administration, Valdosta State University. 
sumer has been using, and the more often he/she uses a technology to make purchases, the higher would be their intention to make such purchases in the future. However, the uncertainties and risks that people may perceive in using such a technology may also affect their online purchase intention (e.g., Gefen, 2000; Ha, Muthaly, \& Akamavi, 2010; Kuhlmeier \& Knight, 2005), especially when those purchases are conducted internationally (e.g., Makhija \& Stewart, 2002; Mitchell \& Vassos, 1997; Verhage, Yavas, \& Green, 1990; Weber \& Hsee, 1998). Risk historically has been considered as a vital influence on any consumer purchase decision (e.g., Bauer, 1960; Dowling \& Staelin, 1994; Weber, Blais, \& Betz, 2002).

The Internet's dynamic nature and tendency to be influenced by such factors as culture, perception of risk, and experience warrant additional research into consumers' online purchase intentions. Therefore, this study will use data from France and the United States to examine the roles and interrelationships of key antecedents in online consumer purchasing. France and the United States were chosen not only because of their similarities in socio-economic, sociocultural, and infrastructure terms, but also because they are both examples of the Western cultures for which most of online practices and procedures were originally developed:

\section{THEORETICAL BACKGROUND}

Firms are confronted by various challenges in using the Internet to market their goods and services around the world. Not only is Internet technology itself challenging because of its complex and dynamic nature, but also the acceptance and presence of Internet technology in a particular country may differ as a result of cultural influences.

One method of explaining as to how technologies are adopted that is often cited is the Technology Acceptance Model (TAM) first proposed by Davis (1989). The TAM implies that the perceived usefulness (U) and perceived ease of use (EOU) of a technology will influence attitudes towards its use. Such attitudes will then influence behavioral intentions, which, in turn, leads to actual use. Although the TAM has been used successfully in the information technology (IT) literature, research as to its applicability to consumer Internet use is limited (e.g., Turner, Kitchenham, Brereton, Charters, \& Budgen, 2010). One exception is Singh et al. (2006) in which the TAM was used to analyze American and Japanese MNE websites as they appeal to Brazilian, German, and Taiwanese consumers. From their study, Singh et al. (2006) established the TAM is indeed useful in an international setting and that cultural adaptation should be included as a variable when using the TAM in cross-cultural studies.

The applicability of the TAM in international settings was further analyzed when Almutairi (2007) applied it within the Middle Eastern culture of Kuwait. Almutairi (2007) discovered that TAM has limited explanatory power when used in conjunction with a non-Western culture, especially one as distinct as Kuwait. Therefore, the external validity of the TAM cannot be established and its use should not be presumed to have explanatory results in all settings. In his seminal work, Hofstede (1991) found fault with many management theories as a result of what could be termed as their ethnocentric North American orientation. As Aharoni and Burton (1994) established, external validity is a central concern of any research, an important element of which for cross-cultural studies is "international validity."

Since the TAM may not apply to all international settings, McCoy, Galletta, and King (2007) warn that caution and rigorous testing should be exercised when applying it in multicultural contexts. They further indicated that technologies such as the Internet are not equally adopted between developed economies and developing economies, which typically suffer from lower levels of education and per capita income. Such a study has emphasized that technology 
adoption theories cannot be uniformly applied in all cultural settings.

With two economically, politically, and socially similar cultures as the present sample (i.e. France and USA), it could be expected that the use of a technology such as the Internet would enjoy a constant and similar diffusion. However, even within a culture it has been found that attitudes toward Internet use can differ according to variables such as age, education, income, and race (Porter \& Donthu, 2006). Although it is acknowledged that such variables can serve as access barriers to the Internet, which can definitely affect its adoption, TAM variables such as ease of use and usefulness tend to have a stronger influence (Porter and Donthu, 2006).

Preceding the TAM as an influence on consumer purchase behavior is the Theory of Reasoned Action (TRA), first proposed by Fishbein and Ajzen (1975). TRA addresses the motivations that influence consumer purchase behavior, especially the motivational roles of attitudes and subjective norms. Regardless, as there are varying levels of technology in the world today, Internet adoption by consumers for purchasing cannot be fully explained unless specific customer situations in the adoption and acceptance of the technology are taken into consideration. Consequently, any explanation that TRA can have in the adoption of the Internet by consumers for purchasing can only be augmented by the TAM. In fact, the TAM was developed by Davis (1989) from the TRA of Fishbein and Ajzen (1975) as a means of extending a general theory to a specific contextual usage, that is, technology.

Equally relevant to how the acceptance and adoption of a technology is influenced by its diffusion as an innovation is the work of Rogers (1983). In his diffusion of innovation theory, Rogers (1983) offered a perspective that differs from that of the TAM and TRA. According to Rogers, the rate of adoption of an innovation was based on the user's perception of the innovation's attributes, i.e. "in the eye of the beholder" (1983, p. 212). Rogers (1983) then posited five attributes or characteristics of an innovation that appeal to the perception of the user to make it distinct from previous technologies: relative advantage refers to "the degree to which an innovation is perceived as being better than the idea it supersedes" (p. 213); compatibility is "the degree to which an innovation is perceived as consistent with the existing values, past experiences, and needs of potential adopters" (p. 223); complexity refers to "the degree to which an innovation is perceived a relatively difficult to understand and use" (p. 230); trialability is "the degree to which an innovation may be experimented with on a limited basis" (p. 231); and observability is "the degree to which the results of an innovation are visible to others" (p. 232).

What Rogers (1983) presents as "relative advantage" and "complexity" closely correlate with the "perceived usefulness" and "perceived ease of use" respectively of TAM (Davis, 1989). As a result, TAM, TRA, and the Diffusion of Innovation perspective present excellent theoretical coordinates from which to examine individual factors that might influence the adoption and use of the Internet by consumers to make purchases (Oh, Ahn, \& Kim, 2003).

Although much has been said for a number of years about the globalization of the consumer market, nothing has had as far-reaching effect on globalization as the Internet. Faced with the growing challenges from well-established, wellconnected, and well-funded corporate giants, a technology like the Internet presents independent and smaller firms a means to level the playing field in marketing their goods and services around the world.

\section{HYPOTHESES DEVELOPMENT}

Any purchase situation entails a certain degree of risk and it has been established (e.g., Akaah \& Korgaonkar, 1988; Cox \& Rich, 1967; Engel \& Blackwell, 1970) that there is a higher degree of risk associated with non-store purchases, such as over the telephone or via a cata$\log$, than with in-store purchases. Various types 
FIGURE 1: Proposed Model

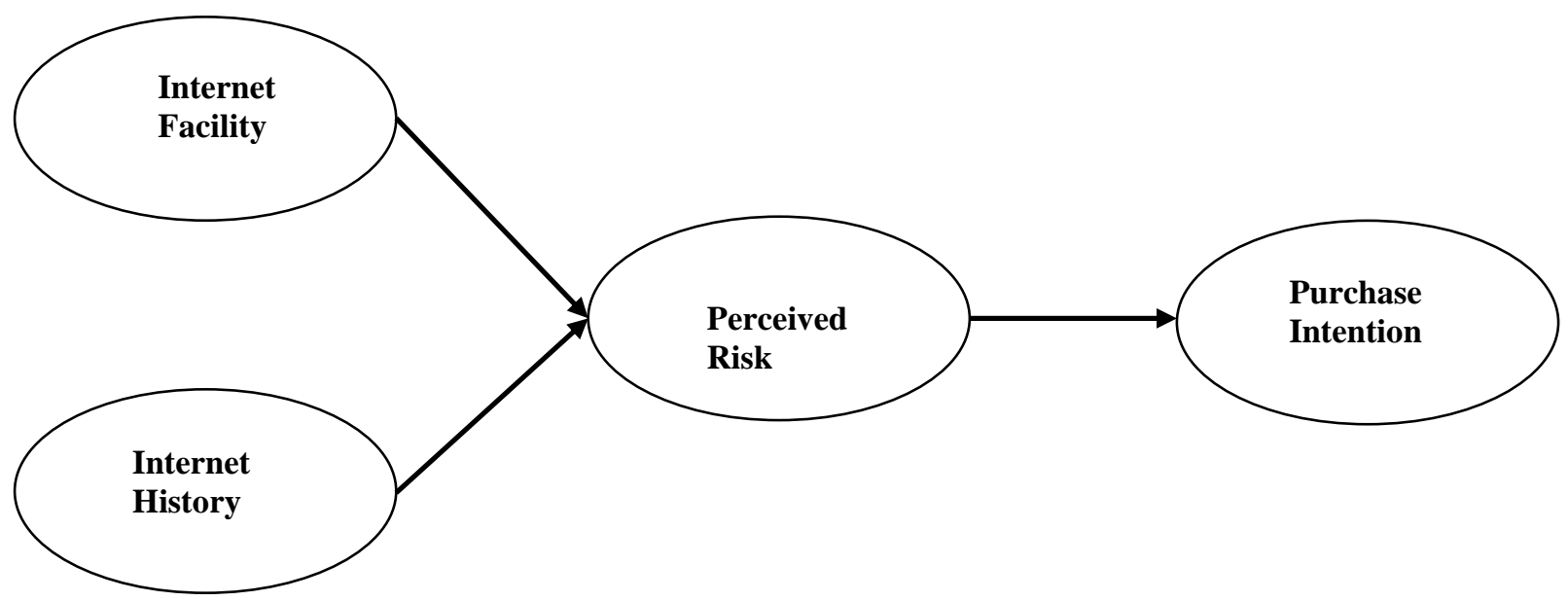

of risk are associated with purchases made over the Internet (e.g., Ernst \& Young, 2010; Modahl, 2000; Quelch \& Klein 1996). In a rather counter-intuitive finding, Hoffman, Novak, \& Peralt (1999) determined that concern for personal information, such as credit card numbers, is positively associated with the number of online purchases made, perhaps reflecting a feeling that increased exposure to the possibility of computer crime increases the probability of being a victim. Additional reasons for perceived risk involved in online purchases include the possibility of receiving faulty or miss-specified goods (Jones \& Vijayasarathy, 1998; Quelch \& Klein, 1996; Tan, 1999). These perceptions of risk are likely to be accentuated when such purchases involve international sellers (Makhija \& Stewart, 2002; Mitchell \& Vassos, 1997; Verhage et al. 1990; Weber \& Hsee, 1998). Simply stated, the more risk a consumer perceives in an Internet-based purchase, the less likely they are to make that purchase.

In general, perceptions of risk arise when a decision-maker has advanced knowledge (i.e. a priori) of the consequences of their choice and the chances of occurrence of alternative choices (Dowling, 1986; Shimp \& Bearden, 1982; White \& Truly, 1989). The consumer's perception of risk influences every step of his/her decision making process (Mitchell, 1992). Consequently, it is useful for marketers to utilize this knowledge of a potential customer's perception of risk in order to gain a competitive advantage in online marketing (Mitchell \& Vassos, 1997).

Even though the trend of purchasing goods and services online is growing, it is still influenced by the perceived risk involved with online transactions (e.g., Aldridge et al., 1997; Ernst \& Young, 2010; Wang, Lee, \& Wang, 1998). Common concepts in the definition of perceived risk include uncertainty and the possibility of adverse consequences of some future event (Bauer, 1960; Cunningham, 1967). Bauer (1960) defines uncertainty as the probability that a person believes an unknown event would occur. Adverse consequences have been defined as the amount a consumer has at stake in achieving a particular set of buying goals (Cox \& Rich, 1967) and the relevance of loss associated with the purchase (Taylor, 1974). In addition, there are various types of loss or consequences involved in perceived risk, including what has been labeled "performance risk" and "psychosocial risk" (e.g., Cox, 1967), with other types of risk pertaining to such dimensions as physical, time, safety, financial, performance (e.g., Cunningham, 1967; Dowling, 1986; Mitchell \& Vassos, 1997; Weber \& Hsee, 1998), and the loss of 
personal information (Miyazaki \& Fernandez, 2001).

Although perceptions of risk can differ across cultures (e.g., Hofstede, 1980), research has established that a person is likely to associate less risk with an innovation the more comfortable they become with that innovation (e.g., Mitchell \& Vassos, 1997, Shimp \& Bearden, 1982; Sood \& Adams, 1984; Tan, 1999). Consequently, an online shopper's perception of risk can be expected to decline the more comfortable or familiar they become with shopping online. A growing familiarity can lead to increased trust (e.g., Kim, Ferrin, \& Rao, 2009; Mitchell \& Vassos 1997; Monroe 1976; Wilson, 1979; Zajonc, 1968), which is partially the result of the increased exposure to the innovation. This familiarity that results from increased exposure and use can lead to a reduction in the anxiety and risk that potential customers perceive in an online purchasing scenario.

The more a potential customer uses the Internet, the more aware they would become of the potential risks of using the Internet for purchasing and the security challenges it may present (e.g., Kim, Ferrin, \& Rao, 2009). These perceived risks can be made more credible to a consumer from word-of-mouth stories and advertisements promoting the sale of services such as identity theft prevention software and insurance. However, increased factual knowledge obtained from more personal use and history with the Internet can minimize such anxiety. Consequently, consumers who have been using the Internet longer in terms of years and more often in terms of hours per week should experience lower levels of perceived risk towards making online purchases. In other words, Internet Facility and Internet History are negatively associated with the perceived risk associated with online purchases.

For this study, Internet history is defined as the amount of time, in years, that a consumer has been using the Internet. Internet facility is defined as the frequency, in hours per week, that a consumer uses the Internet. It is argued that the greater the history and facility consumers have with the Internet, the more trusting they will be and the less perceived risk they will have in using the Internet for purchases. This reasoning therefore leads to the first two hypotheses:

H1: Internet Facility negatively affects Perceived Risk of Internet-based purchase.

H2: Internet History negatively affects Perceived Risk of Internet-based purchases.

For the purposes of this study, Purchase Intention is defined as the willingness of a consumer to utilize the Internet to purchase goods or services and is measured by frequency of purchase. This willingness or intention has been found to increase as a person's use of the Internet increases (Aldridge, White, \& Forcht, 1997). As previously mentioned, this familiarity, which has been connected to a person's purchase intention, can be influenced by the regular use and history that a person has with an innovation and can be associated with a person's intention to purchase (e.g., Biswas, 1992; Dahl, Manchanda, \& Argo, 2001; Monroe 1976; Zajonc, 1968). This tendency is a result of what Zajonc (1968) referred to as the "exposure effect," which increases a person's comfort with, and acceptance of, a given innovation via continuous exposure. Quite simply, people will adapt and become more comfortable with foreign items, such as new technologies, the more they use them and become more familiar with them. This principle would apply whether it is something as simple as a bicycle or as complex as the Internet.

In addition to a person's degree of familiarity, trust could also have an effect on the level of comfort in making purchases online (Chen \& Dubinsky, 2003; Luo, 2002; Mitchell \& Vassos 1997, Van Slyke, Belanger, \& Comunale, 2004). The quality and nature of relationships, particularly those in business, are affected by trust (e.g., Fukuyama, 1995; Moorman, Zaltman, \& Deshpande, 1992). This trust tends to in crease with the level of familiarity (Doney \& Cannon, 1997; Luhmann, 1979). Increased trust is likely to de- 
crease the perceived risk the consumer will experience in using the Internet for purchases (e.g., Chouk \& Perrien, 2005). Based on this reasoning, this study's last hypothesis is as follows:

H3: Perceived Risk of Internet-based purchases negatively affects Purchase Intention.

\section{METHOD}

To provide empirical support for the hypotheses proposed above, a survey was conducted of consumers in France and the United States to collect primary data. The survey instrument was developed in several stages, based on insights gained from the extant literature. The literature was searched to obtain information on the key constructs and scales appropriate for measuring them. The subjects were masters-level business students at large universities in France and the United States, countries that are key exemplars in global trade. France and the United States are advanced economies with leading-edge technological platforms. Each country is representative of a key world region in international trade.

The survey instrument was developed in several stages, following appropriate procedures (e.g., Churchill, 1979; Fowler, 1988). Once a draft questionnaire was created, it was pretested in a pilot study of 34 international students and refined based on resultant findings. Individuals who purchase goods via the Internet tend to be young and well-educated (Modahl, 2000). Accordingly, university students can be said to be strongly representative of typical online buyers. Properly completed surveys were received from 193 respondents in France and 151 respondents in the United States. On average, French respondents were 25 years old and 44 percent male; U.S. respondents were 29 years old and 56 percent male.

The survey scales and measurement information are presented in the Appendix. The unit of analysis for all constructs was the level of the consumer. All measures were assessed via fivepoint Likert scales, to reduce the potential for respondent fatigue. Purchase Intention online is the same scale used by Goldsmith (2002) and assesses the respondent's willingness to buy a product via the Internet. Perceived Risk of Internet-based purchases was measured using a scale similar to that developed by Shimp and Bearden (1982). Internet facility was gauged as the number of hours per week the respondent uses the Internet for purposes other than e-mail and is similar to the scale used by Miyazaki and Fernandez (2001). Internet history was assessed as the number of years the respondent had used the Internet for purposes other than e-mail. This is similar to "duration" (Miyazaki \& Fernandez, 2001) and is used here as a measure of the length of time a respondent has used the Internet for activities such as "surfing", research, and shopping online.

\section{RESULTS}

Initially, we subjected the construct measurement scales to a purification process. As single-item measures, Internet Facility and Internet History are not true constructs and were not subjected to psychographic evaluation. Other measures were assessed for reliability and validity (Gerbing \& Anderson, 1988; Joreskog \& Sorbom, 1997; Joreskog et al., 2000). Specifically, the scales for Purchase Intention and Perceived Risk were assessed via Cronbach's alpha (Nunnally, 1978) and confirmatory factor analysis (CFA) using LISREL8, in a single measurement model for each country sample (Gerbing \& Anderson, 1988; Jöreskog \& Sorbom, 1997; Jöreskog et al, 2000). The final scales for Purchase Intention and Perceived Risk achieved Cronbach's alphas of.93 and .69 in the France sample and.90 and .79 in the U.S. sample, respectively (Nunnally, 1978). In CFA analyses, the measurement models attained satisfactory fit: $\chi^{2}=28, \mathrm{df}=24, p=0.26, \mathrm{CFI}=.97$ for France, and $\chi^{2}=31$, df $=24, p=0.16, \mathrm{CFI}=.94$ for the United States (Gerbing \& Anderson, 1988; Jöreskog \& Sorbom, 1997; Jöreskog et al, 2000). The root mean square error of appropriation 
(RMSEA) in all assessments was less than 0.08, which suggests a solid fit between the populations of interest and the sample models (Browne \& Cudeck, 1993; Jöreskog \& Sörbom, 1997). In both measurement models, all the path coefficients linking major constructs to scale items were significant at the .01 level, which suggests satisfactory convergent validity. The minimum standardized coefficient loading for each measurement item was .43 in the France model and .57 in the U.S. model.

Several methods were used to assess discriminant validity between the constructs. First, in each CFA measurement model the correlation between each pair of constructs (the phi coefficient) was constrained and freed. The resulting change in $\chi^{2}$ was 43 in the France model and 37 in the U.S. model. These were all very significant $(p<.01)$, which implies all the constructs are independent. Second, in the correlation matrix on the full sample $(n=344)$ among all study constructs, no two constructs were correlated at more than $r=|0.32|$. Finally, CFA modification indices in each measurement model revealed that no item cross-loaded onto any construct it was not intended to measure (Jöreskog \& Sorbom, 1997; Jöreskog et al, 2000). Collectively, these tests suggest that all construct measures achieved reliability and validity.

Next, using path analysis in LISREL8, for both country samples we estimated two models that portray the relationships proposed in the hypotheses (Jöreskog \& Sorbom, 1997; Jöreskog et al, 2000). Findings revealed that Internet Facility is negatively and significantly related to Perceived Risk $(p<.05)$ in the France sample, but not in the U.S. sample. This suggests partial support for hypothesis H1. Results also suggested that Internet History is negatively and significantly related to Perceived Risk $(p<.01)$ in the U.S. sample. However, this finding did not hold in the France sample, which provides only partial support for H2. Finally, Perceived Risk of Internet-based purchases is significantly and negatively associated Purchase Intention $(p<.01)$ in both the France and U.S. analyses, which supports H3. Collectively these findings offer some evidence for a mediating role of perceived risk in Internet-based purchases.

\section{DISCUSSION}

Today, the widest range of products and services-from car parts to bank loans to finding romance - is marketed online. Transmitting data and images are essentially costless. Widespread availability of the Internet makes company internationalization cost-effective, and has opened a whole new arena for marketing offerings to buyers around the world. Findings in this study imply that various factors can affect consumer perceptions of risk about buying products and services via the Internet. On the one hand, how often, i.e. "facility," with using the Internet appeared to diminish risk perceptions among online buyers in France. On the other hand, how much experience, i.e.'history," with the Internet emerged as a key factor reducing risk perceptions in the United States. In both countries, risk perceptions significantly affected the likelihood that a consumer would purchase goods online.

The lack of support for Internet History as a factor influencing risk perceptions in the France sample could be a result of the slower diffusion of Internet technology in France compared to the U.S. (e.g., World Bank, 2009). A contributing factor could have been France's adoption of the Minitel system in 1982. Minitel was the world's most successful "online" system before the advent of the World Wide Web and utilized telephone lines to provide television screen access for subscribers in making purchases, train reservations, and performing other functions in a way similar to what is now common via the Internet.

Brousseau (2003) suggests that longstanding reliance on the Minitel system may have inhibited early adoption of the Internet in France, but simultaneously provided French citizens with substantial facility in using online services before the appearance of the Internet. By using the Minitel system, the French gained an advanced 
FIGURE 2: Results of Analyses on Each Country Model Showing Standardized Coefficients and (T-Values)

FRANCE $(n=193)$

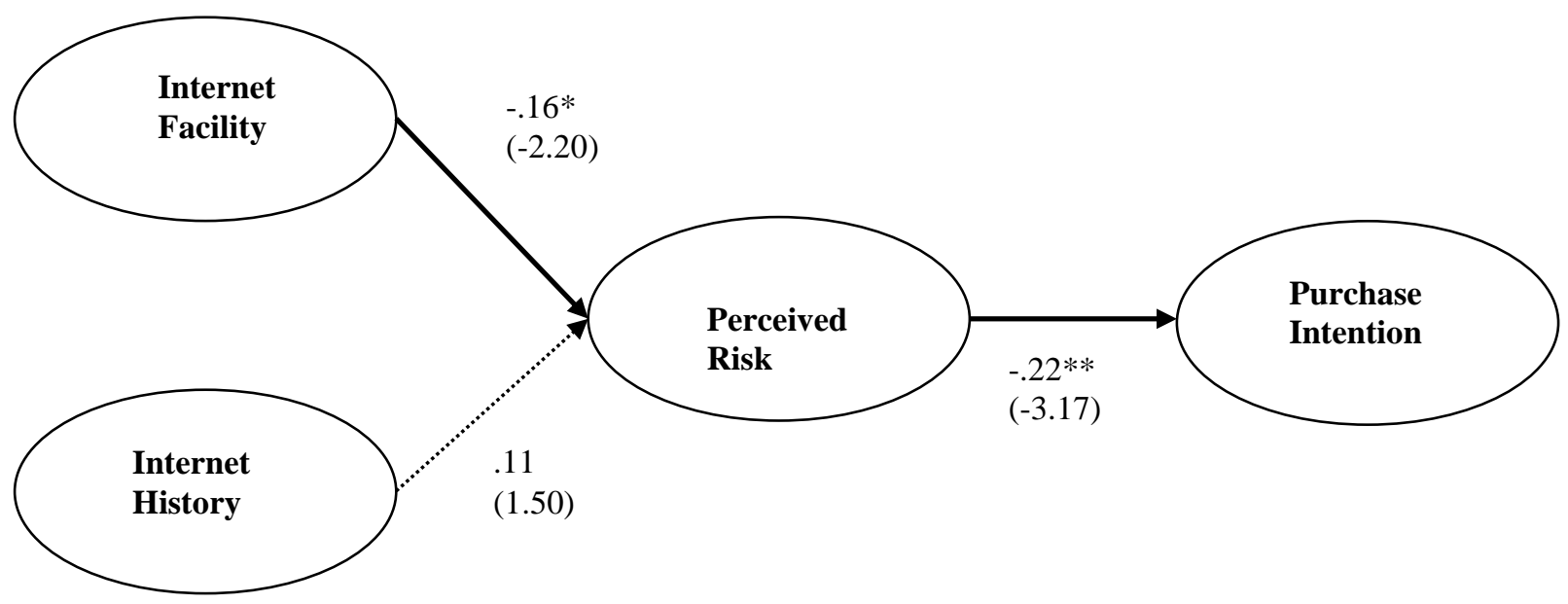

USA $(n=151)$

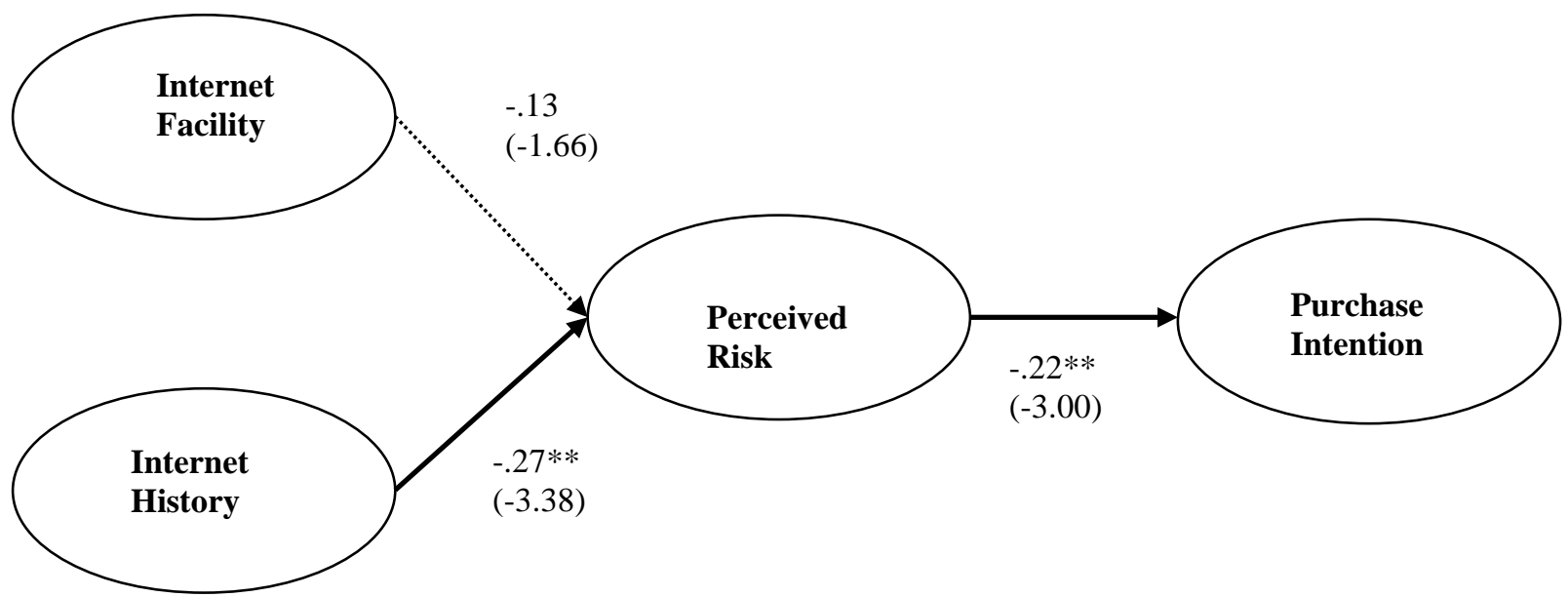

NOTE: ** relationship is significant at $p<.01 ;$; relationship is significant at $p<.05$

conceptual understanding of electronic businessto-consumer (B2C) exchanges. Such exposure could have diminished the perception of benefit presented by the Internet and, thus, presented no clear "relative advantage" (Rogers, 1983) or "perceived usefulness" (Davis, 1989) to the French.

According to Fornerino (2003) France's use of Minitel had an uncertain affect on whether its adoption of the Internet was delayed or acceler- ated. What was certain to Fornerino (2003) was that the Mintel experience changed France's behavior toward the Internet, making them "less surprised than the rest of the world" (p. 120) with it. Having already been exposed to the technological workings and efficiency of electronic commerce by using Minitel, it is possible the French did not perceive the Internet as being "relatively difficult to understand and use" according to the "complexity" characteristic of 
Rogers (1983). It also could have resulted in a "perceived ease of use" under TAM (Davis, 1989). Although such influences could have actually helped France adopt the Internet, according to Fornerino (2003) the Internet appeared as a substitution of one technology for another, not as a superior replacement technology.

Differences in the role of risk perception antecedents implies that even though two countries that are relatively similar in terms of economic and technological development may exhibit differing patterns of adoption of Internet-based systems as a function of their own specific needs and circumstances. Indeed, these findings suggest that France has followed a different path to electronic commerce than that taken by the United States. Since France has similar qualities and infrastructure as the United States, these findings serve as evidence that technologies diffuse at different rates due to multiple influences. Since countries take different paths to adoption, firms cannot take the same approach to marketing their products and services online in all markets.

In both France and the United States users perceived making purchases online as risky to varying degrees. However, study findings suggest that in cross-national settings, the antecedents to perceived risk and risk perceptions themselves may be relatively complex. There appears to be significant variation in the role of perceived risk in individual countries. More research is needed to discover the nature and extent of its influence, particularly in ecommerce conducted internationally. Depending on the country, it is likely that consumers process information on e-commerce constructs differently from consumers in other nations. The outcome is likely affected by the rate of technological diffusion in individual countries.

Companies seek increasingly to market their products and services via the Internet. Managers should seek ways to reduce the perceived risk that consumers may experience in making purchases online. This can be achieved by ensuring privacy of buyer information, such as credit card information. In advanced economies like France and the United States, managers should focus their attention primarily on the role of risk perceptions of Internet usage. Managers should take steps to increase the confidence with which buyers perceive making purchases via the Internet. This might include steps to ensure buyers receive reliable service and receive the merchandise they expect to receive, based on its presentation online.

The Internet has opened up the global marketplace to small- and medium-sized enterprises and other firms that historically lacked the resources to do international business. By establishing a presence on the Web, even small firms can offer their products and services to buyers around the world. In order to support economic development, countries need strong infrastructure in communications, such as reliable information technology systems. Internationally, the Internet is an important business resource due to its low cost and power to reach customers worldwide. As firms transform their businesses through the adoption of electronic commerce, there is a growing need to understand the factors that facilitate customer adoption of the Internet for making purchases of products and services.

Findings suggest that antecedents and use of the Internet to make purchases can also vary cross-nationally, even between two relatively similar countries like France and the United States. Companies face obstacles to influencing the intention that customers have for shopping online. Determining the appropriate conditions for adopting Internet-based selling, and what factors facilitate or inhibit buyers in using the Internet to make purchases is an important managerial challenge.

Findings also suggest that managers may need to overcome the potentially negative image that Internet purchasing may present to consumers in global markets. Efforts should be made to minimize buyers' perceptions of risk, or target buyers whose risk perceptions are already minimal. 
It is necessary for the findings of this study to be interpreted in light of specific limitations. First, Internet Facility and Internet History were measured using individual items. Second, subjects were graduate students who may not be perfectly representative of typical Internet-based consumers. Third, the nature of cross-cultural research is such that it is often difficult to control for all possible country-specific influences, such as culture, commercial patterns, socioeconomic conditions, and other such factors. Differences in results between France and the United States might result from cultural factors. For example, Hofstede (1991) found that various cultural factors present in one national setting might not be present, or present to a more limited degree, in other countries. Risk perceptions, as well as the feelings of trust, faith, and confidence in retailers and other businesses are likely to vary between the two countries. It is also possible that attitudes about such issues as risk perception vary among those who reside in cities, and those in more rural areas.

Findings and limitations of the present research suggest several avenues for future research. First, future research might employ more comprehensive measures of key concepts and constructs. Second, additional research can investigate the mediating effect of perceived risk on other dimensions of purchasing via the Internet. Research might examine whether risk perceptions vary due to differences in culture or differences in understanding of the nature of online transactions and processes. Increasingly, governments in some countries are providing legal and other protections for consumers who shop online. Research might investigate the effect of such safeguards on buyer perceptions of risk.

Third, the study subjects (relatively young and college-educated) represented one segment of the potential population of individuals who purchase products and services via the Internet. Future research should incorporate other categories of consumers. Fourth, future studies might seek to identify other factors that contribute to, or mitigate, perceptions of risk about buying goods via the Internet. Such findings would guide future efforts at marketing offerings online. Finally, similar studies can be conducted in other national settings to determine further generalizability of the current findings.

Results of the foregoing provide insights into Internet buyer behavior, which may enhance the level of online business adoption by firms. Such insight and adoption could increase the likelihood of success of firms that find themselves in a world increasingly affected by Internet technology.

\section{REFERENCES}

Aharoni, Y., \& Burton, R. (1994). Is management science international: In search of universal rules. Management Science, 40(1), 13.

Akaah, I.P., \& Korgaonkar, P. (1988). A conjoint investigation of the relative importance of risk relievers in direct marketing. Journal of Advertising Research, (August/September), 38-44.

Aldridge, A., White, M., \& Forcht, K. (1997). Security considerations of doing business via the internet: Cautions to be considered. Internet Research, 7(1), 9-15.

Almutairi, H. (2007). Is the technology acceptance model universally applicable?: The case of Kuwaiti Ministries. Journal of Global Information Technology Management, 10(2), 57-80.

Bauer, R. (1960). Consumer behavior as risk taking, in Hancock, R. (Ed.), Dynamic Marketing for a Changing World. American Marketing Association, Chicago.

Biswas, A. (1992). The moderating role of brand familiarity in reference price perceptions. Journal of Business Research, 25(3), 251-262.

Brousseau, E. (2003). E-commerce in France: Did early adoption prevent its development? Information Society, 19(1), 45-57. 
Browne, M. W., \& Cudeck, R. (1993). Alternative ways of assessing model fit. In: Bollen, K. A.and Long, J. S. (Eds.) Testing Structural Equation Models (pp. 136-162). Beverly Hills, CA: Sage.

Chen, Z., \& Dubinsky, A. (2003). A conceptual model of perceived customer value in ecommerce: A preliminary investigation. Psychology and Marketing, 20(4), 323-33.

Chouk, I., \& Perrien, J. (2005). Consumer confidence and the Internet: Proposition of a measurement scale. Revue Française $d u$ Marketing, 20(5), 5-21.

Chiu, Y., Fang, S., Tseng, C. (2010). Early versus potential adopters: Exploring the antecedents of use intention in the context of retail service innovations. International Journal of Retail \& Distribution Management, 38(6), 443-51.

Churchill, G.A. (1979). A paradigm for developing better measures of marketing constructs. Journal of Marketing Research, 16(February), 64-73.

Cox, D.F. (1967). Risk taking and information handling in consumer behavior. Harvard University Press, Boston, MA.

Cox, D.F., \& Rich, S. (1967). Perceived risk and consumer decision-making - The case of telephone shopping, in Cox, D.F. (Ed.), Consumer Behavior, Harvard University Press, Boston, MA.

Cunningham, S.M. (1967). The Major Dimensions of Perceived Risk, in Cox, D.F. (Ed.), Risk Taking and Information Handling in Consumer Behavior, Harvard University Press, Boston, MA.

Dahl, D., Manchanda, R., \& Argo, J. (2001). Embarrassment in consumer purchase: The roles of social presence and purchase familiarity. Journal of Consumer Research, 28(3), 473-482.

Davis, F.D. (1989). Perceived usefulness, perceived ease of use and user acceptance of information technology, MIS Quarterly, 13(3), 319-339.
Doney, P., \& Cannon, J. (1997). An examination of the nature of trust in buyer-seller relationships. Journal of Marketing, 61, 35-51.

Dowling, G.R. (1986). Perceived risk: The concept and its measurement. Psychology and Marketing, 3(3), 193-210.

Dowling, G.R., \& Staelin, R. (1994). A model of perceived risk and intended risk-handling activity. Journal of Consumer Research, 21(June), 119-134.

Engel, J., \& Blackwell, R. (1970). Perceived risk in mail-order and retail store buying. Journal of Marketing Research, August, 364-369.

Ernst \& Young (2010). Insights on IT Risk, April, www.ey.com, accessed May 29, 2010.

Fishbein, M. \& Ajzen, I. (1975). Belief, attitude, intention, and behavior: An introduction to theory and research. Addison-Wesley, Reading, MA.

Fornerino, M. (2003). Internet adoption in France. The Service Industries Journal, 23(1), 119-135.

Fowler, F. (1988). Survey Research Methods. Sage, Newbury Park, CA.

Fukuyama, F. (1995). Trust: The Social Virtues and the Creation of Prosperity. The Free Press, New York.

Gefen, D. (2000). E-Commerce: The role of familiarity and trust. Omega, 28, 725-737.

Gerbing, D., \& Anderson, J. (1988). An updated paradigm for scale development incorporating unidimensionality and its assessment. Journal of Marketing Research, 25(May), 186-92.

Goldsmith, R.E. (2002). Explaining and predicting consumer intention to purchase over the internet: an exploratory study. Journal of Marketing Theory and Practice, 10(2), 2228.

Ha, H., Muthaly, S., \& Akamavi, R. (2010). Alternative explanations of online repurchasing behavioral intentions: A comparison study of Korean and UK young customers. 
European Journal of Marketing, 44(6), 87485.

Hoffman, D.L., Novak, T.P., \& Peralt, M. (1999). Building consumer trust in online environments: the case for information privacy. Communications of the ACM, 42(4), 80-85.

Hofstede, G. (1991). Culture's and organizations: Software for the mind. London: McGraw- Hill.

Jarvenpaa, S.L., Tractinsky, N., Saarinen, L., \& Vitale, M. (1999). Consumer trust in an Internet store: A cross-cultural validation. Journal of Computer-Mediated Communications, 5(2).

Jones, J.M., \& Vijayasarathy, L.R. (1998). Internet consumer catalog shopping: Findings from an exploratory study and directions for future research. Internet Research, 8(4), 322-330.

Jöreskog, K. \& Sörbom, D. (1997). LISREL 8: A guide to the program, SPSS, Inc., Chicago.

Jöreskog, K. \& Sörbom, D., Du Toit, S., and Du Toit, M. (2000). LISREL 8: New Statistical Features, Scientific Software International, Inc., Lincolnwood, IL.

Kim, D., Ferrin, D., Rao, H. (2009). Trust and satisfaction, two stepping stones for successful E-commerce relationships: A longitudinal exploration. Information Systems Research, 20(2), 237-57.

Kuhlmeier, D. \& Knight, G. (2005). Antecedents to Internet-based purchasing: A multinational study. International Marketing Review, 22(4), 460-73.

Luhmann, N. (1979). Trust and Power, Wiley Press (translation from German), Chichester, UK.

Luo, X. (2002). Trust production and privacy concerns on the internet: A framework based on relationship marketing and social exchange theory. Industrial Marketing Management, 31(2), 111-123.

Makhija, M., \& Stewart, A. (2002). The effect of national context on perceptions of risk: A comparison of planned versus free-market managers. Journal of International Business Studies, 33(4), 737-748.

McCoy, S., Galletta, D., \& King, W. (2007). Applying TAM across cultures: the need for caution. European Journal of Information Systems, 16(1), 81-90.

Mitchell, V.W. (1992). Understanding consumers' behavior: Can perceived risk theory help? Management Decision, 30, 26-31.

Mitchell, V.W., \& Vassos, V. (1997). Perceived risk and risk reduction in holiday purchases: A cross-cultural and gender analysis. Journal of Euromarketing, 6(3), 47-79.

Miyazaki, A.D., \& Fernandez, A. (2001). Consumer perceptions of privacy and security risks for online shopping. The Journal of Consumer Affairs, 25(1), 27-44.

Monroe, K. (1976). The influence of price differences and brand familiarity on brand preference. Journal of Consumer Research, 3(June), 42-9.

Modahl, M. (2000). Now or Never: How Companies Must Change Today to Win the Battle for Internet Consumers. HarperCollins, New York.

Moorman, C., Zaltman, G., \& Deshpande, R. (1992). Relationships between providers and users of market research: The dynamics of trust within and between organizations. Journal of Marketing Research, 29, 314328.

Nunnally, J. C. (1978). Psychometric Theory. McGraw-Hill, New York.

Oh, S., Ahn, J., \& Beomsoo, K. (2003). Adoption of broadband Internet in Korea: The role of experience in building attitudes. Journal of Information Technology, 18(December), 267-280.

Porter, C., \& Donthu, N. (2006). Using the technology acceptance model to explain how attitudes determine internet usage: The role of perceived access barriers and demographics. Journal of Business Research, 59(9), 999-1010. 
Quelch, J., \& Klein, L. (1996). The internet and international marketing. Sloan Management Review, (Spring), 60-75.

Robichaux, B., \& Cooper, R. (1998). GSS participation: A cultural examination. Information and Management, (33), 287-300.

Rogers, E.M. (1983). Diffusion of Innovations. The Free Press, New York, NY.

Shimp, T., \& Bearden, W. (1982). Warranty and other extrinsic cue effects on consumers' risk perceptions. Journal of Consumer Research, 9(June), 38-46.

Singh, N., Fassott, G., Chao, M., \& Hoffmann, J. (2006). Understanding international web site usage: A cross-national study of German, Brazilian, and Taiwanese online consumers. International Marketing Review, 23(1), 83-98.

Sood, J., \& Adams, P. (1984). Model of management learning styles as a predictor of export behavior and performance. Journal of Business Research, 12(2), 169-182.

Straub, D., Keil, M., \& Brenner, W. (1997). Testing the technology acceptance model across cultures: a three country study. Information \& Management, 33, 1-11.

Tan, S.J. (1999). Strategies for reducing consumer's risk aversion in internet shopping. Journal of Consumer Marketing, 16(2), 163180.

Taylor, J.W. (1974). The role of risk in consumer behavior. Journal of Marketing, 38(2), 54-60.

Thornton, J., \& S. Marche (2003). Sorting through the dot bomb rubble: How did the high-profile e-tailers fail? International Journal of Information Management, 23(2), 121-138.

Turner, M., Kitchenham, B., Brereton, P., Charters, S., \& D. Budgen (2010). Does the technology acceptance model predict actual use? A systematic literature review. Information and Software Technology. 52(5), 463-474.
Van Slyke, C., Belanger, F., \& Comunale, C. (2004). Factors influencing the adoption of web-based shopping: The impacts of trust. The Data Base for Advances in Information Systems, 35(2), 32-49.

Van Slyke, C., Lou, H., Belanger, F., \& Sridhar, V. (2010). The influence of culture on consumer-oriented electronic commerce adoption. Journal of Electronic Commerce Research, 11(1), 30-40.

Verhage, B.J., Yavas, U., \& Green, R.T. (1990). Perceived risk: A cross-cultural phenomenon? International Journal of Research in Marketing, 7, 297-303.

Wang, H., Lee, M., \& Wang, C. (1998). Consumer privacy concerns about internet marketing. Communications of the ACM, 41(3), 63-70.

Weber, E., Blais, A., \& Betz, N.E. (2002). A domain-specific risk-attitude scale: measuring risk perceptions \& risk behaviors. Journal of Behavioral Decision Making, 15(4), 263-290.

Weber, E., \& Hsee, C. (1998). Cross-cultural differences in risk perception, but similarities in attitudes towards perceived risk. Management Science, 44(9), 1205-1218.

White, J.D., \& Truly, E.L. (1989). Price-quality integration in warranty evaluation - a preliminary test of alternative models of risk assessment. Journal of Business Research, 19, 109-125.

Wilson, W. R., (1979). Feeling more than we can know: exposure effects without learning. Journal of Personality and Social Psychology, 37(6), 811-821.

World Bank, (2009). World economic development indicators, The world bank, Washington, DC.

Zajonc, R. (1968). The attitudinal effects of mere exposure. Journal of Personality and Social Psychology Monograph, 9(2), 1-27. 


\section{APPENDIX}

\section{Internet Facility}

\section{Measurement Information}

On average, how many hours per week do you spend using the Internet, for any tasks except e-mail? (Choices ranged from "0-1 hours per week" to "Over 40 hours per week")

\section{Internet History}

How long have you been using the Internet? (Choices ranged from "Less than 1 year" to "Over 8 years")

\section{Perceived Risk (France $\alpha=.69 ; \mathrm{USA} \alpha=.79)$}

If I buy on the Internet, my purchase might not be worth the money that I paid for it

The price that I pay for something on the Internet is not worth the risk of buying on the Internet

The risk of losing money from buying on the Internet is greater than the risk of losing money from buying in a store

If I buy on the Internet, I might not get my money back if I am dissatisfied

If I buy on the Internet, the supplier might not send me the product and keep my money

If I buy on the Internet, my private information (e.g., credit card number) might be used by someone else without my permission

(Choices ranged from Strongly Agree to Strongly Disagree)

Purchase Likelihood (France $\alpha=.93 ;$ USA $\alpha=.90$ )

How often would you say you buy on the Internet? (Choices ranged from "Very Often" to "Never") Asked another way, how often do you buy on the Internet? (Choices ranged from "More than once a week" to "I never do")

How many times have you bought something on the Internet during the previous 12 months? (Fill in blank)

Note 1: The reliability of Internet Facility and Internet History was not assessed since these are one-item scales.

Note 2: Results of LISREL CFA analyses for each country on Perceived Risk and Purchase Likelihood follow:

France

$\chi^{2}=28$, with $24 \mathrm{df}$

$p=0.26$

$\mathrm{CFI}=.97$

RMSEA $=0.05$
USA

$\chi^{2}=31$, with $24 \mathrm{df}$

$p=0.16$

$\mathrm{CFI}=.94$

RMSEA $=0.08$ 


\title{
How Global are Global Brands? An Empirical Brand Awareness and Image Analysis
}

\author{
Thomas Cleff \\ César Javier Sepúlveda Martinez \\ Nadine Walter
}

\begin{abstract}
In this empirical study, the authors aim to answer two questions related to global brand awareness and image: (1) whether brand awareness and image for the same brand differs between international markets and (2) what influencing factors have an impact on any brand image discrepancy between these markets. In an empirical study, respondents in Germany $(n=426)$ and Mexico $(n=296)$ reported their brand perceptions. The study revealed that brand awareness rates differ significantly between Germany and Mexico and brand image vary considerably. The highest impact on brand image differences are due to the factors "satisfaction with the brand," "usage rate" and "influence of reference groups."
\end{abstract}

KEYWORDS. Global marketing, international marketing, global branding, brand image, brand awareness, brand equity, influencing factors, standardization, iPod, Apple

\section{DEFINITION OF BRAND AWARENESS AND IMAGE}

Brand awareness and brand image are defined as part of the broader term brand equity (Aaker 1991; Keller 1993). The definitions of brand equity can be broadly classified into two categories: the first one is based on the financial-perspective which sees brand equity as a part of the financial value of the firm (e.g., Brasco 1988; Mahajan et al.1990; Simon and Sullivan 1993, the second one is based on the consumer-perspective which categorizes brand equity as the value to the consumer. When focusing on brand awareness and image from a Marketing perspective, consumer-based brand equity is the concept to focus on. Consumerbased brand awareness and image has long been recognized (Gardner and Levy 1955). However, definitions have varied ever since. Dobni and Zinkha (1990) have categorized the broad variety of definitions into five categories (blanket definitions, emphasis on symbolism, emphasis on meanings or messages, emphasis on personification, and emphasis on cognitive or psychological elements). They came to the

Thomas Cleff, Ph.D. and Nadine Walter, Ph.D. are affiliated with Pforzheim University, Tiefenbronner Strabe 65, 75175 Pforzheim, Germany. Cesar Javier Sepulveda Martinez, Ph.D, is affiliated with Technolgico de Monterrey, Ave. Eugenio Garza Sada, 2501 Sur. Col. Technologico, C.P. 64849 Monterrey, Nuevo Leon, Mexico.

Address correspondence to Nadine Walter, Professor of International Marketing, Pforzheim University, 75175 Pforzheim, Germany. E-mail: Nadine.walter@hs-pforzheim.de 
conclusion that brand image's "definition and operationalization have been fairly irregular" (Dobni and Zinkha, 1990 p. 17). However, the brand equity concepts proposed by Aaker (1991) and by Keller (1993) have succeeded in generating a common understanding of the concept of brand equity within the Marketing research community. Their theoretical work was recognised by a large group of authors and laid the foundation of further empirical analysis (Cobb-Walgren et al. 1995; Sinha and Pappu 1998; Yoo et al. 2000; Low and Lamb 2000; Faircloth 2001; Hsieh 2002; Yoo and Donthu 2001 and 2002; Washburn and Plank 2002).

Aaker and Keller see brand equity as a consumer's subjective evaluation of a brand. Aaker (1991) understands brand equity as a set of assets or liabilities and breaks it down into the five dimensions; brand awareness, brand associations, perceived quality, brand loyalty and other proprietary assets.

Keller defines brand equity as "the differential effect of brand knowledge on consumer response to the marketing of the brand" (Keller 1993). Hence, brand knowledge which consists of the dimensions brand awareness and brand image is key to create customerbased brand equity. Brand image is defined as the brand associations in the consumers mind. The definitions of the two authors, Aaker and Keller, have in common that they refer to brand awareness and image from the consumer's standpoint. In addition, both see it consisting of several dimensions. Nevertheless, both authors differ regarding the dimensions of brand equity. Whereas Keller states that brand equity consists only of the dimensions brand awareness and brand image (= brand associations), Aaker defines the term broader and includes in addition to these two the dimensions quality, loyalty and other proprietary assets.

According to Keller, brand awareness refers to the strength of a brand's presence in consumer's memory and defines the ability to identify this brand. The two main components of brand awareness are brand recall and brand recognition. Brand recall refers to the consum- er's ability to retrieve the brand from memory when given a cue (usually in the form of naming a product category) whereas brand recognition shows that the customer is able to affirm previous exposure to a certain brand when given the brand as a cue (Keller 2008; Aaker 1996).

Beside brand awareness, brand image represents the second major dimension of brand equity. Keller defines it as "the perceptions of a brand as reflected by brand associations held in consumer memory" (Keller 1993) and Aaker similarly as "anything linked in memory to a brand" (Aaker 1991, p. 109).

The brand image concept is based on the associative network model (Farquhar and Herr 1993) which describes a person's memory as a combination of links and nodes; links represent the relationships and nodes represent concepts (e.g. brand associations) and objects (e.g. brands).

For measurement approaches, brand associations have to be split into different parts. Friedman and Lessig (1986), Kirmani and Zeithaml (1993) as well as Keller (1993) classify brand associations into three major categories: attributes, benefits and brand attitudes. This classification is based on the level of abstraction, i.e. how much information is summarized or subsumed in the association (Keller 1993, p.4). Attributes are descriptive features that describe a product (can be product-related or non-product related). Benefits are the personal value consumers attach to the product. Brand attitudes are the consumers' overall evaluation of the brand.

It is common practice in brand research nowadays to measure brand image based on multidimensional brand associations (CobbWalgren et al. 1995; Sinha and Pappu 1998; Yoo and Donthu 2001; Washburn and Plank 2002; Tong and Hawley 2009). Washburn and Plank (2002) and Pappu et al. (2005) urge researchers to enrich the measurements by analyzing a larger variety of discriminating factors, especially those that include brand personality. The latter can be seen as another subdimension of brand association and is sup- 
posed to contribute to brand equity (Aaker 1996). Brand personality can be defined as a set of human characteristics which are transferred to a brand (Aaker 1997, p. 347). Hence, brand personality was included in the study.

\section{BRAND AWARENESS AND IMAGE IN THE INTERNATIONAL CONTEXT}

With globalization continuing to accelerate at a steady rate, consumers nowadays can choose from a variety of brands - both foreign and domestic (Hsieh 2002). As a result, brands which are sold internationally are already of significant importance. Schuiling and Kapferer (2004) show that these so called "global brands" already have a share of more than $60 \%$ in selected markets (e.g., in countries such as Germany or Italy).

Characteristics of global brands are numerous. Besides the obvious fact that global brands must be available worldwide, Özsomer and Altaras (2008, p. 1) argue that global brands have "widespread regional/global awareness, availability, acceptance, and demand". Other authors state that global brands follow a globally integrated marketing strategy and have one brand name around the world (Johansson and Ronkainen 2005, p. 339 and De Mooij 2005, p. 14). "Consistent positioning, personality, look, and feel in major markets" are mentioned as key features of global brands (Özsomer and Altaras 2008, p. 1).

The debate on standardization versus localization in marketing has been ongoing for several decades. Global, standardized marketing programs are said to achieve economies of scale, advertising and message consistency and the ability to attract homogenous crossnational market (Levitt 1983). However, due to significant differences in consumers' needs, cultural and socio-economic conditions and market structures, customization to national markets might be necessary (e.g. Douglas and Wind 1987). The influencing factors on marketing in general (esp. on the marketing-mix such as product, price and communication) have been widely researched (Buzzell 1968; Jain 1989; Onkvisit and Shaw 1987; Baalbaki and Malhotra 1995; Whitelock et al. 1995; Zou and Cavusgil 2002).

Although global brands play a significant role in today's marketing, and also research on marketing standardization is various, research on brand image standardisation across countries is surprisingly weak. Although, most researchers agree that differences across markets are an indicator that consumers in different nations have different needs, and hence may require tailored brand images. Roth claims "to manage brand images successfully internationally, managers must be cognizant of and responsive to important differences across international markets" (Roth 1995, p. 58).

A large number of studies exist which analyse brand equity on a national level (Low and Lamb 2000; Vazquez et al. 2002; Tong and Hawley 2009; Agarwal and Rao 1996; Faircloth et al. 2001). Multi-national studies which test the comprehensive "brand equity concept" based on Aaker (1991) and Keller (1993) comparing countries hardly exist. Jung and Sung (2008) state correctly: "There is a lack of studies on brand equity, especially those based on consumers across different cultures" (Jung and Sung 2008, p. 25). Besides their work, only the studies by Buil et al. (2008) which test a consumer-based brand equity scale in the UK and Spain as well as studies by Yoo and Donthu (2001) and Yoo et al. (2000) exist. The last two studies examine brand equity in the USA and South Korea based on brand equity dimensions such as brand awareness, brand associations, and perceived quality.

Other cross-cultural studies focus only on specific, single dimensions of the brand, but not on the complete brand equity concept. Lee et al. (2008) look at the differences of the perception towards brand associations, brand impressions and brand commitment of a US global brand versus domestic brands in Mexico, Korea, and Japan. Foscht et al. (2008) compare Red Bull's brand personality in the UK, Singapore, Austria, Germany, the Netherlands and the US. 
Hsieh (2002) measures the degree of brand image globalization in 20 countries by focusing on 14 brand associations for car brands in the areas of economic-symbolic dimensions, the sensor dimension and the utilitarian dimension. Witkowski et al. (2003) analyze KFC's brand identity in China and the US based on the dimensions property (e.g., restaurant façade, colors), product (e.g., menus, taste), presentation (e.g., trays, packaging) and publications (e.g., promotions, advertising). Oliveira-Castroa et al. (2008) investigated 15 product categories in Brazil and the UK with respect to brand familiarity and quality levels.

These studies come to the conclusion that the brands analyzed show some similarities but partially show significant differences between countries or cluster of countries. Therefore, the authors conclude that, marketing management needs to carefully analyze brands in different nations in order to apply the right marketing instruments.

\section{RESEARCH METHODOLOGY AND HYPOTHESES}

The empirical research of this study will measure brand awareness and image of the brand iPod in Germany and Mexico. The iPod was chosen as the investigated brand because it satisfied the following prerequisites:

- iPod is a global brand, available around the world and marketed by Apple following a rather standardized approach (e.g. products iPod classic, nano, shuffle and video are identical in each market; premium-price strategy is followed everywhere; advertising campaigns such as the "silhouette campaign" are shown worldwide; the iPod is sold in all Apple's 200 flagship stores, which follow the same concept around the world) (Verma 2006).

- Consumers are familiar with the brand - since it is the world's best selling MP3 player - and are therefore able to describe and comment on the brand image dimensions asked in the quantitative research (Reppel 2006).

- Global brand awareness and image research has so far included globally known brands, such as Hugo Boss (Matthiesen and Phau 2005), Red Bull (Foscht et al. 2008) or Kentucky Fried Chicken (Witkowski et al. 2003). However, the iPod brand has never been used in such an investigation.

The markets Germany and Mexico were chosen because of the heterogeneity of the markets, not only on an economic but also on a cultural comparison:

- Mexico is a mid-income country (with a GDP per capita of $\$ 13.400$ in 2009), whereas Germany is a high income country (with a GDP per capita of $\$ 34.500$ in 2009) (CIA 2010).

- Regarding Hofstede's cultural dimensions, Mexico scores high on power distance and uncertainty avoidance, whereas Germany shows high levels of individuality (Hofstede 1984 and Hofstede et al. 2010, p. 57).

The empirical research will be based on the brand equity concept by Aaker (1991) and Keller (1993) and hence will measure brand awareness (i.e., brand recall) and brand image. Brand image will be broken down into the dimensions: brand attitude, brand associations and brand personality. The brand associations were split into functional associations and emotional associations in order to do their different natures justice (Hartmann et al. 2005).

Drawing on the results of other international comparisons which have found differences in brand perception (Lee et al. 2008; Hsieh 2002; Witkowski et al. 2003; OliveiraCastroa et al. 2008) across countries, we also assume that brand awareness and image will differ between Germany and Mexico.

Brand recall is expected to differ in a global comparison, since differences in market structure and hence a different category development index and brand development index are likely to occur. Therefore, H1 must be rather seen as a necessary condition. Brand re- 
call rates of the product brand iPod in Mexico and Germany are unfortunately not assessed by general market research. However, brand recall rates of the corporate brand Apple are available and show large differences: whereas in Germany $71 \%$ of the population have heard about Apple (and the iPod has a market share of $21 \%$ ), in Mexico $90 \%$ of the population knows the Apple brand (and the iPod has a larger market share of 30\%) (Wittman and Scott 2006, p.10). Due to these facts, it is likely that brand recall of the iPod will also be higher in Mexico than in Germany.

Besides brand recall, brand image of the iPod is likely to differ in both countries. Brand image will be analyzed by focusing on the dimensions brand attitude, (functional and emotional) brand associations and brand personality.

Brand attitude is the overall evaluation of the brand by consumers (Keller 1993). Wiedemann (2006) states that consumers wish to own an iPod in order to belong to a group or to be cool. Mexicans are strongly group oriented (Herbig and Genestre 1996, p. 55; Lee et al. 2008, p. 170) whereas Germans consider the individual's benefits to be more important than the group's benefits (Bos 1994). Therefore, it is assumed that the brand attitude will differ in the two countries.

Brand associations are the informational nodes linked to the brand node in memory and contain the meaning of the brand for consumers (Keller 1993, p.3). Although the iPod campaigns communicate similar associations in Mexico and Germany, it is still assumed that consumers will perceive the brand differently. This is due to the fact, that Mexicans are rather emotional consumers, who base their opinion of a brand largely on liking, emotions and feelings (Gannon 2004, p. 133). In contrast, German consumers judge brands based on neutral information, facts and logical reasoning (Seitz and Handojo 1997, p. 173). Therefore, it is assumed that, the associations linked with the brands will be quite different in Mexico and in Germany.
Brand personality is defined as a set of human characteristics which are transferred to a brand (Aaker 1997, p. 347). The iPod does not state in its marketing a clear brand personality, but lets its users identify with their own picture of the brand (e.g. on the homepage Apple asks users the question: "which iPod are you" and offers different types of iPod personalities (Solomon 2008, p. 277)). German consumers are said to rather focus on the technical and tangible characteristics of the brand, Mexican consumers are likely to see the brand personality as more life-style oriented (Seitz and Handojo 1997, p. 173). Therefore, brand personality of iPod is very likely to differ between Mexico and Germany.

These results can be summarized in the following hypotheses:

H1: Brand recall of iPod differs in Germany and Mexico

$\mathrm{H} 2$ : Brand image of iPod differs in Germany and Mexico

H2.1: Brand attitude of iPod differs in Germany vs. Mexico

$\mathrm{H} 2.2$ : Functional brand associations of iPod differ in Germany vs. Mexico

H2.3: Emotional brand associations of iPod differ in Germany vs. Mexico

$\mathrm{H} 2.4$ : Brand personality of iPod differs in Germany vs. Mexico

In addition to examining brand image dimensions, the study aims to also analyze the underlying reasons for the differences. Key influencing factors identified are perceived quality, satisfaction, purchase intention and brand loyalty (which are summarized under the term customer commitment), usage rate and influence of reference group.

Perceived quality is the consumer's subjective evaluation of the product and it increases the purchase intention as it provides value to the consumer. Consequently, it can be said that the perception of a product's quality leads to the differentiation of the respective brand from competing brands (Lee et al. 2008a, pp. 165). Kirmani and Zeithaml (1993, p. 145) also share the assumption that "per- 
ceived quality can affect brand image directly or indirectly through the constructs of perceived value or brand attitude". Moreover, perceived quality is linked to how a brand is perceived and even drives this perception (Aaker 1996, p. 17).

Another element of customer commitment is satisfaction. A consumer having certain prepurchase expectations towards a particular brand will be satisfied with it if it fulfills these expectations (Sheth et al. 1999, p. 549). This satisfaction will most likely result in a positive brand image and hence in brand loyalty. According to Blackwell et al. (2006, p. 213) consumers holding negative evaluations of the product are unlikely to buy again and those holding positive evaluations are much more likely to repurchase the product and remain loyal.

Purchase intention and brand loyalty are the main factors influencing brand image. In Aaker's (1991) framework brand loyalty is one of the dimensions defining brand equity. He claims that brand loyalty has an impact on brand image which reflects current perceptions of a brand (Aaker 1996, p. 180). Lee et al. (2008, p. 166) define brand loyalty "as the tendency to be loyal to a focal brand, which is demonstrated by the intention to buy the brand as a primary choice". It can be assumed that both factors, purchase intention and brand loyalty have an impact on brand image.

Usage rate is defined as the quantity consumed within a certain time frame (Kerin et al. 2003, p. 193). It has an influence on brand recall and brand image (Weitz and Wensley 2006, p.155). According to Bird et al. (1970) the proportion of people who express a favorable attitude toward a brand is related to the recency and frequency of their brand usage. Additionally, current consumers perceive brands in a more favorable way than former users, and non-users have the least positive associations with that brand (Castleberry and Ehrenberg 1990).

According to Childers and Rao (1992) reference groups - being the circle of friends and family members - have an influence on a con- sumer by sharing their experiences with brands and products: in particular, family is said to have a higher influence than peer-based reference groups as one's brand loyalty and brand preference are influenced to a higher degree by family communication. This is especially true in developing countries, where families stick together (Childers and Rao 1992, pp. 198). Consequently, the consumer's reference groups can positively change his perception of a brand, thus the brand image, by emphasizing the advantages of a particular product (Wiedemann 2006, pp. 50).

The influencing factors can be summarized in the following hypotheses:

H3: Customer commitment has an impact on brand image perception

H3.1: Perceived quality has an impact on brand image perception

H3.2: Satisfaction has an impact on brand image perception

H3.3: Purchase intention has an impact on brand image perception

H3.4: Brand loyalty has an impact on brand image perception

H4: Usage rate has an impact on brand image perception

H5: Influence by reference groups has an impact on brand image perception

\section{DATA COLLECTION AND SAMPLING PROCEDURES}

The authors conducted the empirical research during May and June 2009 with similarly aged Bachelor students studying at business schools in Germany $(\mathrm{n}=426)$ and Mexico $(n=296)$. The realized sample size with 722 respondents is comparable to research studies with similar scope (Esch et al. 2006) or even exceeds these (Foscht et al. 2008; Lee et al. 2008).

Knowing that an online survey is difficult to administer, especially in a country like Mexico where people need incentives to do a certain task (Kumar 2000, p. 380), a paper- 
based questionnaire was chosen as instrument for the study in Germany and in Mexico.

The questions were kept simple and direct so that the students could answer them without having to look for additional information in order to generate an adequate answer to the question. Mainly closed questions using a five-point Likert scale were chosen for statements and attributes. The questionnaire also included a few open questions, e.g. to determine brand recall which can only be measured using an open question to assess the relevant mind set of the interviewees.

Even though measurement scales for the different brand dimensions had already been developed by other authors (e.g. Aaker 1997; Keller 2008) the original scales were not used in the present study. Due to their length, they are not practical to use in empirical studies. The researchers therefore used these scales in an abbreviated and adapted form. For other scales the authors applied established scales used by different authors before (cf. Table 2), which makes a separate testing of reliability and validity unnecessary. Table 1 shows how each brand dimension and each influencing factor was measured.

A first draft questionnaire in German was improved and amended with the use of experts' knowledge and a pretest with 17 German students. In the pretest, the participants got detailed information about the purpose of the study and the research topic so that they were able to make adequate proposals based on the given background. They were questioned about any problems of understanding the questions, the clearness of the given instructions and their overall opinion of the questionnaire, e.g. length, interest and attention. The first questionnaire draft contained a large number of attributes of which some were quite similar. The objective was to eliminate part of them with the aid of Cronbach's alpha. In conclusion, after a thorough process of improvements with the use of experts' knowledge, pretest and Cronbach's alpha statistics, the final questionnaire was determined. For the translation of the German questionnaire into Spanish, the back translation method was used (Cleff 1997, p. 155; Kumar 2000, p. 431). Nevertheless, despite the dedicated accuracy of this method, the back translation cannot guarantee complete reliability and validity of the data. For the Mexican pretest, 13 Mexicans, studying at a German Business School were asked to make suggestions of improvements.

It must be emphasized again that the translated questionnaires were not tested entirely regarding validity or reliability. Even though many scales - e.g. the scales to measure the brand dimensions - were already used elsewhere by other authors, it does not apply for the corresponding translations into the German and Spanish language. Validity and reliability checks of the translated versions are still pending. However, the authors have tried to assure the quality of measurement of both questionnaires with an elaborate pretest procedure.

The survey took place between May and June 2009 at the two Business Schools. The paper-based questionnaires were distributed at the beginning of the lectures to ensure that the students were concentrating and were highly motivated to answer them in the best possible way.

The selection of similar aged business students seems to be appropriate for the following reasons:

First, previous studies have shown that the choice of students as a sample is highly convenient and has often been used in previous studies (e.g., Dimofte et al. 2008). Consequently, the comparison of results between the different studies using students as a sample is possible and easy. Secondly, a comparison of countries should always be based on homogeneous sub-samples. The influence of subcultural interfering variables on the dependent 


\section{TABLE 1: Measurement of Brand Dimensions and of Influencing Factors}

\begin{tabular}{|c|c|c|c|}
\hline $\begin{array}{l}\text { Brand di- } \\
\text { mension }\end{array}$ & Component & Question & Scaling Technique \\
\hline $\begin{array}{l}\text { Brand } \\
\text { Awareness }\end{array}$ & Brand Recall & Which MP3 player brands do you know? (state up to 5 brands) & Open Question \\
\hline \multirow[t]{4}{*}{$\begin{array}{l}\text { Brand } \\
\text { image }\end{array}$} & $\begin{array}{l}\text { Brand } \\
\text { Attitude }\end{array}$ & $\begin{array}{l}\text { What do you associate with the brand iPod? } \\
\text { "1. Are a symbol of liberty"; "2. Are products for show-offs"; "3. Are a } \\
\text { mean of self-expression"; "4. Are too expensive"; " } 5 \text {. Are something for } \\
\text { followers"; " } 6 \text {. Just need to be loved"; "8. Are not better than other MP3 } \\
\text { players"; "9. Fill their owners with pride" }\end{array}$ & $\begin{array}{l}\text { 5-point Likert Scale } \\
\text { (strongly agree to } \\
\text { strongly disagree) }\end{array}$ \\
\hline & $\begin{array}{l}\text { Functional } \\
\text { Brand } \\
\text { Associations }\end{array}$ & $\begin{array}{l}\text { iPods are... } \\
\text { "1. High-quality products"; "2. Multifunctional"; "3. Easy-to-use"; " } 4 \text {. Inflex- } \\
\text { ible (e.g. only in combination with iTunes)"; "5. Powerful”; "6. Satisfacto- } \\
\text { ry"; "7. Time-saving"; "8. Elegant" }\end{array}$ & $\begin{array}{l}\text { 5-point Likert Scale } \\
\text { (strongly agree to } \\
\text { strongly disagree) }\end{array}$ \\
\hline & $\begin{array}{l}\text { Emotional } \\
\text { Brand } \\
\text { Associations }\end{array}$ & $\begin{array}{l}\text { iPods are... } \\
\text { "1. A must have"; "2. Inspirational"; "3. Different"; “4. Exaggerated"; “5. } \\
\text { Innovative"; "6. Mainstream (everybody owns one)" }\end{array}$ & $\begin{array}{l}\text { 5-point Likert Scale } \\
\text { (strongly agree to } \\
\text { strongly disagree) }\end{array}$ \\
\hline & $\begin{array}{l}\text { Brand } \\
\text { Personality }\end{array}$ & $\begin{array}{l}\text { Imagine an iPod was a person, how much do you agree on the following } \\
\text { characteristics? An iPod as a person is... } \\
\text { "1. Aesthetic"; "2. Cool"; "3. Cocky"; "4. American"; " } 5 \text {. Creative"; "6. So- } \\
\text { phisticated"; "7. Full of the joys of life"; "8. Passionate"; "9. Intelligent"; } \\
\text { "10. Social responsible"; "11. Trustworthy"; "12. Stylish"; "13. Unique"; } \\
\text { "14. Young" }\end{array}$ & $\begin{array}{l}\text { 5-point Likert Scale } \\
\text { (strongly agree to } \\
\text { strongly disagree) }\end{array}$ \\
\hline $\begin{array}{l}\text { Influencing } \\
\text { factors }\end{array}$ & Component & Question & Scaling Technique \\
\hline Usage rate & $\begin{array}{l}\text { Heavy vs. } \\
\text { light user }\end{array}$ & How many hours per day do you use your MP3 player? & $\begin{array}{l}\text { Ordinal: "less than 1"; "1 } \\
\text { to 2"; "2 to 3"; "3 to 4"; "5 } \\
\text { to 6"; "more than 6" }\end{array}$ \\
\hline $\begin{array}{l}\text { Influence by } \\
\text { reference } \\
\text { groups }\end{array}$ & $\begin{array}{l}\text { Influence } \\
\text { behalf of } \\
\text { reference } \\
\text { groups }\end{array}$ & $\begin{array}{l}\text { For iPod-purchasers: "I have bought an iPod because a friend/family } \\
\text { member recommended it."; "I have bought an iPod because a } \\
\text { friend/family member already owns an iPod."; "People show their affilia- } \\
\text { tion with a group by the ownership of an iPod."; "People who do not own } \\
\text { an iPod are seen as outsiders by others." } \\
\text { For non-iPod-purchasers: "I would buy an iPod if a friend/family member } \\
\text { recommended it."; "I would buy an iPod if a friend/family member already } \\
\text { owned an iPod."; "People show their affiliation with a group by the own- } \\
\text { ership of an iPod."; "People who do not own an iPod are seen as outsid- } \\
\text { ers by others." }\end{array}$ & $\begin{array}{l}\text { 5-point Likert Scale } \\
\text { (strongly agree to } \\
\text { strongly disagree) }\end{array}$ \\
\hline \multirow[t]{5}{*}{$\begin{array}{l}\text { Customer } \\
\text { commitment }\end{array}$} & $\begin{array}{l}\text { Perceived } \\
\text { Quality }\end{array}$ & "iPods are high quality products" & $\begin{array}{l}\text { 5-point Likert Scale } \\
\text { (strongly agree to } \\
\text { strongly disagree) }\end{array}$ \\
\hline & Satisfaction & "iPods are satisfactory" & $\begin{array}{l}\text { 5-point Likert Scale } \\
\text { (strongly agree to } \\
\text { strongly disagree) }\end{array}$ \\
\hline & $\begin{array}{l}\text { Brand } \\
\text { Loyalty }\end{array}$ & "How many iPods have you already bought?" & $\begin{array}{l}\text { Ordinal: "1"; "2"; "3"; } \\
\text { "more than 3" }\end{array}$ \\
\hline & & $\begin{array}{l}\text { "I would definitely buy an iPod again, if my current one got lost/stolen or } \\
\text { if it was damaged." }\end{array}$ & $\begin{array}{l}\text { 5-point Likert Scale } \\
\text { (strongly agree to } \\
\text { strongly disagree) }\end{array}$ \\
\hline & $\begin{array}{l}\text { Repurchase } \\
\text { Intent }\end{array}$ & $\begin{array}{l}\text { For iPod-purchasers: "I always need to have the latest iPod generation." } \\
\text { For non-iPod-purchasers: "I would definitely buy an iPod, if I needed a } \\
\text { new MP3 player." }\end{array}$ & $\begin{array}{l}5 \text {-point Likert Scale } \\
\text { (strongly agree to } \\
\text { strongly disagree) }\end{array}$ \\
\hline
\end{tabular}


TABLE 2: The Most Relevant Scales Used in the Literature

\begin{tabular}{|c|c|}
\hline Attributes & Scales used by given author(s) before \\
\hline Aesthetic & $\begin{array}{l}\text { "Aesthetics play a key role in such brands as [...] Apple computers [...]" (Ko- } \\
\text { tler and Keller } 2009, \text { p. } 363 \text { ); "[Apple] took care to differentiate itself from its } \\
\text { competitors through its aesthetic design and innovative features, for its prod- } \\
\text { ucts." (Philkhana and John } 2007, \text { p. } 2 \text { ) }\end{array}$ \\
\hline American & „iPod soon became a symbol of American pop culture” (Verma 2006, p. 5) \\
\hline Cool & $\begin{array}{l}\text { "[...] the most important aspect of this success story is that Apple was able to } \\
\text { extend the iPod market from the group of early adopters to the early majority } \\
\text { "without diminishing the product's cool factor" (Olson et al. 2005, p. 14); "A } \\
\text { product that had become so cool and funky that it becomes a social acces- } \\
\text { sory as much as anything else." (Vandermerwe and Taishoff 2004, p. 2) }\end{array}$ \\
\hline $\begin{array}{l}\text { Creative } \\
\text { Easy-to-us }\end{array}$ & $\begin{array}{l}\text { "The Company is therefore uniquely positioned to offer superior and well- } \\
\text { integrated digital lifestyle products and solutions, which are further enhanced } \\
\text { by the Company's emphasis on ease-of-use and creative industrial designs." } \\
\text { (Apple Inc. 2008, p. } 33 \text { ); "[...] Apple, which has a reputation for simply de- } \\
\text { signed and easy-to-use products." (Trott } 2008, \text { p. } 32 \text { ) }\end{array}$ \\
\hline
\end{tabular}

Elegant iPod as "an elegant method of promoting individual choice" (Anderson 2005, p. 29)

Different "Think different"

Iconic "[...] for the iconic brand and market leader, iPod" (Reppel et al. 2006, p. 241 ; "Thanks to its sleek design, it soon became an icon of the Digital Age." (Yoffie and Slind 2008, p. 10)

Inflexible "[...] Music downloaded from iTunes could only be played on the iPod, and of Expensive course, retail price was high relative to competition." (Crawford and Di Benedetto 2008, p. 313); "[... ] iTunes works only with iPods, and iPods play only music purchased from iTunes." (Nightingale and Syed 2008, p. 8)

Intelligent "It's like having your own highly intelligent, personal DJ." (Apple Inc. 2009b)

Fill their "The iPod is not only easy to use, but it also makes its users feel proud, owners with which, in turn, helps them to feel good." (Reppel et al. 2006, p. 244)

pride

Individual "The iPod's design satisfies users' desire for beauty and helps them to feel individual." (Reppel et al. 2006, p. 244)

Innovative "The Company is focused on providing innovative products and solutions to consumer, SMB, education, enterprise, government and creative customers that greatly enhance their evolving digital lifestyles." (Apple Inc. 2008, p. 33) 


\begin{abstract}
Multi- func-
"The iPod's functionality extends beyond playing music and listening to audio tional books. Other key capabilities include data storage, calendar and contact information utility, and a selection of games. With the addition of third-party iPod peripherals, the capabilities of certain iPods can be enhanced to include voice recording and photo downloading directly from certain digital cameras." (Apple Inc. 2004, p. 5)

Must-have "[...] these pocket-sized pleasure zones have become the first must-have accessory of the $21^{\text {st }}$ century" (Vandermerwe and Taishoff 2004, p. 2); "[The iPod] was extremely fashionable and immediately became a must-have for the trendy set." (Hennessy 2004, p. 4)

Passionate "It is said that both people working for Apple and fans of its products are passionate and proud to be part of the Apple community." (Heracleous and Papachroni 2009, p. 13).

Satisfactory "[...] the iPod's durability is gradually improving with each new model and surveys show that users' satisfaction remains above those of competitors" (Wingfield 2006, p. DI)

Social re- "Apple recognizes its responsibility as a global citizen and continually strives sponsible to reduce the environmental impact of the work we do and the products we create, e.g. Apple is on track to eliminate toxic chemicals from its products." (Apple Inc. 2009a)
\end{abstract}

Sophisticat- "[...] many consumers were under the impression that it was a sophisticated ed device for tech fans, rather than the average music lover." (Keller 2008, p. 244)

Stylish "Research findings reveal just how important design is in how customers feel about their iPods. [...] The research makes clear that a key attribute of importance for the iPod user is its design." (Reppel et al. 2006, pp. 244)

Unique "The Company believes it is unique in that it designs and develops nearly the entire solution for its personal computers, consumer electronics, and mobile communication devices, including the hardware, operating system, several software applications, and related services." (Apple Inc. 2008, p.15)

User- "Apple Computers have always been designed to look user-friendly." (Crawfriendly ford and Di Benedetto 2008, p. 294)

Young " $[\ldots]$ among the target group iPods are popular, it is seen as hip, young and fashionable" and "it pushes a strong identification with everything young, upto the minute and smart" (Nightingale and Syed 2008, p. 8)

variable is kept constant with comparable subsamples. The comparable samples differ only by their national and cultural environment. Above all, students are in a certain age range and the choice of particular majors should further contribute to the homogeneity of the sam- ple. Furthermore, research indicates that young people are more open to new ideas and innovation. They are more similar to their peers worldwide in their needs than other age groups (Foscht et al. 2008, p. 134). This convergence also means that the cultural differ- 
ence of the students is larger than in comparison to the total population. However, one has to bear in mind that although the selected German and Mexican students are relatively homogeneous in terms of important demographics as age and educational background, they still differ in terms of language, social background and cultural frames of reference. The difference between the students and the resulting limited representativeness has to be considered by the later analysis of the results. Table 3 gives an overview of the sampling procedure.

\section{RESULTS}

The authors aim to answer whether brand awareness and image for the same brand differs between international markets and what influencing factors have an impact on any brand image discrepancy between these markets. The authors could not base the research on existing empirical literature or other empirical studies. Therefore, in a first step, the data were analyzed by using different explorative statistical methods, e.g. factor analysis, and bivariate methods like correlation analysis and parametrical and non-parametrical test. This is to gain a first qualitative understanding of cultural influences on different brand dimensions to prepare further - more conclusive - studies in the future, using e.g. structural equation modeling and path analysis.

Brand recall was measured by considering the answers of MP3 player-users in both countries. Students in Mexico and Germany are very familiar with iPod as they exhibit a high level of recall. On average about three brands were recalled by the German students, whereby $88 \%$ recalled iPod or Apple. In Mexico the brands iPod or Apple was recalled by about 97\%. Brand recall of iPod is higher among Mexican students (78\%) than German students $(62 \%)$ and for Apple it is the opposite $(27 \%$ for German and 19\% for Mexican Students).

The Chi-square test of independence was used to prove whether the differences of frequencies are significant between the two countries. In summary, as the brand recall of iPod differs significantly between Germany and Mexico, the hypothesis "brand recall of iPod differs in Germany and Mexico" (H1) can be adopted. The following analyses will explore

\section{TABLE 3: Sampling Design Process}

\begin{tabular}{|c|c|}
\hline $\begin{array}{l}\text { Target popula- } \\
\text { tion/ sampling } \\
\text { frame }\end{array}$ & $\begin{array}{l}\text { Bachelor students studying at two business schools in Germany and } \\
\text { Mexico: } \\
\text { - Faculty: business and management } \\
\text { - Age range: } 19-23\end{array}$ \\
\hline $\begin{array}{l}\text { Sampling tech- } \\
\text { nique }\end{array}$ & $\begin{array}{l}\text { Convenience sampling: Participants of business courses in the 4th se- } \\
\text { mester or higher }\end{array}$ \\
\hline Response rate & Almost $100 \%$ of the distributed questionnaires \\
\hline Sample size & $\mathrm{n}_{\mathrm{G}}=426$ Germans and $\mathrm{n}_{\mathrm{M}}=296$ Mexicans; total of 722 respondents \\
\hline Execution & $\begin{array}{l}\text { The survey took place during lecture time in May and June 2009. Paper- } \\
\text { based questionnaires were distributed at the beginning of the lectures to } \\
\text { ensure that the students are concentrated and have a high motivation to } \\
\text { answer them in the best possible way. }\end{array}$ \\
\hline
\end{tabular}


whether brand image also differs between the two countries.

The non-parametric Mann-Whitney U-test was chosen for the comparison of the mean ranks for all attributes belonging to brand image between the two countries. This dimension was defined as a generic term for its subdimensions "brand attitude", "functional brand associations", "emotional brand associations", and "brand personality". Detailed statistical results can be drawn from the statistical appendix. First, comparing the mean ranks for the attributes belonging to brand attitude, the findings showed that on the five percent level the means of only one out of eight statements did not differ significantly between Mexico and Germany. This indicates that the hypothesis "brand attitude of iPod differs in Germany and Mexico" (H2.1) could be adopted. Secondly, the cross-national comparison of the functional and emotional brand associations revealed that all mean ranks are statistically different on the five percent level. The hypotheses "functional and emotional brand associations of iPod differs in Germany and Mexico" (H2.2 and H2.3) could be adopted. The brand personality was the most extensive section as it included 14 out of 34 brand image attributes. The Mann-Whitney U-test revealed that only two (not cocky $(\alpha=0.64)$ and not so- phisticated $(\alpha=0.28))$ were not significantly different.

Due to the high number of significantly different means for the remaining eleven respectively twelve attributes, the hypothesis "brand personality of iPod differs in Germany and Mexico" (H2.4) could be adopted. As all of the four dimensions belonging to brand image are statistically different between Germany and Mexico, the hypothesis "brand image of iPod differs in Germany and Mexico" (H2) could be affirmed.

Due to the high amount of items, a factor analysis had to be accomplished considering the rated attributes for the four brand image sub-dimensions. The brand image subdimensions are "meritorious" (Kaiser and Rice 1974, pp. 111) for a factor analysis because the Kaiser-Meyer-Olkin Measure of Sampling Adequacy is equal to 0.822 . Table 4 gives an overview of the nine resulting factors used as reduced brand image dimensions in the following analysis.

The answers for the factor "influence by reference groups" also had to be compressed in order to allow for further analysis. After this data preparation, the factor analysis of "influence by reference groups" could be accomplished with the following results shown in Table 5.

TABLE 4: Factor Analysis of the Brand Image Dimensions

\begin{tabular}{|c|c|}
\hline Factors & Attributes \\
\hline Factor 1: "Basics" & $\begin{array}{l}\text { Elegant; A "must-have"; Inspirational; Different; Innovative; Aesthet- } \\
\text { ic; Cool; Creative }\end{array}$ \\
\hline Factor 2: "Performance" & $\begin{array}{l}\text { Just need to be loved; Multifunctional; Easy-to-use; Powerful; Time- } \\
\text { saving; Are better than other MP3 players }\end{array}$ \\
\hline Factor 3: "Esteem" & $\begin{array}{l}\text { Are a symbol of liberty; Are a mean of self-expression; Fill their } \\
\text { owners with pride; Are no products for show-offs; Are nothing for } \\
\text { followers }\end{array}$ \\
\hline Factor 4: "Apple's Core" & Intelligent; Stylish; Trustworthy; Unique; Young \\
\hline Factor 5: "Attitude" & Full of the joys of life; Passionate; Not sophisticated \\
\hline Factor 6: "Normality" & American; Unexaggerated \\
\hline Factor 7: "Exclusiveness" & Not mainstream; Not cocky \\
\hline Factor 8: "Convenience" & Not too expensive; Flexible \\
\hline Factor 9: "Responsibility" & Social responsible \\
\hline
\end{tabular}


Table 5: Factor Analysis of the Influence by Reference Group

\begin{tabular}{cl}
\hline \multicolumn{1}{c}{ Factors } & \multicolumn{1}{c}{ Question type } \\
\hline Factor 1: "Purchase Influence" & Recommendation \\
& Ownership \\
Factor 2: "Group Aspiration" & Affiliation \\
& Outsiders \\
\hline
\end{tabular}

A bivariate correlation analysis was used to prove whether brand image is affected by the "influence by reference groups" (H5), "the usage rate" (H4) and "the customer commitment" (H3). The last one was sub-divided into "brand loyalty" (H3.4), "purchase intention" (H3.3), "perceived quality" (H3.1) and "satisfaction" (H3.2).

The analysis had to be conducted for each of the nine - from the factor analysis derived brand image factors with every single influencing factor. As the Kolmogorov-Smirnov test revealed that the variables to be tested differ significantly from a normal distribution, Kendall's Tau rank correlation coefficient was used to the influence on the brand image perception. Table 6 shows the respective results: It can be seen that all of the influencing factors have an impact on brand image.

Moreover, satisfaction, usage rate and the purchase intention show the highest impact on brand image as each of them correlates with five of the nine factors defined for this dimension. Consequently, every influencing factor has a significant impact on brand image. "Customer commitment $(\mathrm{H} 3)$, usage rate $(\mathrm{H} 4)$ and reference groups (H5) have an impact on brand image perception."

Before the t-test of independent samples and the Mann-Whitney U-test were conducted to analyze whether the influencing factors on brand image in Germany and Mexico differ significantly, a closer look at the central tendencies of these factors in Table 7 was taken to reveal a first insight; the means in Germany are always higher (on the Likert scale 1 ="strongly agree" and $5=$ "strongly disagree") which means that the German students have a lower degree of agreement with the attributes or statements than the Mexicans. In addition, usage rate is lower in Germany with an average of 1.6 hours per day in comparison of 2.6 hours per day in Mexico.

The t-test for independent samples and the Mann-Whitney U-test both showed that only the factor group aspiration did not differ significantly between Germany and Mexico. Thus, the other six influencing factors (purchase influence, usage rate, perceived quality, satisfaction, purchase intention, and brand loyalty) were significantly different at the five percent level.

In conclusion, perceived quality, satisfaction, purchase intention, brand loyalty, usage rate, and the influence by reference groups differ significantly between Germany and Mexico.

\section{CONCLUSION AND IMPLICATIONS}

Many companies design a global marketing mix for its products and services (Johansson and Ronkainen, 2005). However, consumers' perception of it can be different (e.g., the comprehension of brand equity). The main purpose of this research was to answer two questions related to global brand equity: (1) whether brand awareness and brand image for the same brand differ between international markets and (2) what influencing factors have an impact on any brand image discrepancy between these markets.

According to the results of the first part of the research the awareness and image of a well known brand were different in the two countries. First, the brand iPod was more highly regarded in Mexico than in Germany and secondly, in most attributes Mexicans have 
Table 6: Correlation Analysis (Kendall's Tau) of Brand Image and Influencing Factors

\begin{tabular}{|c|c|c|c|c|c|c|c|c|}
\hline & & $\begin{array}{c}\text { Perceived } \\
\text { Quality }\end{array}$ & Satisfaction & $\begin{array}{l}\text { Purchase } \\
\text { Intention }\end{array}$ & $\begin{array}{l}\text { Brand } \\
\text { Loyalty }\end{array}$ & $\begin{array}{l}\text { Usage } \\
\text { rate }\end{array}$ & $\begin{array}{l}\text { Purchase } \\
\text { influence }\end{array}$ & $\begin{array}{c}\text { Group } \\
\text { aspiration }\end{array}$ \\
\hline \multirow[t]{3}{*}{ Basics } & Tau & $\begin{array}{l}-, 033 \\
\end{array}$ & , 101" & ,082 &,- 017 &,$- 131^{* *}$ & ,050 & ,015 \\
\hline & $\begin{array}{l}\text { Sig.(2- } \\
\text { tailed) }\end{array}$ & ,314 & ,002 & ,068 & ,721 & ,000 & ,099 & ,618 \\
\hline & $\mathrm{N}$ & 539 & 539 & 266 & 274 & 545 & 494 & 494 \\
\hline \multirow[t]{3}{*}{ Performance } & Tau &, $315^{* *}$ &, $556^{* *}$ & , 427 & $125^{* *}$ &,$- 180^{* *}$ & ,262** &,- 030 \\
\hline & $\begin{array}{l}\text { Sig.(2- } \\
\text { tailed) }\end{array}$ & , 000 & , 000 & , 000 & ,007 & , 000 & , 000 & 328 \\
\hline & $\mathrm{N}$ & 539 & 539 & 266 & 274 & 545 & 494 & 494 \\
\hline \multirow[t]{3}{*}{ Esteem } & Tau &, $082^{*}$ &,$- 100^{\star *}$ &,- 080 &,- 012 & ,045 &,$- 105^{\star \star}$ &, $155^{* *}$ \\
\hline & $\begin{array}{l}\text { Sig.(2- } \\
\text { tailed) }\end{array}$ & ,012 & , 002 & 079 & (796 & 167 & , 001 & , 000 \\
\hline & $\mathrm{N}$ & 539 & 539 & 266 & 274 & 545 & 494 & 494 \\
\hline \multirow{3}{*}{$\begin{array}{l}\text { Apple_ } \\
\text { core }\end{array}$} & Tau &,- 025 & ,091* & ,086 &,- 019 &,$- 116^{\star *}$ & ,082** &,- 030 \\
\hline & $\begin{array}{l}\text { Sig.(2- } \\
\text { tailed) }\end{array}$ & ,451 & ,005 & ,057 & ,690 & , 000 & ,007 & ,325 \\
\hline & $\mathrm{N}$ & 539 & 539 & 266 & 274 & 545 & 494 & 494 \\
\hline \multirow[t]{3}{*}{ Attitude } & Tau &,- 007 & ,014 & ,025 & ,067 &,- 044 &, $061^{*}$ &,- 037 \\
\hline & $\begin{array}{l}\text { Sig.(2- } \\
\text { tailed) }\end{array}$ & 821 & 667 & 573 & 151 & 176 & ,046 & 221 \\
\hline & $\mathrm{N}$ & 539 & 539 & 266 & 274 & 545 & 494 & 494 \\
\hline \multirow[t]{3}{*}{ Normality } & Tau & $\begin{array}{l}-008 \\
\end{array}$ & ,000 & $\begin{array}{l}-, 044 \\
\end{array}$ &,- 075 &,- 032 & ,005 & ,000 \\
\hline & $\begin{array}{l}\text { Sig.(2- } \\
\text { tailed) }\end{array}$ & 815 & 982 & 327 & 109 & 326 & 867 & 995 \\
\hline & $\mathrm{N}$ & 539 & 539 & 266 & 274 & 545 & 494 & 494 \\
\hline \multirow[t]{3}{*}{ Exclusiveness } & Tau &,$- 224^{\star *}$ &,$- 070^{*}$ &, $120^{* *}$ & 072 &,$- 102^{* *}$ &, $087^{* *}$ &,- 020 \\
\hline & $\begin{array}{l}\text { Sig. }(2- \\
\text { tailed) }\end{array}$ & , 000 & ,034 & ,008 & 124 & ,002 & , 004 & ,514 \\
\hline & $\mathrm{N}$ & 539 & 539 & 266 & 274 & 545 & 494 & 494 \\
\hline \multirow[t]{3}{*}{ Convenience } & Tau &,$- 080^{*}$ &,- 037 &,- 061 & ,020 & $\begin{array}{l}-, 033 \\
\end{array}$ &,- 044 &,- 010 \\
\hline & $\begin{array}{l}\text { Sig.(2- } \\
\text { tailed) }\end{array}$ & ,014 & ,257 & , 177 & ,668 & ,309 & ,153 & ,741 \\
\hline & $\mathrm{N}$ & 539 & 539 & 266 & 274 & 545 & 494 & 494 \\
\hline \multirow[t]{3}{*}{ Responsibility } & Tau &,- 045 & ,062 & ,000 & $143^{* *}$ &,$- 088^{* *}$ & ,018 & ,037 \\
\hline & $\begin{array}{l}\text { Sig.(2- } \\
\text { tailed) }\end{array}$ & , 170 & , 060 & 994 & ,002 & ,007 &, 560 & 227 \\
\hline & $\mathrm{N}$ & 539 & 539 & 266 & 274 & 545 & 494 & 494 \\
\hline
\end{tabular}


Table 7: Overview of the Means of the Influencing Factors

\begin{tabular}{rcc}
\hline & Germany & Mexico \\
\hline Perceived quality & 2.3 & 1.9 \\
Satisfaction & 2.2 & 1.7 \\
Purchase intention & 3.6 & 2.1 \\
Brand loyalty & 1.9 & 1.6 \\
Influence by reference groups & 4 & 3.5 \\
Usage rate & 1.6 hours & 2.6 hours \\
\hline
\end{tabular}

The means of the factor "influence by reference group" have been calculated with the mean of all eight questions belonging to this section

a better brand image of iPod than Germans.

The results of this research are also supported by the findings of other researchers. For instance Foscht et al. (2008) using Aaker's brand personality dimensions found significant differences for the Red Bull brand personality across six different countries. Also, Hsieh (2002) found clusters of countries that share similar brand image perceptions among one cluster for car brands but different image perception in relation to a different cluster. The difference in perception was due to factors such as economic development, cultural dimensions, and geographic distances.

The second part of the research is related to the influencing factors that may have an impact on the difference of brand image. It was found that customer commitment, usage rate, and reference groups have an impact on brand image perception. More specifically, satisfaction, usage rate and purchase influence (recommendation and ownership) are the most important factors with an impact on brand image perception. Foscht et al. (2008) also found that culture is an important factor that has an impact on brand image perception even though companies follow a similar positioning strategy.

This study provides support that the same brand can have different image perception in different countries. These results in several managerial implications: Not only does it allow companies to identify the level of brand standardization - according to Hsieh (2002) the degree of brand globalization is related to a similar perception of the brand across coun- tries - but it also allows companies to act according to the respective brand perception in a particular country. As Roth (1995) asserts, managers should be sensitive of the differences that exist from country to country. Foscht et al. (2008) also recommend emphasizing the features that influence consumers in perceiving the product or brand in a similar manner. For instance, if perceived quality of the iPod in Germany is lower than in Mexico, Apple might want to raise quality perception in Germany by a new marketing strategy.

The second part of the study supports that satisfaction, usage rate and purchase influence have an important impact on a brand image. Managerial implications should focus on recognizing that customer satisfaction is a key element as it can lead to loyalty and to recommendation of a product or service to others.

Consumers feel satisfied or dissatisfied depending on the expectation level and the perceived performance relative to expectations. Therefore, managers should pay special attention to "over promising" (or "undelivering").

\section{LIMITATIONS AND FURTHER RESEARCH}

The findings of this study should be interpreted with prudence, as there are several limitations that can be addressed in further studies. First, the research was only conducted in two countries. The sample can be expanded to other countries. A second limitation is related to a possible bias due to the country-of-origin ef- 
fect (Foscht et al., 2008). Customers' perceptions on the brand can be predisposed by the fact that iPod is an American brand and therefore is influenced by the perception of that country. According to Lee et al. (2008) American brands are perceived as demonstrating high status and quality. Third, this study selected only one brand (i.e. iPod). Future studies are recommended to test the hypotheses with other global brands so that findings may be generalized. Fourth, the sample can be expanded to other consumer groups besides students. Young people may represent an important segment for brand such as iPod. However, there are other important segments that may have a different perception of the brand (e.g., older segments). Fifth, the empirical results are only providing a first qualitative understanding of cultural influences on different brand dimensions. Further studies have to be more conclusive using multivariate methods, e.g. structural equation models and path analysis. Finally, further research besides the influencing factors customer commitment, usage rate and influence by reference groups as factors can be analyzed (e.g. cultural factors) to better explain the differences on image brand perception.

\section{REFERENCES}

Aaker, D.A. (1991). Managing brand equity. New York, NY, The Free Press.

Aaker, D.A. (1996). Building strong brands. New York, NY, The Free Press.

Aaker, J. L. (1997). Dimensions of brand personality. Journal of Marketing Research, 34.(3), 347-56.

Agarwal, M.K., and Rao, V.R. (1996). An empirical comparison of consumer-based measures of brand equity. Marketing Letters, 7 (3),. 237-247.

Anderson, M. (2005). The quality instinct: How an eye for art can save your business. The Journal of Business Strategy, 26 (5), 29-32.
Apple Inc. (2004). Annual Report for the fiscal year ended September 25, 2004. Retrieved from: http://media.corporateir.net/media_files/irol/ 10/107357/reports/ 10K-FY2004.pdf.

Apple Inc. (2008). Annual Report for the fiscal year ended September 27, 2008. Retrieved from: http://library.corporateir.net/library/10/107/107357/items/ 315133/AAPL_10K_FY08.pdf.

Apple Inc. (2009a). Apple and the environment. Retrieved from: www.apple.com/environment.

Apple Inc. (2009b). iPod Nano: Rockalicious. Retrieved from: http://www.apple.com/iPodnano/features.h tml

Baalbaki, I., and Malhotra, N. (1995). Standardization versus customization in international marketing: An investigation using bridging conjoint analysis. Journal of the Academy of Marketing Science, (3), 182194.

Bird, M., Channon, C., and Ehrenberg, A. S. C. (1970). Brand image and brand usage. Journal of Marketing Research, 7, 307314.

Blackwell,R. D., Miniard, P. W., and Engel, J. F. (2006). Consumer Behavior, 10th edition. Mason, Thomson South-Western.

Bos, C.A. (1994). The road to Mexico. Target Marketing, 17(4), 48-49.

Brasco, T.C. (1988). How brand names are valued for acquisition? In Leuthesser, L. (Eds.), Defining, Measuring and Managing Brand Equity: A Conference Summary Report. Marketing Science Institute, Cambridge, MA, No. 88-104.

Buil, I., de Chernatory, L., and Martínez, E. (2008). A cross-national validation of the consumer-based brand equity scale. Journal of Product and Brand Management, 17(6), 384-392.

Buzzell, R. (1968). Can you standardize multinational marketing? Harvard Business Review, 46(6), 102-113. 
Castelberry, S., and Ehrenberg, A.S.C. (1990). Brand usage: A factor in consumer beliefs. Marketing Research, 2, 14-20.

Childers, T.L., and Roa, A. (1992). The influence of familial and peer-based reference groups on consumer decisions. Journal of Consumer Research, 19(2), 198-211.

CIA, (2010). The CIA World Factbook. New York, NY, Skyhorse Publishing.

Cleff, T. (1997). Industrielle Beziehungen im kulturellen Zusammenhang. Munich, Rainer Hampp Verlag.

Cobb-Walgren, C.J., Beal, C., and Donthu, N. (1995). Brand equity brand preferences, and purchase intent. Journal of Advertising, 24(3), 25-40.

Crawford, M., and Di Benedetto, A. (2008). New Products Management. 9th edition. New York, NY, McGraw-Hill.

De Mooij, M. (2005). Global Marketing \& advertising - understanding cultural paradoxes, 2nd edition. London, Sage Publications, Inc.

Dimofte, C.V., Johansson, J. K., and Ronkainen, I. A. (2008). Cognitive and affective reactions of U.S. consumers to global brands. Journal of International Marketing, 16(4), 113-153.

Dobni, D., and Zinkhan, G.M. (1990). In search of brand image: a foundation analysis. Advances in Consumer Research, 17, 110-19.

Douglas, S., and Wind, Y. (1987). The myth of globalization. Columbia Journal of World Business, (Winter), 19-29.

Esch, F.R., Langner, T., Schmitt, B.H., and Geus, P. (2006). Are brands forever? How brand knowledge and relationships affect current and future purchases. Journal of Product and Brand Management, 15(2), 98-105.

Faircloth, J.B., Capella, L.M., and Alford, B.L. (2001). The effect of brand attitude and brand image on brand equity. Journal of Marketing, 9(3), 61-75.

Farquhar, P.H., and Herr, P.M. (1993). The dual structure of brand associations. In Aaker, D. A. and Biel, A.B. (Eds.), Brand
Equity and Advertising: Advertising's Role in Building Strong Brands, pp. 263-279. Hillsdale, NJ, Laurence Erlbaum Associates.

Foscht, T., Maloles III, C., Swoboda, B., Morschett, D., and Sinha, I. (2008). The impact of culture on brand perceptions: A sixnation study. Journal of Product and Brand Management, 17(3), 131-142.

Friedman, R., and Lessig, V.P. (1986). A framework of psychological meaning of products. Advances in Consumer Research,46(2), 60-73.

Gannon, M. J. (2004). Understanding global cultures - metaphorical journeys through 28 Nations, clusters of nations, and continents. London, Sage Publications Inc.

Gardner, B.B., and Levy, S.J. (1955). The Product and the Brand. Harvard Business Review, 33(2), 33-39.

Hartmann, P., Ibanez, V., and Sainz, F.J.F. (2005). Green branding effect on attitude: functional versus emotional positioning strategies. Market Intelligence \& Planning, 23(1), 9-29.

Hennessy, J. (2004). Apple Computer Inc.: Think different, Think Online Music. Kellogg School of Management, Northwestern University, Reference No. 617-783-7860.

Heracleous, L., and Papachroni, A. (2009). Strategic leadership and innovation at Apple Inc.. Warwick Business School, Reference No. 309-038-1.

Herbig, P., and Genestre, A. (1996). An examination of the cross cultural differences in service quality: the example of Mexico and the USA. Journal of Consumer Marketing, 13(3), 43-53.

Hofstede, G. (1984). Culture's Consequences. Beverly Hills, CA, Sage Publications, Inc.

Hofstede, G., Hofstede, G.J., and Minkov M. (2010). Cultures and Organizations: Software for the Mind. New York, NY, McGraw-Hill.

Hsieh, M.H. (2002). Identifying brand image dimensionality and measuring the degree of brand globalization: a cross-national 
study. Journal of International Marketing, 10(2), 46-67.

Jain, S.C. (1989). Standardization of international marketing strategy: Some research hypotheses. Journal of Marketing, 53(1), 70-79.

Johansson, J. K., and Ronkainen, I. A. (2005). The esteem of global brands. Journal of Brand Management, 12(5), 339-54.

Jung, J., and Sung, E. (2008). Consumer based brand equity: Comparisons among Americans and South Koreans in the USA and South Koreans in Korea. Journal of Fashion Marketing and Management, 12(1), 24-35.

Kaiser, H. F., and Rice, J. (1974). Little Jiffy, Mark IV. Educational and Psychological Measurement, (34), 111-117.

Keller, K.L. (1993). Conceptualizing, measuring and managing customer-based brand equity. Journal of Marketing, 57(1), 1-22.

Keller, K.L. (2008). Strategic brand management: Building, measuring and managing brand equity. 3rd Edition. New Jersey, Prentice Hall.

Kerin, R. A., Hartley, S. W., and Rudelius, W. (2003). Marketing: The Core. New York, NY, McGraw Hill Professional.

Kirmani, A., and Zeithaml, V. (1993). Advertising, perceived quality, and brand image. In Aaker, D.A., and Biel, A. L. (Eds.), Brand Equity and Advertising: Advertising's Role in Building Strong Brands (pp. 143-61). Hillsdale, NJ, Laurence Erlbaum Associates.

Kotler, P., and Keller, K. L. (2009). Marketing Management. 13th edition. New Jersey, Pearson Prentice Hall.

Kumar, V. (2000). International marketing research. New Jersey, Prentice Hall.

Lee, M.-Y., Knight, D., and Kim, Y.-K. (2008). Brand analysis of a US global brand in comparison with domestic brands in Mexico, Korea and Japan. Journal of Product and Brand Management, 17(3), 163-74.

Low, G.S., and Lamb, C.W. (2000). The measurement and dimensionality of brand associations. Journal of Product and Brand Management, 9(6), 350-368.

Mahajan, V., Rao, V.R., and Srivastava, R.K. (1990). Development, testing, and validation of brand equity under conditions of acquisition and divestment. Maltz, E. (Eds.), Managing Brand Equity: A conference summary report, marketing science institute (pp. 14-15). Cambridge, MA, No. 91-110.

Matthiesen, I., and Phau, I. (2005). The 'Hugo Boss' connection: Achieving global brand consistency across countries. Journal of Brand Management, 12(5), 325-338.

Nightingale, F., and Syed, S. (2008). Apple The Most Admired Brand. Case Studies: ICFAI Business School, Chennai, Reference No. 308-219-1.

Oliveira-Castroa, J.M., Foxall, G.R., James, V.K., Pohl, R., Dias, M.B., and Chang, S.W. (2008). Consumer-based brand equity and brand performance. The Service Industries Journal, 28(4), 445-461.

Olson, E. M., Czaplewski, A. J., and Slater, S. F. (2005). Stay cool. Journal of Marketing Management, 14(5), 14-17.

Onkvisit, S., and Shaw, J. (1987). Standardized international advertising: A review and critical evaluation of the theoretical and empirical evidence. Columbia Journal of World Business, 22(3), 43-56.

Özsomer, A., and Altaras, S. (2008). Global brand purchase likelihood: A critical synthesis and an integrated conceptual framework. Journal of International Marketing, 16(4), 1-28.

Pappu, R., Quester, P.G., and Cooksey, R.W. (2005). Consumer-based brand equity: improving the measurement - empirical evidence. Journal of Product and Brand Management, 14(3), 142-154.

Philkhana, S., and John, D. R. (2007). Apple's Future - Expansion into Different Product Lines. ICFAI Business School, Chennai, Reference No. 307-282-1.

Reppel, A., Szmigin, I., and Gruber, T. (2006). The iPod phenomenon: Identifying a market leader's secrets through qualitative 
marketing research. Journal of Product and Brand Management, 15(4), 239-49.

Roth, M.S. (1995). Effects of global market conditions on brand image customization and brand performance. Journal of Advertising, 24(4), 55-75.

Roth, M.S. (1995). The effects of culture and socioeconomics on the performance of global brand image strategies. Journal of Marketing Research, 32, 163-175.

Schuiling, I., and Kapferer, J.-N. (2004). Real differences between local and international brands: strategic implications for international marketers. Journal of International Marketing, 12(4), 97-112.

Seitz, V.A., and Handojo, D. (1997). Market similarity and advertising standardization A study of the UK, Germany and the USA. Journal of Marketing Practice: Applied Marketing Science, 3(3), 171-183.

Sheth, J. N., Mittal, B., and Newman, B. I. (1999). Customer behavior - consumer behavior and beyond. Orlando, The Dryden Press.

Simon, C.J., and Sullivan, M.W. (1993). The measurement and determinants of brand equity: a financial approach. Marketing Science, 12(1), 28-52.

Sinha, A., and Pappu, R. (1998). Parcelling of the sub components of consumer-based brand equity using factorial survey: an empirical investigation in the New Zealand consumer electronics sector. Proceedings, Australia New Zealand Marketing Academy Conference (ANZMAC) University of Otago, pp. 2433-38.

Solomon, M.R. (2008). Consumer Behavior: Buying, having, and being. 8th international edition. New Jersey, Pearson Education.

Tong, X., and Hawley, J.M., (2009). Creating brand equity in the Chinese clothing market: The effect of selected marketing activities on brand equity dimensions. Journal of Fashion Marketing and Management, 13(4), 566-581.

Trott, P. (2008). Innovation management and new product development. 4th edition. New Jersey, Prentice Hall.
Vázquez, R., del Rio, A.B., and Iglesias, V. (2002). Consumer-based brand equity: development and validation of a measurement instrument. Journal of Marketing Management, 18(1/2), 27-48.

Vandermerwe, S., and Taishoff, M. (2004). iPod, iTunes, and Steve Jobs: Apple driving market growth through technology. Imperial College, Tanaka Business School, London, Reference No. 504-099-1.

Verma, M. (2006). Is Apple Managing its 4P's Effectively? Reference No. 506-124-1, ICFAI, Business School, Pune.

Washburn, J. H., and Plank, R. E. (2002). Measuring brand equity: an evaluation of a consumer-based brand equity scale. Journal of Marketing Theory \& Practice, 10(1), 46-46.

Weitz, R.A., and Wensley, R. (2006). Handbook of Marketing. London, Sage Publications Inc.

Whitelock, J., Roberts, C., and Blakeley, J. (1995). The reality of the Eurobrand: An empirical analysis. Journal of International Marketing, (3), 77-95.

Wiedemann, K. (2006). Brand meaning and virtual brand community among teenagers - a study of the iPod brand. Nottingham.

Wingfield, N. (2006, May 17). How Apple's store strategy beat the odds. Wall Street Journal, p. B1.

Witkowski, T., Ma, Y., and Zheng, D. (2003). Cross-cultural influences on brand identity impressions: KFC in China and the United States. Asia Pacific Journal of Marketing and Logistics, 15(1/2), 74-88.

Wittman, R., and Scott, K. (2006). Survey of adults in Mexico and Puerto Rico about the use of personal electronic devices with head phones. Zogby International.

Yoffie, D. B., and Slind, M. (2008). Apple Inc., 2008. Harvard Business School, Reference No. 9-708-480.

Yoo, B., and Donthu, N. (2001). Developing and validating a multidimensional consumer-based brand equity scale. Journal of Business Research, 52(1), 1-14. 
Yoo, B., and Donthu, N. (2002). Testing cross-cultural invariance of the brand equity creation process. Journal of Product and Brand Management, 11(6), 380-98.

Yoo, B., Donthu, N., and Lee, S. (2000). An examination of selected marketing mix elements and brand equity. Journal of the
Academy of Marketing Science, 28(2), 195-211.

Zou, S., and Cavusgil, S. T. (2002). The GMS: A broad conceptualization of global marketing strategy and its effect on firm performance. Journal of Marketing, (4), 4056.

\section{APPENDIX 1: U-TEST FOR INDEPENDENT SAMPLES: TEST VARIABLE BRAND ATTITUDE}

\begin{tabular}{|ll|r|r|r|}
\hline \multicolumn{4}{|c|}{ Ranks } \\
\hline Are a symbol of liberty & Nationalitv & \multicolumn{1}{|c|}{ N } & Mean Rank & Sum of Ranks \\
& German & 234 & 232,18 & 54330,00 \\
& Total & 506 & 299,80 & 91740,00 \\
& Mexican & 233 & 299,83 & 69861,00 \\
\hline Are a mean of self- & German & 307 & 248,24 & 76209,00 \\
expression & Total & 540 & & \\
\hline Just need to be loved & Mexican & 234 & 179,04 & 41894,50 \\
& German & 305 & 339,79 & 103635,50 \\
& Total & 539 & & \\
\hline Fill their owners with & Mexican & 234 & 300,06 & 70214,50 \\
pride & German & 306 & 247,89 & 75855,50 \\
& Total & 540 & & \\
\hline Are no products for show- & Mexican & 234 & 292,40 & 68421,50 \\
offs & German & 308 & 255,62 & 78731,50 \\
& Total & 542 & & \\
\hline Are not too expensive & Mexican & 234 & 308,26 & 72132,50 \\
& German & 309 & 244,54 & 75563,50 \\
& Total & 543 & & \\
\hline Are nothing for followers & Mexican & 232 & 269,87 & 62610,50 \\
& German & 308 & 270,97 & 83459,50 \\
& Total & 540 & & \\
\hline Are better than other MP3 & Mexican & 233 & 302,87 & 70568,50 \\
players & German & 305 & 244,01 & 74422,50 \\
& Total & 538 & & \\
\hline
\end{tabular}

\begin{tabular}{|c|c|c|c|c|c|c|c|c|}
\hline \multicolumn{9}{|c|}{ Test Statistics ${ }^{a}$} \\
\hline & $\begin{array}{c}\text { Are a symbol } \\
\text { of liberty }\end{array}$ & $\begin{array}{c}\text { Are a mean of } \\
\text { self- } \\
\text { expression }\end{array}$ & $\begin{array}{l}\text { Just need to } \\
\text { be loved }\end{array}$ & $\begin{array}{c}\text { Fill their } \\
\text { owners with } \\
\text { pride }\end{array}$ & $\begin{array}{l}\text { Are no } \\
\text { products for } \\
\text { show-offs }\end{array}$ & $\begin{array}{l}\text { Are not too } \\
\text { expensive }\end{array}$ & $\begin{array}{l}\text { Are nothing } \\
\text { for followers }\end{array}$ & $\begin{array}{c}\text { Are better } \\
\text { than other } \\
\text { MP3 players }\end{array}$ \\
\hline Mann-WhitneyU & 26835,000 & 28931,000 & 14399,500 & 28884,500 & 31145,500 & 27668,500 & 35582,500 & 27757,500 \\
\hline Wilcoxon W & 54330,000 & 76209,000 & 41894,500 & 75855,500 & 78731,500 & 75563,500 & 62610,500 & 74422,500 \\
\hline z & $-5,206$ & $-3,918$ & $-12,161$ & $-3,960$ & $-2,809$ & $-4,865$ &,- 083 & $-4,448$ \\
\hline Asymp. Sig. (2-tailed) &, 000 &, 000 &, 000 &, 000 & ,005 &, 000 & ,933 &, 000 \\
\hline
\end{tabular}

a. Grouping Variable: Nationality: 
APPENDIX 2: U-TEST FOR INDEPENDENT SAMPLES: TEST VARIABLE FUNCTIONAL BRAND ASSOCIATION

\begin{tabular}{|lc|r|r|r|}
\hline \multicolumn{1}{|c|}{ Ranks } \\
\hline Multifunctional & Nationality. & \multicolumn{1}{|c|}{$\mathrm{N}$} & Mean Rank & Sum of Ranks \\
& Mexican & 234 & 224,90 & 52626,00 \\
& German & 307 & 306,14 & 93985,00 \\
& Total & 541 & & \\
\hline Easy-to-use & Mexican & 233 & 203,41 & 47394,00 \\
& German & 305 & 319,99 & 97597,00 \\
& Total & 538 & & \\
\hline Powerful & Mexican & 234 & 241,40 & 56488,00 \\
& German & 302 & 289,50 & 87428,00 \\
& Total & 536 & & \\
\hline Time-saving & Mexican & 234 & 206,51 & 48324,50 \\
& German & 303 & 317,26 & 96128,50 \\
& Total & 537 & & \\
\hline Elegant & Mexican & 234 & 251,75 & 58909,00 \\
& German & 304 & 283,16 & 86082,00 \\
& Total & 538 & & \\
\hline Flexible & Mexican & 234 & 252,29 & 59035,50 \\
& German & 302 & 281,06 & 84880,50 \\
& Total & 536 & & \\
\hline
\end{tabular}

Test Statistics ${ }^{a}$

\begin{tabular}{|l|r|r|r|r|r|r|}
\hline & Multifunctional & Easy-to-use & Powerful & Time-saving & Elegant & Flexible \\
\hline Mann-WhitneyU & 25131,000 & 20133,000 & 28993,000 & 20829,500 & 31414,000 & 31540,500 \\
Wilcoxon W & 52626,000 & 47394,000 & 56488,000 & 48324,500 & 58909,000 & 59035,500 \\
Z & $-6,463$ & $-9,358$ & $-3,769$ & $-8,502$ & $-2,480$ & $-2,200$ \\
Asymp. Sig. (2-tailed) &, 000 &, 000 &, 000 &, 000 &, 013 &, 028 \\
\hline
\end{tabular}

a. Grouping Variable: Nationality:

\section{APPENDIX 3: U-TEST FOR INDEPENDENT SAMPLES: TEST VARIABLE EMOTIONAL BRAND ASSOCIATION}

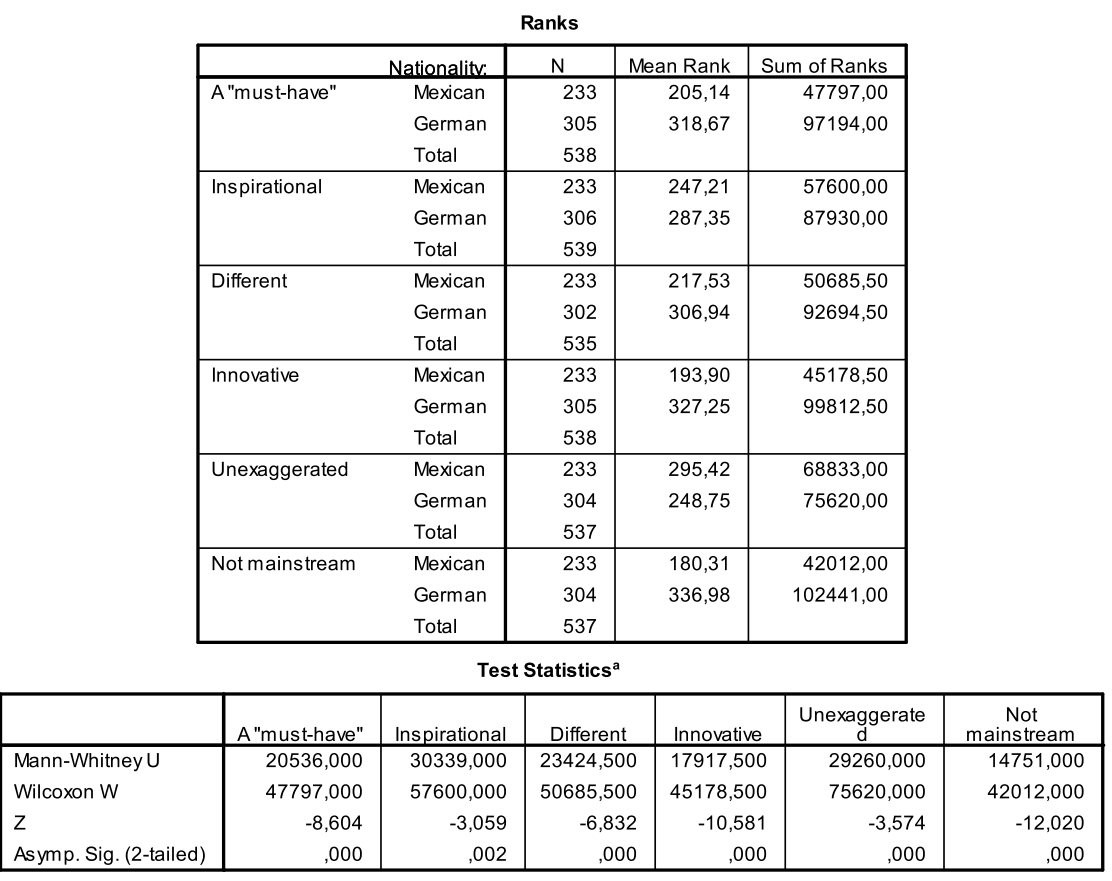

a. Grouping Variable: Nationality. 


\section{APPENDIX 4: U-TEST FOR INDEPENDENT SAMPLES: TEST VARIABLE BRAND} PERSONALITY

\begin{tabular}{|c|c|c|c|c|}
\hline \multicolumn{5}{|c|}{ Ranks } \\
\hline & Nationalitv: & $\mathrm{N}$ & Mean Rank & Sum of Ranks \\
\hline \multirow[t]{3}{*}{ Aesthetic } & Mexican & 232 & 219,75 & 50983,00 \\
\hline & German & 300 & 302,65 & 90795,00 \\
\hline & Total & 532 & & \\
\hline \multirow[t]{3}{*}{ Cool } & Mexican & 234 & 203,28 & 47567,50 \\
\hline & German & 301 & 318,31 & 95812,50 \\
\hline & Total & 535 & & \\
\hline \multirow[t]{3}{*}{ American } & Mexican & 233 & 250,99 & 58480,00 \\
\hline & German & 302 & 281,13 & 84900,00 \\
\hline & Total & 535 & & \\
\hline \multirow[t]{3}{*}{ Creative } & Mexican & 234 & 202,15 & 47303,50 \\
\hline & German & 304 & 321,34 & 97687,50 \\
\hline & Total & 538 & & \\
\hline \multirow[t]{3}{*}{ Full of the joys of life } & Mexican & 233 & 219,46 & 51134,00 \\
\hline & German & 302 & 305,45 & 92246,00 \\
\hline & Total & 535 & & \\
\hline \multirow[t]{3}{*}{ Passionate } & Mexican & 234 & 222,89 & 52156,50 \\
\hline & German & 301 & 303,07 & 91223,50 \\
\hline & Total & 535 & & \\
\hline \multirow[t]{3}{*}{ Intelligent } & Mexican & 233 & 208,97 & 48689,00 \\
\hline & German & 301 & 312,81 & 94156,00 \\
\hline & Total & 534 & & \\
\hline
\end{tabular}

\begin{tabular}{|ll|r|r|r|}
\hline \multicolumn{1}{|c|}{ Ranks } \\
\hline & Nationality & \multicolumn{1}{c|}{$\mathrm{N}$} & Mean Rank & Sum of Ranks \\
\hline Social responsible & Mexican & 224 & 205,45 & 46020,00 \\
& German & 300 & 305,10 & 91530,00 \\
& Total & 524 & & \\
\hline Trustworthy & Mexican & 224 & 186,89 & 41864,00 \\
& German & 300 & 318,95 & 95686,00 \\
& Total & 524 & & \\
\hline Stylish & Mexican & 226 & 222,13 & 50202,50 \\
& German & 303 & 296,97 & 89982,50 \\
& Total & 529 & & \\
\hline Unique & Mexican & 224 & 216,01 & 48386,00 \\
& German & 303 & 299,48 & 90742,00 \\
& Total & 527 & & \\
\hline Young & Mexican & 225 & 218,10 & 49073,50 \\
& German & 302 & 298,19 & 90054,50 \\
& Total & 527 & & \\
\hline Not cocky & Mexican & 234 & 272,50 & 63765,00 \\
& German & 303 & 266,30 & 80688,00 \\
& Total & 537 & & \\
\hline Not sophisticated & Mexican & 233 & 261,02 & 60817,50 \\
& German & 304 & 275,12 & 83635,50 \\
& Total & 537 & & \\
\hline
\end{tabular}

Test Statistics ${ }^{\mathrm{a}}$

\begin{tabular}{|l|r|r|r|r|r|r|r|}
\hline & Aesthetic & \multicolumn{1}{c|}{ Cool } & American & Creative & $\begin{array}{r}\text { Full of the joys } \\
\text { of life }\end{array}$ & Passionate & Intelligent \\
\hline Mann-WhitneyU & 23955,000 & 20072,500 & 31219,000 & 19808,500 & 23873,000 & 24661,500 & 21428,000 \\
Wilcoxon W & 50983,000 & 47567,500 & 58480,000 & 47303,500 & 51134,000 & 52156,500 & 48689,000 \\
Z & $-6,499$ & $-9,003$ & $-2,293$ & $-9,275$ & $-6,635$ & $-6,116$ & $-7,969$ \\
Asymp. Sig. (2-tailed) &, 000 &, 000 &, 022 &, 000 &, 000 &, 000 &, 000 \\
\hline
\end{tabular}

a. Grouping Variable: Nationality.

Test Statistics ${ }^{\mathrm{a}}$

\begin{tabular}{|l|r|r|r|r|r|r|r|}
\hline & \multicolumn{1}{|c|}{$\begin{array}{c}\text { Social } \\
\text { responsible }\end{array}$} & Trustworthy & \multicolumn{1}{c|}{ Stylish } & Unique & \multicolumn{1}{c|}{ Young } & Not cocky & $\begin{array}{c}\text { Not } \\
\text { sophisticated }\end{array}$ \\
\hline Mann-WhitneyU & 20820,000 & 16664,000 & 24551,500 & 23186,000 & 23648,500 & 34632,000 & 33556,500 \\
Wilcoxon W & 46020,000 & 41864,000 & 50202,500 & 48386,000 & 49073,500 & 80688,000 & 60817,500 \\
Z & $-7,775$ & $-10,188$ & $-6,366$ & $-6,403$ & $-6,373$ &,- 471 & $-1,086$ \\
Asymp. Sig. (2-tailed) &, 000 &, 000 &, 000 &, 000 &, 000 &, 638 &, 278 \\
\hline
\end{tabular}

a. Grouping Variable: Nationality: 


\title{
Profiles and Preferences of Online Millennial Shoppers in Bulgaria and Croatia
}

\author{
Patricia R. Loubeau \\ Elitsa Alexander \\ Georgi Kalchev ${ }^{1}$
}

\begin{abstract}
Generation Y consumers are an influential online shopping segment. This article empirically assesses the factors affecting the online purchase among millennials in Croatia and Bulgaria. The results obtained indicate that while convenience is reported as the most common reason for online shopping worldwide, the primary reason Bulgarian and Croatian millennials shop online is the pursuit of better prices. While security concerns are reported as a major online shopping barrier, Eastern-European millennials are more concerned with other factors. In Croatia and Bulgaria "audio-video" is among the least purchased categories online and "apparel and accessories" is among the most purchased categories.
\end{abstract}

KEYWORDS. Internet buying; online shopping; Generation Y; purchasing patterns; consumer behavior; Eastern Europe

\section{INTRODUCTION}

With more than 1.9 billion users worldwide (Internet World Stats, 2011) the web has become a major contributor to business globalization and trade, but also a tool for consumer choice and empowerment. Nie and Erbring (2000) suggest consumers use the Internet for product information, for travel information, and for buying. According to a Nielsen global survey $(2008$, p.1), over $85 \%$ of the world's online population has used the Internet to make a purchase, up $40 \%$ from two years ago and more than half of Internet users are regular online shoppers, making online purchases at least once a month. According to Forrester research (2010) the seven largest markets in Eu- rope for online retail are France, Germany, Italy, the Netherlands, Spain, Sweden, and the United Kingdom. There are key differences among the markets. According to a report by the Centre for Retail Research, British consumers are the largest online spenders in $\mathrm{Eu}-$ rope, with a third of all 2009 Internet purchases across the continent taking place in the UK (McAdam, 2010). In Italy and Spain, Internet commerce only represents a fraction of total retail volume (von Abrams, 2010). Recent research shows that Western Europe leads the world in retail-e-commerce sales and this dominance is expected to continue through 2012 (Business Wire, 2010).

Patricia R. Loubeau, Ph.D. is affiliated with Hagan School of Business, Iona College, New York, USA. Elitsa Alexander, Ph.D. and Georgi Kalchev, Ph.D. are affiliated with Department of Business Administration, The American University in Bulgaria, 1 Georgi Izmirliev Square, Blagoevgrad 2700, Bulgaria.

Address correspondence to Elitsa Alexander, Assistant Professor of Business Administration, The American University in Bulgaria, 1 Georgi Izmirliev Square, Blagoevgrad 2700, Bulgaria.

E-mail: eshumarova@aubg.bg 
Growth in Internet usage and e-commerce is expected to come from regions outside the United States (Brashear et al., 2009, p.268). Even though the growth rate in Internet usage worldwide has been dramatic, Internet penetration statistics reveal that most regions of the world offer opportunity for substantial growth and there is wide variation in penetration rates among countries (Internet World Stats, 2011; European Commission Eurostat, 2011). Various social, economic and political factors have been determined to affect Internet growth.

One group of Internet users that are especially wired and therefore a significant influence in the marketplace are the Generation Y consumers, also called millennials. Generation $\mathrm{Y}$ are those born between 1977 and 1990, are now ages 18-32, and represent $35 \%$ of the Internet using population (Pew Internet and American Life Project, 2010, p.4). The first wave of this generation began graduating from college in Spring 2004. This generation are demanding, highly wired and knowledgeable consumers. Gen-Y consumers' sheer numbers and spending power transform the market for every life stage they enter (Morton, 2002; Paul, 2001, p.44). Further, their generation is considered very techno-literate. Sarbu (2008) has described them as the first generation of digital natives. They have been computer able since childhood and have become accustomed to depending on computers for almost all facets of their daily lives. Generation Y consumers also have a fair degree of disposable income available to spend online. In the United States, students earn $\$ 200$ billion a year in part- or full-time jobs and in 2006 purchased $\$ 190$ billion worth of goods (Tapscott, 2009, p.188). Therefore, Generation $Y$ is the future prevailing consumer of the $21^{\text {st }}$ century, permanently connected, informed, and with a wide power of control in the product and service world.

With these considerations in mind, the purpose of this study was to empirically analyze online buying behavior among Generation Y college students. This research will go beyond previous studies that looked at only one product category, such as apparel, or that looked at Internet shopping in general (and not by specific product categories). This study will focus on generation $\mathrm{Y}$ consumers, a specific market segment that is more technologically adept than prior generations. Many studies have been published to analyze both the behavior and the main traits that define the online consumer. This research extends the work of Brashear et al. (2009), Calik and Ersoy (2008) and others and addresses the need for a non U.S. centric view of Internet usage. Specifically, this exploratory study will focus on two emergent market segments in Eastern Europe for which limited prior work has been accomplished: namely Croatia and Bulgaria. The results of this study should be of value to retailers interested in buying behaviors, educators interested in consumer behavior, and consumer theorists.

\section{LITERATURE REVIEW AND RESEARCH QUESTION DEVELOPMENT}

E-commerce is best regarded as a particular type of retail channel that can be compared with both traditional shopping channels, such as specialty stores or supermarkets, and with other indirect channels such as telephone and catalogue purchasing (Alreck and Settle, 2002). Nie and Erbring (2000, p.9) suggest that $62 \%$ of the consumers use the Internet for product information, 54\% for travel information, and $36 \%$ for buying. Rohm and Swaminathan (2004) developed a typology based upon motivations for shopping online. Their analysis of these motives suggested the existence of four shopping types. They labeled the four types as convenience shoppers, variety seekers, balanced buyers, and store-oriented shoppers.

Numerous studies have been published to profile and analyze both the behavior and the main traits that define the online consumer. Not surprisingly, they sometimes bring into attention different results perhaps based on the 
time of the analysis and the country of origin. Looking at various demographic factors that exhibit distinct purchasing behaviors in the US, an early study by Donthu and Garcia (1999) pointed out that motivational factors as well as age and income status had an impact on online acquisition. They found that mainly older and those with higher incomes were likely to buy online. The relative strength of these predictors was not assessed. Bellman et al. (1999) found that the three strongest predictors of Internet shopping were looking for product information, number of months of online experience, and the number of daily emails received. These variables are somewhat reflective of the ability to navigate the Internet. Swinyard and Smith (2003, p.573) found that, compared with online non-shoppers, online shoppers are younger, wealthier, better educated, have higher computer literacy, spend more time on their computer, and spend more time on the Internet. Generation X accounted for more than one third of all online purchases in 2006 (MarketingVOX, Anon., 2006) while in 2008 a Price Grabber research showed that Generation Y shoppers are most active and comfortable with online and mobile activities being the busiest online shoppers (Jones, 2008). Demographic variables have been reported as significant variables influencing Internet usage and buying. Males were found to use the Internet for purchasing activities to a greater extent compared to females (Teo, 2001, p.133). Brown et al. (2003) also found a relationship between gender and online purchasing. In general, advantages of online shopping as perceived by consumers include convenience, selection, price, original services that may be available online but not elsewhere, personal attention, easy and abundant information access, and privacy (consumers may be able to buy items that they may be reluctant to buy in-store).

Ahuja et al. (2003, p.149) examined the reasons why people shop online and found that $28 \%$ cite convenience, $25 \%$ better prices, and $23 \%$ saves time. Kwek, Tan, and Lau (2010, p.15) also found that convenience orientation is the most important contributor to the online purchase intention. Ahuja et al. (2003, p.147) found that of those consumers that do shop online, travel and audio-video were the most popular categories. Another study by Fraser and Henry (2007, p.12) looked specifically at purchasing behaviors in the Caribbean and found that books and clothes were the most popular purchases online.

With respect to reasons for not shopping online, numerous theories have been postulated. Kiran, Sharma, and Mittal (2008, p.65) have noted that the lack of opportunity to examine products, or to feel or touch have been regarded as the specific factor affecting the online buying decision. Consumer attitudes powerfully affect their buying decisions. A study by Vellido et al. (2000) extracted nine factors associated with users' perceptions of online shopping. Among these factors, risk perception of users was demonstrated to be the main discriminator between people buying online and people not buying online.

The review of the above studies indicates that although there have been a number of studies done on Internet usage and e-shopping, no such study has been undertaken in Eastern Europe and especially in Bulgaria and Croatia. The present research has been undertaken with this perspective.

\section{THE CROATIAN AND BULGARIAN INTERNET ENVIRONMENT}

The growth in supply and demand for the Internet is undisputed. The pattern of online shopping behavior is likely to differ across cultures. Lynch and Beck (2001) have found that Internet users from different countries show differences in beliefs, attitudes, perceptions, and Internet buying behavior depending on user experience, and home country or region. Unlike well established and developed mass consumer societies such as the UK and the US, Croatia and Bulgaria have a more recent engagement with global consumerism. As post-transition Eastern Block countries, they 
have a more collectivist heritage and more recent exposure to Internet shopping opportunities. Central and Eastern Europe (CEE) in general and Croatia and Bulgaria specifically provide enormous online buying promise, with eleven million potential customers and increasing spending power. Inclusion in the EU for Bulgaria has also brought increased investment to the country (Credit Suisse, 2007) which should stimulate buying behavior. These countries were chosen as they represent nearly similar positions on important cultural and economic dimensions. As transitional economies, adoption of e-commerce services for them is a significant element of economic development.

\section{Croatia}

In 2010, the population of Croatia was $4,486,881$ and of that number $50 \%$ were Internet users. This compares with a 2010 Internet usage rate in the United States of $77.4 \%$. With the Internet penetration of $50 \%$, Croatia is ahead of Turkey (45\%) and slightly behind Macedonia (51\%). Croatia is lagging behind Internet penetration in EU countries $(67.6 \%)$ (Internet World Stats, 2011). The structure of Internet users in Croatia is supported by investment in information and communication technologies both by private firms and government initiatives.

Croatia is an important context to investigate in light of recent social, political and cultural changes. A recent study on value structures of Croatian youth (aged 15-29 years) indicates that there has been a significant rise in levels of materialism when compared to the result of the same survey conducted in 1986 (Radin, 2002). Croatia's transition from a socialist to a free-market Western society would expect to carry with it expectations of material prosperity and increased consumer spending. At the same time, Croatia as a developing market economy does not have equal financial footing in terms of consumer spending with other stable mass consumer societies like the US. For example, the purchasing power (GDP per capita) in Croatia was only US $\$ 17,500$ in 2010 compared to the United States GDP per capita of $\$ 47,400$ and the EU average of $\$ 32,900$ (Central Intelligence Agency, 2011). Just over $36 \%$ of the population of Croatia over the age of 15 uses the Internet at least once a month. This amounts to 1.2 million people. This conclusion is drawn from a survey by the Zagreb subsidiary of the GfK Group that was conducted in 2004 (GFK, 2010). Internet shopping has been reported to be very uncommon for Croatian students (5.6\%) compared to students in the UK (38.6\%) and Germany (35.3\%) (Jankovič and Dittmar, 2006, p.30).

\section{Bulgaria}

Internet penetration in Bulgaria was $47.5 \%$ based on an estimated population of $7,148,785$ in 2010 (Internet World Stats, 2011). Bulgaria lags behind the EU average of $67.6 \%$ but is still well positioned ahead of Cyprus (39.3\%), Greece (46.2\%), and Romania (35.5\%). The Bulgarian National Statistical Institute has found that the most active group of Internet users was between 16 and 24 years old. The share of people who spend their time on the global network in this age group increased $41.7 \%$ in five years to $75.1 \%$ in 2009 (National Statistical Institute, 2009, p.2). The number of Internet users is increasing at a particularly rapid rate in Bulgaria due to the rise in popularity of Internet and computer gaming clubs.

While Internet shopping has increased in Bulgaria, electronic trade is still underdeveloped. The country was among the lowestranking in the European Union in terms of online shopping services in 2009. In 2002 Bulgaria, Ukraine, and Romania were laggards with respect to online shopping with less than $2 \%$ of the online users shopping online (Chennai, 2002). The Bulgarian National Statistics Institute reported that $3 \%$ of individuals overall bought goods or services online in a three month period in 2009 and Eurostat reported $5 \%$ of the population shopping online in 2009. 
The most regular online buyers are between 18 and 24 years, accounting for $45 \%$ of all shoppers. Shoppers aged 25 to 34 represent the second largest group (Dnevnik.bg, Anon., 2010). Recent data by GfK Market research found that $14.4 \%$ of all Bulgarian consumers have shopped at least once online (GFK, 2010) with the highest percentage of users in the 20-29 years old age group (17.2\%). Internet commerce, although still primarily done on foreign sites, has been stimulated by the development of local online retailers and online payment systems. At the same time, Bulgaria, as a developing market economy, does not have equal financial footing in terms of consumer spending compared to the US or even Croatia. The purchasing power or GDP per capita was $\$ 12,800$ in 2010 (Central Intelligence Agency, 2011).

\section{RESEARCH QUESTIONS AND HYPOTHETICAL MODEL}

Based on the preceding discussion the following research questions were posed in relation to Generation $\mathrm{Y}$ shopping behavior in Bulgaria and Croatia.

1. What are the differences between Gen $\mathrm{Y}$ internet shoppers and non-shoppers?

2. Why do Gen Y consumers decide to buy online?

3. Why do Gen Y consumers decide not to buy online?

4. Are there any differences between Gen Y shopping behaviors in Bulgaria versus Croatia?
5. What products are most commonly purchased online by Gen Y in Bulgaria and Croatia?

In order to answer these research questions, we considered a multitude of consumer factors for inclusion as constructs in a questionnaire. We made use of Zhou et al.'s (2007) major categories of factors (see Table 1), organized along two dimensions, online and shopping:

- Type I consumer factors (e.g., consumer demographics) are independent of both online -and shopping;

- Type II factors (e.g., computer knowledge) are only related to online;

- Type III factors (e.g., shopping orientation) are only related to shopping;

- Type IV factors (e.g., perceived risk) are related to online shopping.

These types of factors have been extensively studied in the technology-adoption literature. The Technology Acceptance model (TAM) (Chen et al., 2002; Davis, 1989) has been adapted for explaining and predicting user behavior in an on-line shopping environment (e.g., Palou, 2003). More recently, the Online Shopping Acceptance Model (OSAM) (Zhou et al., 2007) has been developed to explain consumer acceptance of online shopping. OSAM extends the TAM by taking specific characteristics of online shopping environments into consideration. Consumer demographics include gender, age, and income. There are mixed findings on the relationship between these characteristics and online shopping

TABLE 1: Classification of Consumer Factors Examined in Online Shopping Acceptance Research (Zhou et al., 2007)

\begin{tabular}{|c|c|c|c|}
\hline \multirow{4}{*}{ Online } & & \multicolumn{2}{|c|}{ Shopping } \\
\hline & \multirow[b]{2}{*}{ Not Related } & Not Related & Related \\
\hline & & $\begin{array}{c}\text { Type I } \\
\text { (Consumer demographics) }\end{array}$ & $\begin{array}{c}\text { Type III } \\
\text { (Shopping orientation) }\end{array}$ \\
\hline & Related & $\begin{array}{c}\text { Type II } \\
\text { (Computer knowledge) }\end{array}$ & $\begin{array}{c}\text { Type IV } \\
\text { (Perceived outcome, } \\
\text { Perceived risk) }\end{array}$ \\
\hline
\end{tabular}


behavior. Perceived outcome has largely been theorized as one of the driving forces of technology adoption. Perceived usefulness refers to "the degree to which a person believes that using a particular system (e.g., an online shopping site) would enhance his or her job performance (Davis, 1989, p.320)". Chen et al. (2002) and Pavlou (2003) have used "perceived usefulness" to explain consumer acceptance of online shopping. Limayem et al. (2000) found that "perceived consequence" significantly influenced intention to shop online. Perceived risk refers to the consumers' subjective belief of suffering a loss in pursuit of a desired outcome (Pavlou, 2003).

The research framework (Figure 1) consists of five determinants of acceptance of online shopping: consumer demographics, computer knowledge, perceived outcome, country of origin, and perceived risks of internet buying. Five hypothesized relations between the determinants and consumers' online purchase behaviour were developed. Each of the hypothesized relations is supported by the findings of published empirical research (Alreck and Settle, 2002; Bagchi and Mahmood, 2004; Bhatnagar et al., 2000; Brown et al.,
2003; Chen et al., 2002; Davis, 1989; Donthu and Garcia, 1999; Featherman and Pavlou, 2003; Jarvenpaa et al., 1999; Joines et al., 2003; Korgaonkar and Wolin, 1999; Kolsaker et al., 2004; Levy, 1999; Li et al., 1999; Liang and Jin-Shiang, 1998; Liao and Cheung, 2001; Limayem et al., 2000; Park et al., 2004; Pavlou, 2003; Rodgers and Harris 2003; Ruyter et al., 2001; Slyke et al., 2002; Stafford et al., 2004; Susskind, 2004).

In line with the findings of published empirical research and in line with the OSAM model, we propose the following:

H1. The effects of gender on online shopping behavior are significant.

H2. The effects of age on online shopping behavior are significant.

H3. The effects of income on online shopping behavior are significant.

H4. Computer knowledge has a significant positive impact on online shopping behavior.

FIGURE 1: Research Framework

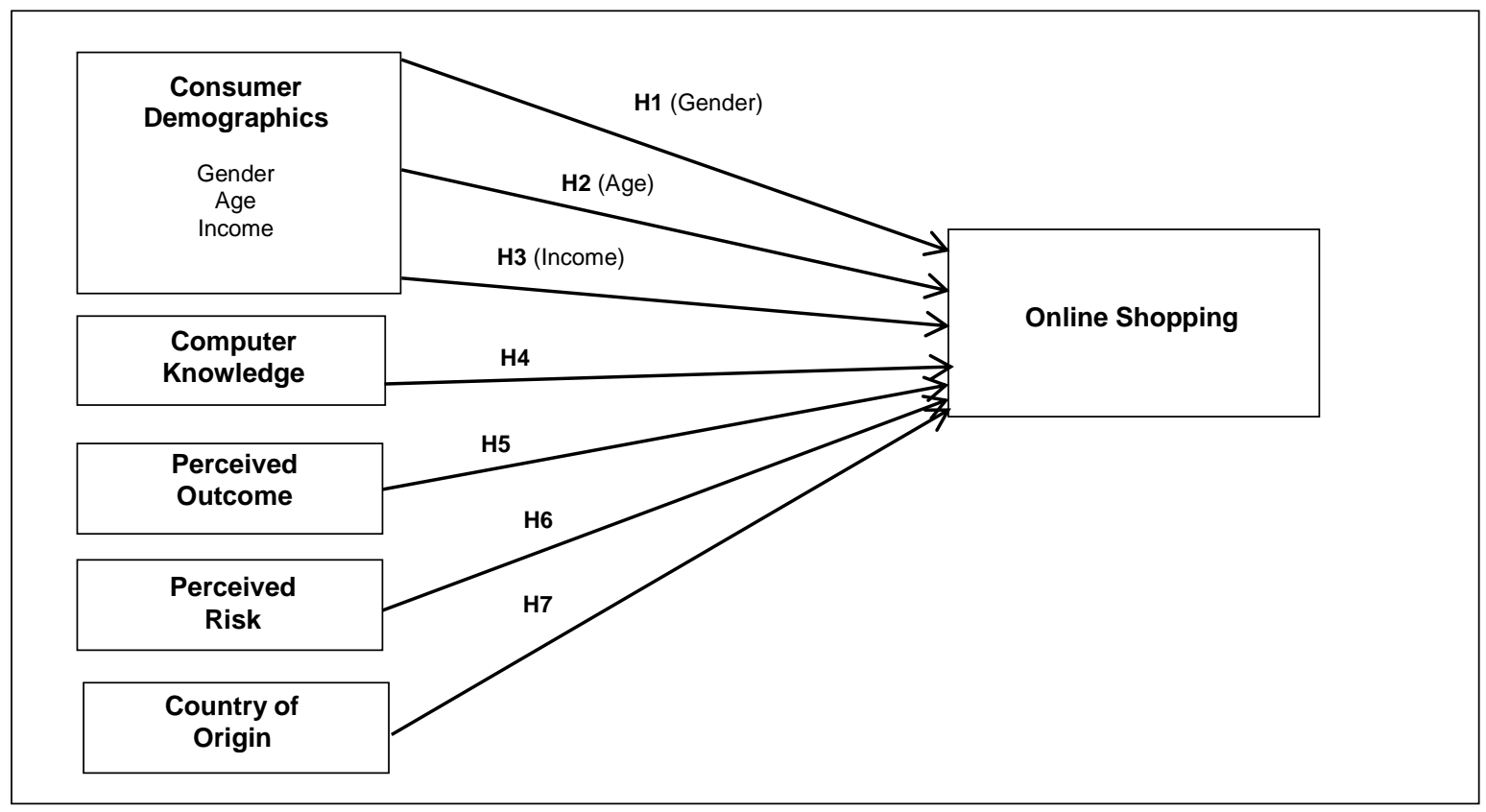


H5. The effects of perceived outcome on online shopping behavior are significant.

H6. The effects of perceived risk on online shopping behavior are significant.

H7. The effects of country of origin on online shopping behavior are significant.

\section{SAMPLE AND METHODOLOGY}

A questionnaire was developed to test the hypotheses outlined above in the context of Eastern European millennials. The participant pool consisted of a convenience sample of college students in Croatia and Bulgaria. To accommodate disparities in income status between Croatia and Bulgaria, income categories were defined as: much worse off than colleagues, worse off than colleagues, same as colleagues, better off than colleagues, and much better off than colleagues. There were nine questions pertaining to internet use and online purchasing behavior. The latter included questions such as if the student shops online, and what products or services are purchased as well as categorical questions relating to level of computer expertise and motivation for online shopping. The product categories were derived from a variety of sources and focused on online shopping behavior across different categories to reflect both products and services. The approach used was similar to that of the online-shopping research companies, Forrester and comScor, both leaders in measuring the digital world. The approach was also consistent with that of Ahuja, Gupta and Raman (2003) who focused on general online purchasing behavior of individual consumers and why they choose to buy or not buy online. Number of internet purchases on the web in the last three months was a ratio scale of never, 1-3 times, 4-6 times, 7-10 times, 11-20 times, and more than 20 times. Computer knowledge was measured using a 5-point interval scale rated from no knowledge to expert. The measures used in this study were al- so obtained in part from previous research by Calik and Ersoy (2008) and Fraser and Henry (2007).

\section{ANALYSIS AND RESULTS}

A total of 538 surveys were distributed. Eleven were eliminated due to incomplete data, leaving a total of 527 usable surveys. The latter corresponds to a successful retrieval rate of $98 \%$. Almost all used the Internet and had a computer at home $(99.8 \%)$. A summary of the most important demographic and behavioral characteristics of the participants are illustrated in Table 2. SPSS 18.0 was used to facilitate data analysis. All relationships were tested at $\mathrm{p} \leq 0.05$ significance level. The analysis included t-tests for continuous measures and chisquare tests for categorical data, as well as regression analysis of the probability to shop online. All the above research questions and hypotheses were investigated, yielding the following results.

\section{INTERNET SHOPPERS VERSUS NON- SHOPPERS}

Our study found that $67 \%$ of all students have shopped online at least once, i.e. belong to the "internet shoppers" category. Approximately one-half $(54.7 \%)$ of those who shopped online made a purchase one to three times in the last three months. Fifty eight percent of Croatian college students indicate that they do shop online. This percent is significantly higher than the research by Jankovič and Dittmar (2006, p.30) which reported that internet shopping was very uncommon for Croatian students. Table 3 details the differences between internet shoppers and non-shoppers with respect to demographics and computer knowledge.

A regression analysis was performed to study the effects of the independent variables ("Gender", "Age", "Income", "Computer knowledge", "Country of origin", "Price", "Anxiety", "Cannot see, feel, touch, or try on 
item") on the probability of shopping online. The dependent variable was a dummy variable equal to 1 for shopping and 0 for nonshopping. This was essentially a linear probability model. The model was significant with $\mathrm{F}(8,487)=190.05, \quad \mathrm{P}$-value $=0.000$ and $\mathrm{R}$ squared $=0.6765$. Robust standard errors were used due to heteroskedasticity. At the 5\% level, the results indicated that significant are "Income", "Computer knowledge", "Price", "Anxiety", and "Cannot see, feel, touch, or try on item". The regression-analysis results also showed that gender and age do not have a significant effect on shopping behavior. Our findings contrasted with the findings of Alreck and Settle (2002), Brown et al. (2003), Donthu and Garcia (1999), Korgaonkar and Wolin (1999), Levy (1999), Li et al. (1999), Rodgers and Harris (2003), Slyke et al. (2002), Stafford et al. (2004), and Teo (2001) who found that male consumers make more online purchases and women are more skeptical of e-business than men.

As expected, income status is associated with online acquisition. The majority of students in Bulgaria and Croatia who indicate being "better off" than their colleagues also indicate that they do shop online $(86.2 \%)$. The same is true for respondents who indicate being "much better off" than their colleagues. Our chi-square tests indicate that higher income is positively correlated with probability to shop online. The regression analysis results indicate that one level increase in income increases the probability of shopping online by 0.07. Our findings confirm those of Bagchi and Mahmood (2004), Donthu and Garcia

TABLE 2: Description of Most Important Demographic and Behavioral Participant Characteristics

\begin{tabular}{|c|c|c|c|c|c|c|}
\hline \multirow[t]{2}{*}{ Nationality } & \multicolumn{2}{|c|}{ Croatian } & \multicolumn{2}{|c|}{ Bulgarian } & \multicolumn{2}{|c|}{ Total } \\
\hline & No. & $(\%)$ & No. & $(\%)$ & No. & $(\%)$ \\
\hline \multicolumn{7}{|l|}{ Gender } \\
\hline Male & 142 & $(42.9)$ & 89 & $(45.4)$ & 231 & $(43.8)$ \\
\hline Female & 189 & (57.1) & 107 & (54.6) & 296 & (56.2) \\
\hline \multicolumn{7}{|l|}{ Age } \\
\hline $18-22$ & 59 & $(17.8)$ & 181 & (92.3) & 240 & $(45.5)$ \\
\hline $23-29$ & 272 & (82.2) & 15 & $(7.7)$ & 287 & (54.5) \\
\hline \multicolumn{7}{|l|}{ Computer Knowledge } \\
\hline No Knowledge & 0 & $(0.0)$ & 0 & $(0.0)$ & 0 & $(0.0)$ \\
\hline Some Knowledge & 36 & (10.9) & 6 & (3.0) & 42 & (8.0) \\
\hline Average & 167 & (50.5) & 84 & (42.9) & 251 & $(47.6)$ \\
\hline Above-Average & 109 & (32.9) & 97 & (49.5) & 206 & (39.1) \\
\hline Expert & 19 & $(5.7)$ & 9 & $(4.6)$ & 8 & (5.3) \\
\hline \multicolumn{7}{|l|}{ Ever shopped online } \\
\hline Yes & 192 & $(58.0)$ & 161 & (82.1) & 353 & $(67.0)$ \\
\hline No & 139 & $(42.0)$ & 35 & $(17.9)$ & 174 & $(33.0)$ \\
\hline \multicolumn{7}{|l|}{ Income ${ }^{2}$} \\
\hline Much worse off than colleagues & 3 & $(0.9)$ & 2 & (1.1) & 5 & $(1.0)$ \\
\hline Worse off than colleagues & 31 & $(9.8)$ & 10 & (5.5) & 41 & (8.3) \\
\hline Same as colleagues & 210 & $(66.7)$ & 142 & $(78.5)$ & 352 & $(71.0)$ \\
\hline Better off than colleagues & 61 & $(19.4)$ & 26 & (14.4) & 87 & (17.5) \\
\hline \multirow{2}{*}{$\begin{array}{l}\text { Much better off than colleagues } \\
\text { Total }\end{array}$} & 10 & $(3.2)$ & 1 & $(0.5)$ & 11 & $(2.2)$ \\
\hline & 331 & $(100.0)$ & 196 & $(100.0)$ & 527 & $(100.0)$ \\
\hline
\end{tabular}


(1999), Korgaonkar and Wolin (1999), Li et al. (1999) and Susskind (2004) who found that income was positively related to online shopping tendency.

We find that internet shoppers have better computer knowledge than non-shoppers. Online shopping behavior seems to correlate directly to the computer-knowledge level. The higher the computer-knowledge level, the higher the percentage of internet shoppers versus non-shoppers. All respondents with expert computer knowledge shop online. Approximately eighty one percent of respondents with above-average computer knowledge shop online. There is a significant difference in the rate of computer knowledge between respondents who shop and don't shop online, i.e. millennials with better computer knowledge exhibit a higher probability to shop online. The regression analysis results indicate that one level increase in the rate of computer knowledge increases the probability of shopping online by 0.09 . Our findings confirm the findings of Swinyard and Smith (2003, p.573) that, compared with internet non-shoppers, internet shoppers are wealthier and have higher computer literacy.

\section{Motivating factors and barriers}

The authors examined reasons why millennials liked to shop online. The most common reason for shopping online among millennials is the pursuit of better prices $(20.5 \%$ in total, see Table 4). This finding differs from the work of Ahuja et al. (2003) and Kwek, Tan, and Lau (2010), who found that convenience was the most common reason given for online shopping. Our study found that better prices are the most common reason why Bulgarian and Croatian millennials shop online. If we compare Bulgarian and Croatian prices to Western-European and US prices we note an interesting fact. While the majority of consumer prices tend to be significantly higher in Western Europe and US compared to Bulgaria

TABLE 3: Internet Shopper versus Non-Shopper Characteristics

\begin{tabular}{|c|c|c|c|c|c|c|}
\hline & \multicolumn{2}{|c|}{$\begin{array}{l}\text { Internet } \\
\text { Shoppers }\end{array}$} & \multicolumn{2}{|c|}{$\begin{array}{c}\text { Internet } \\
\text { Non-shoppers }\end{array}$} & \multicolumn{2}{|c|}{ Total } \\
\hline & No. & $(\%)$ & No. & $(\%)$ & No. & $(\%)$ \\
\hline \multicolumn{7}{|l|}{ Gender } \\
\hline Male & 167 & (72.3) & 64 & $(27.7)$ & 231 & $(100.0)$ \\
\hline Female & 186 & (62.8) & 110 & (37.2) & 296 & $(100.0)$ \\
\hline \multicolumn{7}{|l|}{ Age } \\
\hline $18-22$ & 174 & $(72.5)$ & 66 & $(27.5)$ & 240 & $(100.0)$ \\
\hline $23-29$ & 179 & (62.4) & 108 & (31.6) & 287 & $(100.0)$ \\
\hline \multicolumn{7}{|l|}{ Income } \\
\hline Much worse off than colleagues & 4 & $(80.0)$ & 1 & $(20.0)$ & 5 & $(100.0)$ \\
\hline Worse off than colleagues & 21 & $(51.2)$ & 20 & $(48.8)$ & 41 & $(100.0)$ \\
\hline Same as colleagues & 223 & (63.4) & 129 & (36.6) & 352 & $(100.0)$ \\
\hline Better off than colleagues & 75 & $(86.2)$ & 12 & $(13.8)$ & 87 & $(100.0)$ \\
\hline Much better off than colleagues & 9 & (81.8) & 2 & (18.2) & 11 & $(100.0)$ \\
\hline \multicolumn{7}{|l|}{ Computer Knowledge } \\
\hline No knowledge & 0 & $(0.0)$ & 0 & $(0.0)$ & 0 & $(0.0)$ \\
\hline Some knowledge & 12 & $(28.6)$ & 30 & (71.4) & 42 & $(100.0)$ \\
\hline Average & 146 & $(58.2)$ & 105 & $(41.8)$ & 251 & $(100.0)$ \\
\hline Above-Average & 167 & $(81.1)$ & 39 & (18.9) & 206 & $(100.0)$ \\
\hline Expert & 28 & $(100.0)$ & 0 & $(0.0)$ & 28 & (100.0) \\
\hline Total & 353 & $(100.0)$ & 174 & $(100.0)$ & 527 & $(100.0)$ \\
\hline
\end{tabular}


and Croatia, there is one exception, i.e. prices of brand name products (e.g. Levis, Nike, Zara, HM). One summer dress in a chain store (Zara, H\&M), for example, would cost approximately $14 \%$ less to buy from a store located in Western Europe (e.g. Germany, Spain, France) than from a store located in Bulgaria. The same product category would cost approximately $8 \%$ less to buy from a store located in Western Europe (e.g. Germany, Spain, France) than from a store located in Croatia (NUMBEO, Anon., 2011). The same product would be even less expensive if bought in the US. This may explain why Bulgarian and Croatian millennials (12.4\%) are buying "apparel and accessories" online while looking for better prices. Overall, "apparel and accessories" is the second most popular online-shopping category (see Table 6). For Bulgarian millennials (16.8\%) it is the most popular online-shopping category, which may be a logical response to the higher disparity between Bulgarian and Western European brand-name-apparel prices. Another reason may be the limited opportunities for purchasing a variety of brand names locally.

The authors also examined reasons why millennials chose not to shop online (see Table 5 ). Our study found that the majority of nonshoppers (44.4\% of Bulgarian and Croatian non-shoppers combined) do not shop online because they cannot see, feel or touch the item. This contrasted with the findings of Taylor Nelson and Sofres (Anon., 2001) and of Vellido et al. (2000) who found that online security is the biggest concern in the US keeping Internet users from shopping online. When Bulgarians shop online (e.g. through books.bg), the most common method of payment is COD (Cash on Delivery). consumers need to go to the nearest post office, receive the product and pay cash. The COD method does not require providing personal information like a credit card number. Online payment methods (e.g. credit card payment systems, digital wallet and stored value payment systems), while growing, are still not very prevalent in Eastern Europe.

European browsing and purchasing patterns vary from country to country (Dellner, 2007). Our findings indicate that there are some differences in the shopping behavior online between Bulgaria and Croatia but they are not significant at the $5 \%$ level (with a Pvalue of 0.068 they would have been significant the $10 \%$ level). A higher number of Bulgarian millennials have shopped online compared to a smaller number of Croatians $(82.1 \%$ compared to $58.0 \%$ ). Meanwhile, the majority of Bulgarians (62.1\%) seem to be moderately active in terms of number of Internet purchases, having made only one to three purchases in

TABLE 4: Major Reasons for Shopping Online

\begin{tabular}{|c|c|c|c|c|c|c|}
\hline & \multicolumn{2}{|c|}{ Croatia } & \multicolumn{2}{|c|}{ Bulgaria } & \multicolumn{2}{|c|}{ Total } \\
\hline & No. & $(\%)$ & No. & $(\%)$ & No. & $(\%)$ \\
\hline Convenience & 28 & (8.8) & 66 & (19.0) & 94 & (14.1) \\
\hline Easier than store shopping & 26 & (8.2) & 12 & (3.5) & 38 & (5.7) \\
\hline Better prices & 59 & (18.5) & 77 & (22.2) & 136 & (20.5) \\
\hline Unique products not in stores & 45 & (14.1) & 67 & (19.3) & 112 & (16.8) \\
\hline Saves time & 73 & $(23.0)$ & 51 & $(14.7)$ & 124 & (18.7) \\
\hline Can shop any time of the day & 46 & $(14.5)$ & 38 & $(10.9)$ & 84 & $(12.6)$ \\
\hline Like to compare prices online & 22 & (6.9) & 21 & (6.1) & 43 & (6.5) \\
\hline Less hassle/No crowds & 19 & $(6.0)$ & 15 & (4.3) & 34 & (5.1) \\
\hline Total & 318 & $(100.0)$ & 347 & $(100.0)$ & 665 & $(100.0)$ \\
\hline
\end{tabular}


TABLE 5: Major Reasons for Not Shopping Online

\begin{tabular}{lrrrrrr}
\hline & \multicolumn{2}{c}{ Croatia } & \multicolumn{2}{c}{ Bulgaria } & \multicolumn{2}{c}{ Total } \\
\cline { 2 - 7 } & No. & $(\%)$ & No. & $(\%)$ & No. & $(\%)$ \\
\hline Too slow & 4 & $(2.6)$ & 1 & $(2.8)$ & 5 & $(2.7)$ \\
Insufficient information & 15 & $(9.8)$ & 2 & $(5.5)$ & 17 & $(9.0)$ \\
Anxiety about online trans- & 53 & $(34.6)$ & 8 & $(22.2)$ & 61 & $(32.3)$ \\
action & & & & & & \\
Cannot see, feel, touch, & 64 & $(41.8)$ & 20 & $(55.6)$ & 84 & $(44.4)$ \\
or try on item & 1 & $(0.7)$ & 0 & $(0.0)$ & 1 & $(0.5)$ \\
No access to a computer & 16 & $(10.5)$ & 5 & $(13.9)$ & 21 & $(11.1)$ \\
Other & 153 & $(100.0)$ & 36 & $(100.0)$ & 189 & $(100.0)$ \\
\hline Total & & & & & & \\
\hline
\end{tabular}

the last three months. The majority of Croatians are, in contrast, active online shoppers. In a two-sample t-test with unequal variances, we compared the means of the number of purchases in the two countries. The mean in Croatia is 1.36 , while in BG it is 1 . The difference in means is 0.36 . The frequency of online purchases has a higher mean in Croatia. Compared to Bulgarians, a smaller share of Croatians have limited their online purchases to three within three months (48.4\%). A total of $33.4 \%$ of Croatians have made more than four purchases in a three-month period. This difference in number and frequency of online purchases may be due to the fact that Bulgarians do not have equal financial footing in terms of purchasing power compared to Croatians.

Croatians seem to be more time sensitive than Bulgarians. Twenty three percent of Croatian internet shoppers (compared to $14.7 \%$ of Bulgarians) have indicated "time saving" as an important factor for shopping online. Bulgarians seem to be stronger "variety seekers". Approximately nineteen percent of Bulgarian internet shoppers are motivated by finding unique products on the Web which are not available in stores. The latter percentage is just 14.1 for Croatians (see Table 4). Interestingly, Bulgarians are less concerned with the "ease" of online shopping and the 24/7 availability of online stores compared to physical stores. This may be due to the fact that physical stores are typically open 7 days per week in Bulgaria and some stores are open non-stop. Bulgarians can shop any time of the week and almost any time of the day at a variety of physical stores. The 24/7 availability of online stores is therefore hardly perceived as an advantage for Bulgarians.

\section{What are millenials buying online?}

The survey asked respondents who had purchased online to indicate the categories of items purchased for eleven different product/service categories. The data (see Table 6) indicate the most popular online-shopping category is "air travel", with a total of $16.8 \%$ of Croatian and Bulgarian internet shoppers (combined) having indicated it as part of what they purchase online. Following are "apparel and accessories" (12.4\%), "event tickets" $(12.2 \%)$, and "books and magazines" (12.2\%). Bulgarian shoppers prefer to buy apparel and accessories (16.8\% of Bulgarians compared to $8.4 \%$ of Croatians). Of interest to note is that audio-video are two of the least purchased categories. Only $6.6 \%$ of Croatians indicated they buy CDs online. The share of Bulgarians who buy CDs online is even less - just $1.5 \%$. This may be due to the fact that most audio-video is illegally. 
TABLE 6: Categories of Items Purchased Online

\begin{tabular}{lrrrrrr}
\hline & \multicolumn{2}{c}{ Croatia } & \multicolumn{2}{c}{ Bulgaria } & \multicolumn{2}{c}{ Total } \\
\cline { 2 - 7 } & No. & $(\%)$ & No. & $(\%)$ & No. & $(\%)$ \\
\hline Computers & 37 & $(7.2)$ & 53 & $(11.3)$ & 90 & $(9.1)$ \\
CD's & 34 & $(6.6)$ & 7 & $(1.5)$ & 41 & $(4.2)$ \\
Books and Magazines & 53 & $(10.3)$ & 67 & $(14.2)$ & 120 & $(12.2)$ \\
Event Tickets & 71 & $(13.8)$ & 49 & $(10.4)$ & 120 & $(12.2)$ \\
Consumer Electronics & 37 & $(7.2)$ & 42 & $(8.9)$ & 79 & $(8.0)$ \\
Videos & 32 & $(6.2)$ & 26 & $(5.5)$ & 58 & $(5.9)$ \\
Air travel & 91 & $(17.7)$ & 74 & $(15.7)$ & 165 & $(16.8)$ \\
Health and beauty sites & 43 & $(8.4)$ & 45 & $(9.5)$ & 88 & $(8.9)$ \\
Apparel and accessories & 43 & $(8.4)$ & 79 & $(16.8)$ & 122 & $(12.4)$ \\
Toys & 4 & $(0.8)$ & 4 & $(0.9)$ & 8 & $(0.8)$ \\
Other & 69 & $(13.4)$ & 25 & $(5.3)$ & 94 & $(9.5)$ \\
Total & 514 & $(100.0)$ & 471 & $(100.0)$ & 985 & $(100.0)$ \\
\hline
\end{tabular}

Croatians indicated they buy CDs online. The share of Bulgarians who buy CDs online is even less - just $1.5 \%$. This may be due to the fact that most audio-video is illegally acquired in Bulgaria and Croatia, the latter being especially valid for Bulgaria. Upon the recommendation of the International Intellectual Property Alliance (IIPA), Bulgaria was added to the Special 301 Watch List in 2003. The estimated level of piracy in the Records \& Music industry was $83 \%$ in 2002 (IIPA, 2003, p.348). Bulgaria's overall enforcement system against piracy, especially optical media piracy, continues to be ineffective. While audio-video is among the most popular categories purchased online on a global scale, this is not the case in Croatia and Bulgaria. Audio-video is one of the least purchased categories online in this part of Eastern Europe. On a global scale, Ahuja et al. (2003, p.147) have found that among those consumers that do shop online, travel and audio-video were the most popular categories. Our findings confirm the popularity of travel in Croatia and Bulgaria, but do not confirm the popularity audio-video.

\section{HYPOTHESES TESTING RESULTS}

The hypotheses tests yielded the following conclusions (Two-sample t-tests with unequal variances, Chi Square Tests, Regression Analysis, 0.05 significance level):

- H1 is rejected as the effects of gender on online shopping behavior have proven not to be significant at the 0.05 level (with a Pvalue of 0.091 , gender would have been significant the 0.10 level).

- $\mathrm{H} 2$ is rejected as the effects of age on online shopping behavior have proven not to be significant.

- H3 is sustained as the effects of income on online shopping behavior have proven to be significant. One level increase in income increases the probability of shopping online by 0.07 (see Figure 2).

- $\mathrm{H} 4$ is sustained as computer knowledge has proven to have a significant positive impact on online shopping behavior. One level increase in the rate of computer 
knowledge increases the probability of shopping online by 0.09 .

- H5 is sustained since the effects of perceived outcome on online shopping behavior have proven to be significant. Better prices are the major perceived benefit of online shopping for 22,2\% of Bulgarians and $18,5 \%$ of Croatians. One level increase in perception of better prices online increases the probability of shopping online by 0.22 (Bulgaria) and 0.10 (Croatia).

- H6 is sustained as the effects of perceived risk on online shopping behavior have proven to be significant. Both variables "Anxiety about online transaction", and "Cannot see, feel, touch, or try on item" have P-values of 0.000 . The regression analysis results indicate that one level increase in anxiety decreases the probability of shopping online by 0.60 . The inability to see, feel, touch, or try on item negatively affects the probability of shopping online even stronger (with a probability coefficient of -0.67). This means that Bulgarian and Croatian millennials are more likely not to shop online because of the inability to see, feel or touch the item online, rather than their anxiety about the online transaction. Our findings also reveal that Croatians are more concerned about the perceived risk of online shopping than Bulgarians.

- $\quad \mathrm{H} 7$ is rejected as the effects of country of origin on online shopping behavior have proven not to be significant at the 0.05 level (with a P-value of 0.068 it would have been significant the 0.10 level) (see Figure 2).

FIGURE 2: Causal Paths between Consumer Factors and Online Shopping

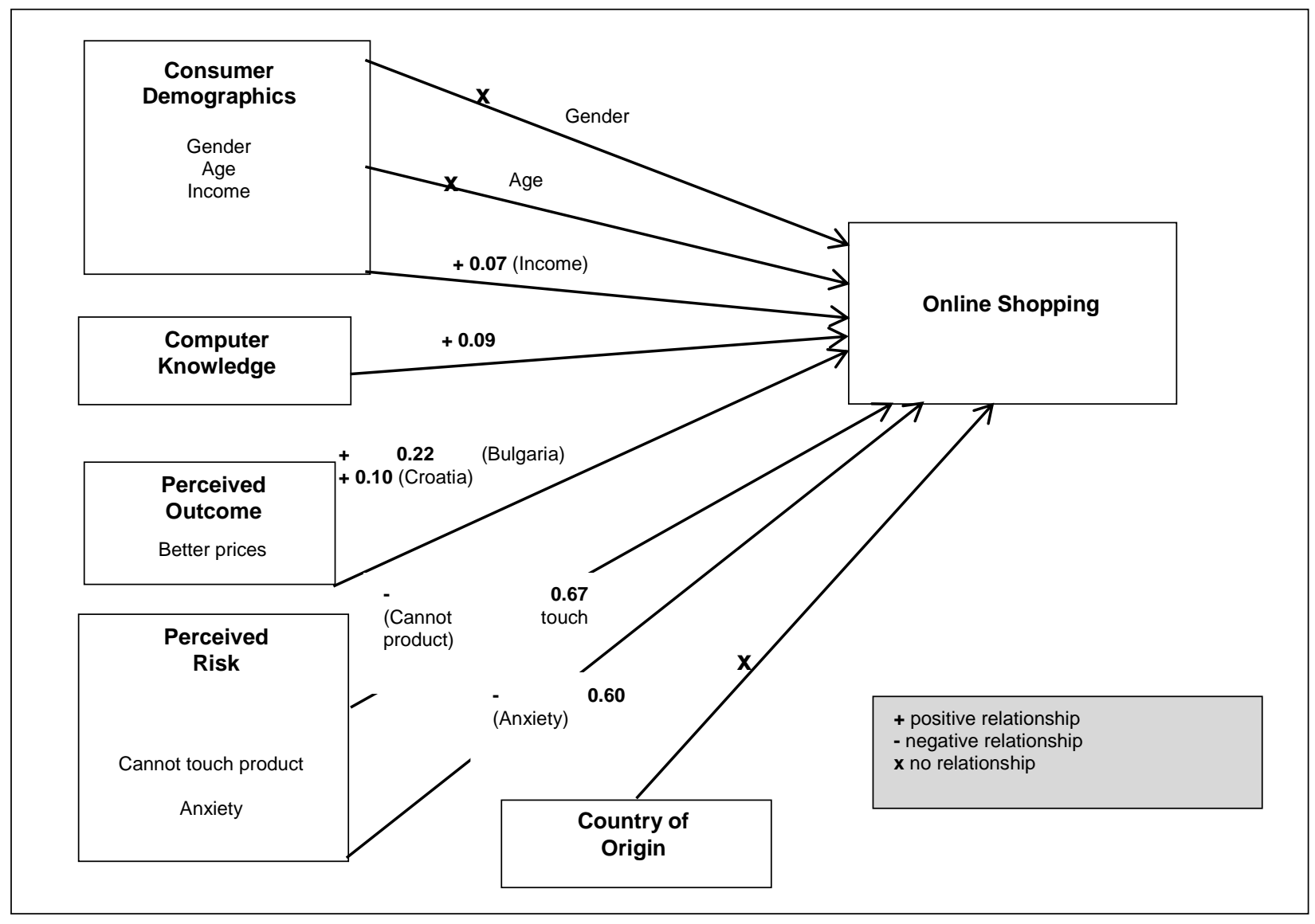




\section{CONCLUSIONS}

Understanding the similarities and differences among millennials in different regions is crucial for both marketing theory and practice. The results of this study are likely to have wider implications for both the research and practice of implementing e-commerce in the context of developing countries. One of the challenges created by global e-commerce is how to understand markets and groups of potential customers on the Internet. Misunderstanding consumer preferences can cause a successful strategy in one country to fail elsewhere. In this light, there may be a need for micro marketing to countries as niche markets. Our findings are consistent with the predictions derived from previous demographic studies only as far as income is concerned. Age and gender are no significant predictors of online shopping behavior. Regarding motivators and barriers to online shopping, the primary reason why Bulgarian and Croatian millennials shop online is the pursuit of better prices and the primary barrier is the inability to see, feel or touch the item online. This study revealed a significant difference in the shopping behavior online between the Eastern-European region of Bulgaria and Croatia and the rest of the world. Overall, the most popular onlineshopping category is "air travel" followed by "apparel and accessories". "Audio-video" is among the least purchased categories online in Croatia and Bulgaria, which deviates significantly from the high popularity of this category on a global scale. While convenience is reported as the most common reason for online shopping worldwide, the most common reason why Bulgarian and Croatian millennials shop online is the pursuit of better prices. Bulgarian and Croatian millennials are more concerned with the inability to see, feel or touch the item online, rather than security. This also deviates significantly from the high relevance of "security concerns" as a major online-shopping barrier on a global scale. Further investigations should address the question of the extent to which university students in Bulgaria and Croatia are representative of the general population of Internet users and consumers who make online purchases. Future research should also address changes in the online shopping behaviors of these groups over time.

\section{NOTES}

2. 31 Respondents gave NO ANSWER to the "Income" question

\section{REFERENCES}

Ahuja, M., Gupta, B., \& Raman, P. (2003). An empirical investigation of online consumer purchasing behavior. Communications of the ACM, 46(12), 145-151.

Alreck, P., and Settle, R. B. (2002). Gender effects on internet, catalogue and store shopping. Journal of Database Marketing, 9(2), 150-162.

Anonymous. (2011). NUMBEO - Internet database about cost of living worldwide. Retrieved from: http://www.numbeo.com, accessed on 15/4/11.

Anonymous. (2010). Online purchases on the rise in Bulgaria. Dnevnik.bg, Retrieved from: http://sofiaecho.com/2010/03/24/877914_o nline-purchases-on-the-rise-in-bulgaria, accessed on 19/3/11.

Anonymous. (2006). gen $\mathrm{Y}$ at forefront of online trends. MarketingVOX: The Voice of Online Marketing. Retrieved from: http://www.marketingvox.com/gen_y_at_f orefront_of_online_trends-022309/, accessed on 19/3/11.

Anonymous. (2001). Government online: an international perspective international perspective. Taylor Nelson \& Sofres Annual Global Report, November 2002. Retrieved from: http://www.epractice.eu/files/media/media _872.pdf, accessed on 09/4/11. 
Bagchi, K., and Mahmood, M. (2004). A longitudinal study of business model of online shopping behavior using a latent growth curve approach. Proceedings of the Tenth Americas Conference on Information Systems, NY.

Bellman, S., Lohse, G.L., and Johnson, E. J. (1999). Predictors of online buying behavior. Communications of the ACM, 42(12), 32-38.

Bhatnagar, A., Misra, S., and Rao, H. (2000). On risk, convenience, and internet shopping behavior. Communications of the ACM, 43(11), 98-105.

Brashear, T., Kashyap, V., Musante, M., and Donthu, N. (2009). A profile of the internet shopper: Evidence from six countries. Journal of Marketing Theory and Practice, 17(3), 267-268.

Brown, M., Pope, N., and Voges, K. (2003). Buying or browsing: An exploration of online purchasing orientations and online purchase intention. European Journal of Marketing, 37(11/12), 1666-1684.

Business Wire. (2010, Aug 24). Research and markets: Retail e-Commerce in Western Europe. available at: http://www.thefreelibrary.com/Research and Markets: Retail E-Commerce in Western Europe.-a0235258054, accessed on 18/3/11.

Calik, N., and Ersoy, N. F. (2008). Online shopping behavior and characteristics of consumers in Eskisehir, Turkey: Who, what, how much and how often? The Business Review, 10(2), 262-268.

Chen, L., Gillenson, M. and Sherrell, D. (2002). Enticing online consumers: An extended technology acceptance perspective. Information \& Management, 39(8), 705719.

Chennai, (2002, Aug. 21). Online shoppers want more: People looking to buy over the Internet are demanding that extra packagea secure payment system. Businessline, p.1.

Central Intelligence Agency. (2011). The World Factbook, Country Comparison:
GDP - per capita, Central Intelligence Agency. Retrieved from: https://www.cia.gov/library/publications/th e-world-

factbook/rankorder/2004rank.html, accessed on 19/3/11.

Credit Suisse. (2007). Bulgaria: EU's newest member offers attractive future investment opportunities. Global Equity Research, 9(February). Retrieved from: https://emagazine.creditsuisse.com/index.cfm?fuseaction=OpenArt icle\&aoid $=178717 \&$ lang $=E N \&$ coid $=1778$ 83, accessed on 19/3/11.

Davis, F. (1989). Perceived usefulness, perceived ease of use, and user acceptance of information technology. MIS Quarterly, 13(3), 319-340.

Dellner, T. (2007). European e-Commerce. Electronic Retailer Magazine, retrieved from:

www.electronicretailermag.com/info/0607 _euro.html, accessed on 08/4/11.

Donthu, N., and Garcia, A. (1999). The internet shopper. Journal of Advertising Research, 52-58.

European Commission Eurostat. (2011). Retrieved from: http://epp.eurostat.ec.europa.eu/portal/page /portal/eurostat/home/, accessed on 18/3/11.

Featherman, M., and Pavlou, P. (2003). Predicting E-Services Adoption: a Perceived Risk Facets Perspective. International Journal of Human-Computer Studies, 59, 451-474.

Frasier, S., and Henry, L. (2007). An exploratory study of residential internet shopping in Barbados. Journal of eastern Caribbean Studies, 32(1), 1-20.

Forrester Research. (2010). Double-digit growth for online retail in the US and Western Europe. Retrieved from: http://www.forrester.com/ER/Press/Releas e/0,1769,1330,00.html, accessed on $15 / 3 / 11$.

GFK. (2010). Personal communication, Svetoslav Petrov Slavov, Managing Director of 
GfK Bulgaria Market Research Institute, November 2010.

IIPA, (2003). International intellectual property alliance 2003 special 301 report BULGARIA. Retrieved from: http://www.iipa.com/rbc/2003/2003SPEC3 01BULGARIA.pdf, accessed on 09/4/11.

Internet World Stats. (2011). Retrieved from: http://www.Internetworldstats.com/, accessed on 15/3/11.

Jankovič, J., and Dittmar, H. (2006). The componential nature of materialistic values and subjective well-being: a comparison of students in Croatia, Germany, and the UK. Retrieved from: http://worlddatabaseofhappiness.eur.nl/hap _bib/freetexts/jankovic_jf_2004.pdf, accessed on 19/3/11, p.30.

Jarvenpaa, S., Tractinsky, N., and Vitale, M. (1999). Consumer trust in an internet store. Information Technology and Management, 1(12), 45-71.

Joines, J., Scherer, C., and Scheufele, D. (2003). Exploring motivations for consumer web use and their implications for e-Commerce. Journal of Consumer Marketing, 20(2), 90-109.

Jones, K. (2008). Gen Y busiest online shoppers. Information Week. Retrieved from: http://www.informationweek.com/news/int ernet/retail/showArticle.jhtml?articleID=2 $10300052 \&$ queryText $=$ Gen $\% 20$ Y\%20Busi est $\% 20$ Online $\% 20$ Shoppers, accessed on 19/3/11.

Kolsaker, A., Lee-Kelley, L., and Choy, P. (2004). The reluctant Hong Kong consumer: Purchasing travel online. International Journal of Consumer Studies, 28(3), 295304.

Korgaonkar, P., and Wolin, L. (1999). A multivariate analysis of web usage. Journal of Advertising Research, 39(2), 53-68.

Kiran, R., Sharma, A., and Mittal, K. (2008). Attitudes, preferences and profile of online buyers in India: Changing trends. South Asian Journal of Management, 15(3), 55.

Kwek, C., Tan, H., and Lau, T. (2010). Investigating the shopping orientations on online purchase intention in the ecommerce environment: A Malaysian study. Journal of Internet Banking and Commerce, 15(2), 15.

Levy, S., (1999). How the internet is changing America. In Levy: E-Life, 38-42.

Li, H., Kuo, C., and Russell, M. (1999). The impact of perceived channel utilities, shopping orientations, and demographics on the consumer's online buying behavior. Journal of Computer-Mediated Communication, 5(2).

Liang, T., and Jin-Shiang, H. (1998). An Empirical study on consumer acceptance of products in electronic markets: a Transaction cost model. Decision Support Systems, 24(1), 29-43.

Liao, Z., and Cheung, M. (2001). Internetbased e-shopping and consumer attitudes an empirical study. Information \& Management, 38(5), 299-306.

Limayem, M., Khalifa, M., and Frini, A. (2000). What makes consumers buy from internet? A longitudinal study of online shopping. IEEE Transactions on Systems, Man, and Cybernetics-Part A: Systems and Humans, 30(4), 421-432.

Lynch, P., and Beck, J. (2001). Profiles of internet buyers in 20 Countries: Evidence for region-specific strategies. Journal of international Business Studies, 32(4), 725-748.

McAdam, C. (2010). Shoppers in UK are Europe's top online spenders. Retrieved from:http://www.heraldscotland.com/news /home-news/shoppers-in-uk-are-europe-stop-online-spenders-1.1002772, accessed on $16 / 3 / 11$.

Morton, L. (2002). Targeting generation Y. Public Relations Quarterly, 47(2), 46-48.

National Statistical Institute [of Bulgaria] (2009). Survey on ICT usage in households and by individuals aged between 16 and 74. Retrieved from: http://www.nsi.bg/EPDOCS/ICT_hh2009_ en.pdf, accessed on 19/3/2011, p.2.

Nie, N., and Erbring, L. (2000). Internet use, Stanford Institute for the Quantitative Study of Society. California. 
Nielsen. (2008). Trends in online shopping. Retrieved from: http://th.nielsen.com/site/documents/Globa 1OnlineShoppingReportFeb08.pdf, accessed on 15/3/11.

Park, J., Lee, D., and Ahn, J., (2004). Riskfocused e-Commerce adoption model: a cross-country study. Journal of Global Information Management, 7, 6-30.

Paul, P. (2001). Getting inside Gen Y. American Demographics, p .44, in Morton, 2002.

Pavlou, P. (2003). Consumer acceptance of electronic commerce: Integrating trust and risk with the technology acceptance model. International Journal of Electronic Commerce, 7(3), 101-134.

Pew Internet and American Life Project. (2010). Generations 2010. Retrieved from: http://pewinternet.org/ /media//Files/Repo rts/2010/PIP_Generations_and_Tech10.pd $\mathrm{f}$, accessed on 15/3/11, p.4.

Radin, (2002). Value hierarchies and structures. In V. Ilisisin, and F. Radin (eds.), Youth and Transition in Croatia. Institute for Social research. Zagreb.

Rodgers, S., and Harris, M. (2003). Gender and e-Commerce: An exploratory study. Journal of Advertising Research, 43(3), 322-330.

Rohm, A., and Swaminathan, V. (2004). A typology of online shoppers based on shopping motivations. Journal of Business Research, 57(7), 748-757.

Ruyter, K., Wetzels, M., and Kleijnen, M., (2001). Customer adoption of e-Service: An experimental study. International Journal of Service Industry Management, 12(2), 184-208.

Sarbu, M. (2008). Cum arata Generatia Y. Business Magazin. Retrieved from: http://www.businessmagazin.ro/opinii/cum -arata-generatia-y-2507667, accessed on $3 / 12 / 10)$

Slyke, C., Comunale, C., and Belanger, F. (2002). Gender differences in perceptions of web-based shopping. Communications of the ACM, 45(7), 82-86.

Stafford, T., Turan, A., and Raisinghani, M. (2004). International and cross-cultural influences on online shopping behavior. Journal of Global Information Management, 7(2), 70-87.

Susskind, A. (2004). Electronic commerce and world wide web apprehensiveness: an examination of consumers' perceptions of the world wide web. Journal of ComputerMediated Communication, 9(3).

Swinyard, W., and Smith S. (2003). Why people (don't) shop online: A lifestyle of the internet consumer. Psychology and Marketing Special Issue, 20(7), 567-597.

Tapscott, D. (2009). Grown up digital; how the net generation is changing your world. New York: McGraw-Hill.

Vellido A., Lisboa P., and Meehan, K. (2000). Quantitative characterization and prediction of On-line Purchasing behavior: A Latent variable Approach. International Journal of Electronic Commerce, 4(4), 83104.

von Abrams, K. (2010). Retail E-Commerce in Western Europe. Retrieved from: http://www.emarketer.com/Reports/All/E marketer_2000679.aspx, accessed on 16/3/11.

Zhou L., Dai L., Zhang D. (2007). Online shopping acceptance model - a critical survey of consumer factors in online shopping. Journal of Electronic Commerce Research, 8(1). 


\title{
Uses and Gratifications of the Internet in Emerging Markets: The Case of Serbia and Ukraine
}

\author{
Gladys Torres Baumgarten \\ William L. James
}

\begin{abstract}
Internet usage may be motivated by either extrinsic factors (such as pleasure derived from online surfing, social networking or chat rooms) or by intrinsic factors (e.g. utility or functionality). This study focuses on Internet users, and in particular, those who derive extrinsic value from its use. This paper seeks to identify whether Internet users that rely heavily on the Internet for social gratification differ from those that are less reliant on the Internet for social purposes, but it looks at Internet usage behavior in emerging markets, specifically in two Easter European countries: Serbia and Ukraine. The primary objective is to gain insight on Internet usage in developing markets. This paper addresses the paucity of research in this area - both thematically and geographically. Respondents were queried about their Internet usage motivations. Binary logistic regression was used to split respondents into light and heavy seekers of social gratification on the Internet. Demographic and psychographic variables and interaction terms were used to identify differences among the two groups of interest and test research propositions. This study reveals that there are differences in the online behavior of heavy (versus light) social gratification Internet users and that these should be taken into consideration by marketers when developing online communications.
\end{abstract}

KEYWORDS. The Internet, emerging markets, Serbia, Ukraine, use and gratification

\section{INTRODUCTION}

Whether consumption is done by rational, information-processing decision-makers (Bettman, 1979; Howard \& Sheth 1969) or by those seeking fun, symbolic or esthetic experiences (Holbrook and Hirschman 1982) has been the subject of much debate over the past several decades; and while the argument has generally focused on the consumption of goods and services, the same arguments can and have been applied to the consumption of new media. New media, after all, may be used for its functional benefits, but also for the ex- trinsic values derived from its use (such as pleasure and status from knowing that you possess the latest media, etc.). Usage of the Internet thus can be thought to be motivated by its intrinsic value (functionality, utility, etc.), and by its extrinsic values as well, such as pleasure from online surfing, socialnetworking, etc. This study focuses on the Internet and seeks to identify and test research propositions about Eastern European emerging market Internet users who derive extrinsic value from use of the Internet, e.g. those who are motivated to use the Internet for social gratification. Of special interest is whether

Gladys Torres Baumgarten, Ph.D.is affiliated with Anisfield School of Business, Ramapo College of New Jersey, Mahwahm, NJ 07430, USA. William James, Ph.D. is a Professor of Marketing and International Business, Zarb School of Business, Hofstra University, 146 Weller Hall \#146, Hampstead, NY 11549-1000.

Address correspondence to Gladys Torres Baumgarten, Associate Professsor-International Business, Ramapo College of New Jersey, 505 Ramapo Valley Road, Mahwah, NJ 07430, USA

E-mail: torresbaumgarten@gmail.com 
those who are heavy seekers of social gratification via the Internet differ from those who are light social gratification seekers.

More importantly, this study's findings will help guide marketing strategy development, particularly with regards to identifying how best to reach those individuals who are highly motivated by extrinsic motivations (such as social gratifications) when using the Internet. Indeed the significant growth in the use of social media, such as Facebook, suggests the value in understanding this segment of the Internet population. Similar attempts at studying the underlying motivations behind Internet usage have been done for online consumers; however, prior studies have largely focused on online consumers in developed markets. This study, by comparison, will focus on the online public in developing/emerging markets, a segment of online consumers largely ignored until recently and a segment where the digital divide may be large. The authors contend that whoever understands the deeprooted impetus for Internet usage among the online public in developing markets may more readily establish a differential advantage vis-àvis its competitors, possibly even catapulting that firm to a dominant position in the market.

Lynch and Beck (2001) were among the first to include Central/ Eastern Europeans in their study. They found that Internet behaviors were relatively homogeneous within the Central/Eastern European area, however, the respondent base consisted of individuals from the same multinational enterprise, and as a result, the findings might also be reflective of a common corporate culture. This study aims to address the paucity of research in this area by looking at Internet usage in developing/emerging market regions. Serbia and Ukraine were chosen for the current study because despite the fact that both are emerging markets in Eastern Europe, their history differs markedly and we felt that this would shed insight into Internet usage behavior within one geographic region, but in distinct markets.
Serbia and Ukraine use languages that are not only very different from each other but also differ from the languages most commonly used on the Internet. While written Ukrainian, from the East Slavic subgroup, uses only the Cyrillic alphabet; written Serbian, from the South Slavic subgroup, uses parallel Cyrillic and Latin alphabets. Ukraine spent much of the $20^{\text {th }}$ Century as part of the USSR while Serbia, was part of the Socialist Federal Republic of Yugoslavia and was largely a nonaligned nation throughout most of the $20^{\text {th }}$ Century. Thus these two countries provide an interesting contrast in their histories and exposure to western developed economies while exhibiting similarities in terms of developing/emerging economies.

Developing markets are of interest for several reasons. First, Internet usage in developed market regions has historically received more attention, leading to a body of literature that can be used to guide online marketing strategy development; however, the extant research is less suitable for charting strategic direction in developing markets. More work on the online community in developing markets is needed to develop effective guidelines for marketing strategy development. Secondly, foreign direct investment (FDI) in developing market regions continues to grow at a faster rate than investments in developed market regions. In fact, a study from the Vale Columbia Center on Sustainable International Investment revealed that emerging markets in 2009 for the first time attracted more than half of (global) outward FDI flows (Kekic 2009). This compares with approximately $33 \%$ of global FDI flows going to emerging markets as recently as 2006 (Hill, p.244). This trend underscores the need to better comprehend consumer behavior in market regions offering the greatest growth potential. Yet, if successfully understanding traditional consumer behavior in developing markets has been elusive, then the phenomenon is even more complicat- 
ed with regards to the online public [in developing markets].

This paper seeks to study the heavy versus light seekers of extrinsic motivations in Internet usage (e.g. social gratifications) in developing markets by testing some research hypotheses with an eye towards developing guidelines for effective online marketing strategies. The paper first reviews the relevant literature, identifies testable research propositions and then describes an empirical study that the authors conducted in two emerging markets (Serbia and Ukraine). Research hypothesis testing and study findings are reported, followed by the final section which identifies some of the study's limitations and offers some directions for future research.

\section{LITERATURE REVIEW}

Several research streams helped establish the foundation for this paper: the uses and gratifications theory from communications, hedonic consumption theory from the marketing literature of the 1980s, and segmentation studies, also from the marketing field.

The uses and gratifications ( $U$ \& G) paradigm was developed to gauge the underlying motivations that help explain consumers' media usage. U\&G theory first surfaced in the 1940 s when it was used to analyze the adoption of the radio, the new medium of the 1920s. Subsequently, it has been used to assess consumer usage of television (including cable television), telephones (Noble 1987, 1989) and more recently, cell phones (Leung \& Wei, 2000) and the Internet (Eighmey, 1997; Novak, Hoffman \& Yung, 2000; Stafford, Stafford and Schkade, 2004; Ko, Cho \& Roberts, 2005). The uses and gratifications literature as it relates to the Internet aims to identify dimensions of consumer uses for the Internet. In developed markets, for example, it is believed that the time spent on the Internet is directly proportional to the amount of online purchases (Stafford, Stafford \& Schkade
2004); however, this assumption may be different for consumers from emerging markets, particularly when a basic distrust of online security may limit online purchases in these markets. While online consumers in developing markets may spend comparable periods of time on the Internet, the uses and gratifications that developing market consumers derive from the Internet may be different from those derived by their counterparts in developed markets. Stafford et al. found that online users in developed markets derive three main uses and gratifications from Internet usage: process gratification, content gratifications and social gratifications. With regards to social gratifications, consumers appear to enjoy the social aspects of Internet usage and Stafford et al. claim that these extend beyond email and LISTSERV operations. They found that chatting and online interaction were key gratifications that arose from Internet usage. In addition, Stafford et al. (2004) offered recommendations to website owners and ISP providers, calling for features that might help to build a sense of community among online users. The Stafford et al. research, while thorough, was focused on online users in developed markets. Indeed the rapid growth of online social networks such as Facebook are indicative that social gratifications are important to online users irrespective of their country's level of economic development. Another example of the $U \& G$ theory applied to Internet users was found in which the focus was on online users in developing markets. Roy (2009) looked at the Indian context and found six gratification factors associated with Internet use that included: "self development, wide exposure, user friendly, relaxation, career opportunities and global exchange". While different from the gratifications that Stafford et al. (2004) had found, they can, nevertheless, fit into the Stafford et al. (2004) broader schema of content gratifications (wide exposure and career opportunities); process gratifications (user friendliness and self-development); and social 
gratifications (global exchange and relaxation). Leung and Wei (2000) discovered similar gratifications factors, such as sociability, relaxation and entertainment among cell phone users in Hong Kong. Yet another paper by Kim and Haridakis (2009) looked at the association between sensation-seeking individuals and their propensity to become heavy Internet users. (The focus of Kim and Haridakis' work was an extreme example of heavy Internet usage in that they looked specifically at Internet addiction.) However, they too hypothesized that high sensation seekers would be more prone to heavy Internet usage. This is one of the relationships that this current study aims to address as well, albeit in the Serbian and Ukrainian context.

Hedonic consumption from the marketing literature is also relevant here in that it focuses not only on the actual consumption of a good, but also on the pleasures that may be derived from the product search as well. The sensory elements of a product experience are key to understanding consumer behavior according to Hirschman and Holbrook (1982). Hedonic consumption looks beyond the functional aspects of product choice decisions and looks to other pleasures derived from the search experience and consumption (Hirschman and Holbrook 1982; Holbrook and Hirschman (1982). Holbrook and Hirschman (1982) define hedonic consumption as "those aspects of consumer behavior that are associated with the multisensory, fantasy and emotive elements of (the) product usage experience." They argue that effective marketing strategies cannot ignore these aspects of consumption. Internet usage can be viewed through the prism of hedonic consumption in that some online users may surf the Internet with the primary intention of making purchase decisions (a utilitarian/ functional view of the Internet), but others may surf the web for the sheer enjoyment that they derive from that activity (a hedonic consumption view of the Internet's use). For example, some consumers may search the web to book a flight or purchase a vacation, while others may engage in regular surfing behavior for the pleasure they derive from it - even if they do not intend to buy airplane tickets each time they are looking at online flight options. They may simply enjoy surfing the travel sites as they dream of traveling to new places, and gather information about new places in the hopes that they may someday travel to their destination(s) of interest. Marketers must develop a deeper understanding of these motivations and how they influence product searches and consumer purchases in order to devise more effective websites. This dovetails with the main premise of this paper in which we aim to profile Internet users who rely on the Internet often as a source of social gratification versus those who do so much less frequently. Holbrook and Hirschman (1982) discussed the "experiential view" of consumption, one that encompasses more than just the functional aspects of consumption to include other underlying motivations for consumption, such as the resulting feelings or fantasies as well as the sheer fun of consumption.

The direct marketing literature was also influential in this paper in that the Internet is one of the newest and more innovative direct marketing vehicles. Prior to the Internet's introduction and acceptance as a direct response vehicle, consumer response cards used to be one of the most common forms of marketing communication between consumers and manufacturers/service firms. Yet the Internet not only provided another more sophisticated direct marketing tool from the marketers' perspective, but it also gave consumers more power over what they choose to be exposed to, from an advertising and marketing communication perspective. The Internet has resulted in a marked shift in the relative power wielded by advertisers and the consuming public. This power shift (or "struggle" from the marketers' perspective) underscores the importance once again of understanding the underlying reasons for Internet use because only then can market- 
ers begin to devise more meaningful and more effective online communications.

A related stream in the marketing field that also formed the basis for this research is segmentation research. Successful market entry is often dependent upon effective segmentation (Kotler and Keller, 2006, p.116), and it cannot be assumed that the same segmentation approach used in the home market (or a developed market) should be applied in a new market entry, particularly when the new market is a developing market. While some segmentation research has been conducted among Internet users (James et al., 2008; Jayawardhena, Wright, Dennis 2007; Assael, 2005) much more is needed to understand the underlying reasons of Internet usage, and in particular, Internet usage in developing markets.

More recently, the Magazine Publishers of America published a document entitled, "Engagement: Understanding Consumers' Relationships with Media" (http://www.magazine.org/advertising/account ability/Engagement_Study.aspx) in which they state that there are seven basic motivations that drive consumer use of specific media: emotional response, enjoyment, consumer control, involvement, multi-tasking, relevance and trust. With the exception of possibly one of those (trust), the Internet appears to offer most of the elements that consumers seek in a medium.

There is some evidence that men and women's online behavior may differ (Armstrong \& McAdams, 2009) and as a result, gender differences in online behavior were also of interest in our study. Moreover, this study aims to address the issue of how culture can affect web usage behavior. A recent study by Gevorgyan and Manucharova (2009) looked at a related issue, i.e., how culture influenced preferences for Web design features and Web design behavior. While the Gevorgyan and Manucharova study (2009) focused on Chinese vis-à-vis American preferences and behavior, it found that preference for culturally-oriented websites was strongest for online users with strong ethnic identities. Gevorgyan and Manucharova (2009) point out that marketers have assumed that culture matters with regard to online communications, but that few have actually tested to see if this is in fact true. That was their study's intent and is also our intent in this current study on the Eastern European nations of Serbia and Ukraine.

\section{RESEARCH PROPOSITIONS}

The independent variables studied can be categorized into three groups. The first group consists of variables related to the digital divide concept. The second group relates to Internet usage and shopping. The last group contains Opinion Leadership and two measures of Innovativeness, psychographic variables linked to Internet usage.

Research Proposition 1: The evolution of Internet usage in developed markets was initially characterized by a digital divide based on demographic characteristics (e.g. Blake et al 2003, Donthu and Garcia 1999, Strauss and Frost, 2009, pp. 81-84), Indeed young (15-35) males often are the focus of Internet studies, because early in the development of the Internet in developed markets this was the demographic group that represented the dominant early adopter/majority groups (Munnukka 2007). Whether or not emerging markets follow a similar digital divide in their early stages of Internet adoption is the question to be investigated. Three demographic variables (age, gender and education) that were common bases for the digital divide in developed markets were selected (see Assael 2005). If emerging markets follow the pattern of developed markets it would be expected that heavy users would be: more likely to be male; more likely to be younger; and more likely to be better educated. 
Research Proposition 2: Three psychographic variables that affect internet usage and shopping behavior were included to determine if they were also related to the use of the internet for social gratification. Attitudes towards computers have been shown to influence Internet usage as has attitude towards the risk in shopping on the Internet (Jarvenpaa and Tractinsky, 1999). Consumer ethnocentrism (Cui and Adams 2002) has been demonstrated to influence both the language and hence home of web sites visited, as well as the amount of Internet usage (James et al 2008). Thus it is expected that: attitude towards computers would be higher for heavier users; heavy users would perceive less risk in Internet shopping; and that high ethnocentric consumers in emerging markets might have fewer opportunities to buy locally and hence use the internet more for social gratification with like minded consumers. Research Proposition 3: In emerging markets, Opinion Leaders and Innovators are likely to be heavy Internet users and hence heavy social gratification users. Kim and Haridakis (2009) suggest that Internet Innovators are motivated by sensation seeking. Thus innovativeness was measured both in terms of cognitive innovativeness and sensory innovativeness. While both should be linked to high social gratification users, the split might reveal differences across samples (James et al. 2008). It is thus expected that opinion leaders will be heavy social gratification users and those high on innovativeness- both sensory and cognitive- will be heavy social gratification users.

\section{METHODOLOGY}

\section{Sample}

Serbia and Ukraine were the markets of interest in this study. While both countries are Eastern European and each of these countries shared some post-World War II similarities, they, however evolved from two very different historical models. Serbia was a part of the Socialist Federal Republic of Yugoslavia, whereas Ukraine was part of the former U.S.S.R. The infrastructure in Serbia and Ukraine also differs markedly. The NATO embargo and military campaign in the 1990s Serbia's infrastructure in shambles. Ukrainian infrastructure, on the other hand, is still struggling from the ill-effects of Soviet dominance. While an earlier study (Lynch and Beck, 2001) found few differences in Internet usage behavior among Eastern Europeans, the current authors seek to explore the implied homogenous behavior in the region, particularly in light of the differences in each country's historical development. If differences in Internet usage behavior exist among individual countries within a region, then marketers need to question the applicability of pan-regional marketing strategies, often undertaken in developing countries. Implementation may be based on sound marketing rationales, yet all too often, pan-regional approaches are used when knowledge about nuances in behavior within the region is lacking. The selection of the two countries of interest in this study, Serbia and Ukraine, seeks to address this often overlooked issue. The most recent data from the CIA web site (www.cia.gov) estimates Internet usage in Ukraine and Serbia are estimated to be about $12 \%$ and $16 \%$ respectively. However, the online populations in each of these markets is growing rapidly, thus underscoring the need for marketers to better comprehend how the Internet is being used in these low penetration/ high growth markets to aid in devising effective marketing strategies.

Anecdotal evidence indicates that Internet users in both of these countries are predominantly urban and the World Factbook (www.cia.gov) indicates that both countries have large urban populations (Ukraine 68\% urban and Serbia 52\% urban). Thus the samples were gathered in each country's primary 
urban area: Kiev and Belgrade. Since the Internet is in the early stages of adoption in these countries the sampling techniques chosen were designed to be as representative as possible of Internet users rather than the population in general. In the Ukraine sample, collection took place in computer clubs (where you can play computer games, work with documents and print them). Two survey gatherers were assigned to each of the city's 10 districts and independently surveyed 10 people at two different locations. Every third person was surveyed with the exception that if the percentage of women participating fell below $40 \%$, the data collector would wait until the next possible participant was female. A total of 400 surveys were collected in Kiev, with
233 of the computer users also being Internet users. Eight data collectors interviewed Serbs in Belgrade: (seven achieved 50 complete interviews, while one was only able to complete 48 interviews). Interviews were conducted at many central city locations including: Internet cafés; university computer labs; computer game places; and retail stores/ company workplaces. In Belgrade the sample of 398 computer users included 345 who were also Internet users. In both situations the data was gathered in locations that would be frequented by Internet users. Frequencies of the demographic composition of the samples (gender, age and education) are presented in Tables 1 through 3 . Table 1 presents the sample distributions by gender:

TABLE 1: Respondent Gender by Country

\begin{tabular}{lccc}
\hline & Serbia & Ukraine & Total \\
\hline Male & 208 & 208 & 416 \\
Female & 189 & 188 & 377 \\
\hline
\end{tabular}

The distribution by gender is similar in both countries and the numbers of females is almost the same as the number of males (this was an objective in the sample design).

Table 2 presents the sample distributions by age.

TABLE 2: Respondent Age by Country

\begin{tabular}{lccc}
\hline & Serbia & Ukraine & Total \\
\hline Under 20 & 83 & 70 & 153 \\
$20-29$ & 208 & 130 & 338 \\
$30-39$ & 36 & 63 & 99 \\
$40-49$ & 35 & 57 & 92 \\
$50-59$ & 34 & 55 & 89 \\
$60+$ & 2 & 21 & 23 \\
\hline
\end{tabular}

TABLE 3: Respondent Highest Level of Education by Country

\begin{tabular}{lccc}
\hline & Serbia & Ukraine & Total \\
\hline Elementary School & 13 & 9 & 22 \\
Secondary School & 60 & 50 & 110 \\
Trade or Vocational School & 61 & 79 & 140 \\
Some University & 193 & 95 & 288 \\
University Graduate & 67 & 163 & 230 \\
Graduate/Professional School & 4 & 0 & 4 \\
\hline
\end{tabular}


The Serbian sample is younger than the Ukrainian sample. Statistics from the World Factbook (www.cia.gov) indicate that the median age in Serbia is 41.3 (39.6 for males versus 43.1 for females) while the median age in Ukraine is 39.9 (36.7 for males versus 43.1 for females). This sample difference may reflect differing rates of Internet adoption by age. Indeed in developed economies Internet adoption was originally primarily young and male.Table 3 presents the sample distributions by education:

The education distributions reflect the previous age data. The Serbian modal group is some university while the Ukrainian modal group is university graduate. Thus the Ukrainian sample overall has more formal education than the Serbian sample.

\section{ANALYTICAL APPROACH}

The analytical approach was binary logistic regression. The dependent variable consisted of two groups. These two groups were approximately the top and bottom thirds based on the percentage of time spent on the Internet in social gratification activities. Social gratification activities were defined as the percentage of the time that they spent on the Internet communicating with others (e.g. emailing, instant messaging, chatting in chat rooms, and posting and/or reading digital bulletin boards). The heavy social gratification users $(34.4 \%$ of sample) spent at least $40 \%$ of their Internet time engaging in social gratification activities. Light social gratification users $(35.1 \%$ of sample) spent $10 \%$ or less of their Internet time engaging in social gratification activities.

The independent variables consisted of three types: demographic variables, psychographic variables and interaction terms. The demographic variables were gender, age, number of hours spent on the Internet in a typical week, and education. The psychographic variables were: cognitive innovativeness (alpha $=0.74$; Venkatraman and Price, 1990), sensory innovativeness (alpha $=0.70$; Venkatraman and Price, 1990), opinion leadership (alpha $=0.84$; Childers 1986 modification of King and Summers 1970), consumer ethnocentrism (alpha $=0.83$; Cui and Adams, 2002), attitudes towards computers (alpha = 0.75; Jarvenpaa and Tractinsky, 1999), and attitudes towards web shopping risk (alpha $=$ 0.72; Jarvenpaa and Tractinsky, 1999). In order to test for intercept differences country (Serbia $=0$, Ukraine $=1$ ) was included as an independent variable. In order to test for slope differences interactions of country and each of the demographic and psychographic variables were included as independent variables. By building in interaction terms allows for testing of country differences in intercepts and slope coefficients (i.e. Chow tests).

\section{RESULTS}

Table 4 presents the significant and marginally significant independent variables in the binary logistic regression. Tables 5 and 6 assess how well the regression equation performs. In particular, the classification results for both the analysis and holdout samples are assessed using the Q statistic from Press (1972). The largest group criterion, the most conservative criterion was used. Interpreting the results from Table 4 leads to the following conclusions with respect to the research propositions:

\section{Research Proposition 1 Results:}

- Females are more likely than males to be light social gratification users of the Internet. While this finding is in line with expectations it does differ from a previous study in which women's web-searching behavior was found to be more hedonicoriented (Lai, Wu and Lin, 2009). It is important to note that respondents in the former study were from Taiwan, while this research was done among Serbian and Ukrainian women. The opposing findings 
suggest that broad-stroke conclusions about women's Internet behavior should not be made, since online behavior may vary across markets/cultures, or at the very least, across regions.

- Those with some university education and those with a trade school/vocational school education are more likely to be light social gratification users of the Internet. This result is in line with the research proposition that those with higher education are more likely to be heavier social gratification users.

- While age category is marginally significant none of the categories is significant thus the impact, if any, of age category is at best unclear

\section{Research Proposition 2 Results:}

- Consumer ethnocentrism is positively related to social gratification use of the Internet for the Serbian sample but inversely related for the Ukrainian sample. The results for the Serbian sample are in line with expectations but those for the Ukrainian sample are the opposite of expectations.

- Attitude towards computers is inversely related to social gratification use of the Internet which is contrary to expectations.

- Attitudes towards risk in Internet shopping was not significant which also was not expected.

\section{Research Proposition 3 Results:}

- Opinion Leadership was not related to amount of social gratification Internet use. This was not expected.

- Cognitive innovativeness is inversely related to social gratification use of the Internet for Ukrainians. This result is inconsistent with our expectations. The Serbian sample showed no relationship with Cognitive Innovativeness, also not in line with expectations.
- Sensory innovativeness is inversely related to social gratification use of the Internet for the Serbian sample but positively related for the Ukrainian sample. The result for the Serbian sample is not in line with expectations while the Ukrainian results are in line with expectations.

- An interesting finding is that for the Ukrainian sample Sensory Innovativeness drives the social gratification use of the Internet while Cognitive Innovativeness reduces the social gratification use of the Internet. The lack of results for Opinion Leadership perhaps relates to the use of the Internet but not to specific uses.

\section{CONCLUSIONS AND IMPLICATIONS}

The results suggest that there are sufficient differences across demographic and psychographic variables that marketers must carefully design their marketing strategies to fit the behavior of their target markets. Men, for example, are more apt to spend their Internet time involved in social gratification activities while surfing the Internet; whereas women are not. While initially, this could be interpreted as implying that online marketing communications for men and women should be different, tailoring to each demographic group's needs; it might also imply that online communications should be direct and informative, thereby effectively reaching women who use the Internet for information- rather than for social gratification-purposes. But, the direct online communications may also be effective in reaching men, because by the time they are finished using the Internet for social gratification, they may be looking for clear, direct, and informative websites. Nevertheless, Internet usage differences between men and women suggest that marketers may need to, at the very least, consider what the implications might be for their website development and online communications. 
TABLE 4: Significant and Marginally Significant Logistic Results

\begin{tabular}{lccc}
\hline Independent Variables & B & Significance Level & Exp(B) \\
\hline Gender & -1.441 & .001 & 0.237 \\
Sensory Innovativeness & -0.092 & .016 & 0.912 \\
Consumer Ethnocentrism & 0.126 & .020 & 1.134 \\
Attitude towards Computers & -0.152 & .059 & 0.859 \\
Cognitive Innovativeness \& Ukrainian & -0.147 & .060 & 0.863 \\
Sensory Innovativeness \& Ukrainian & 0.103 & .074 & 1.109 \\
Consumer Ethnocentrism \& Ukrainian & -0.207 & .004 & 0.813 \\
Age Categories & & .080 & \\
Education Categories & & .037 & 0.159 \\
Trade/Vocational School & -1.837 & .019 & 0.267 \\
Some University & -1.319 & .055 & \\
\hline
\end{tabular}

Table 5

Model Fit Measures

Chi - Square $=78.628, \mathrm{df}=33, \mathrm{p}<.001$

-2 Log Likelihood $=321.925$

Cox \& Snell $\mathrm{R}$ Square $=.238$

Nagelkerke R Square $=.318$

Table 6

Classification Rates for Analysis and Holdout Samples

Analysis Sample:

208 cases correctly predicted $(72 \%)$

81 cases incorrectly predicted $(28 \%)$

Press' $Q$ Statistic $=51.51, \mathrm{df}=1, \mathrm{p}<.001$

Holdout Sample:

47 cases correctly predicted $(63.5 \%)$

27 cases incorrectly predicted $(36.5 \%)$

Press' $Q$ Statistic $=5.41, \mathrm{df}=1, \mathrm{p}<.05$

Similarly, psychographic variables also identified some differences between Ukrainians and the Serbs. Ukrainians who scored high on sensory innovativeness (those who seek new experiences to stimulate the senses) were more apt to use the Internet for social gratification, yet when Ukrainians sought new experiences to stimulate the mind (cognitive innovativeness), they were not as prone to seeking social gratification from the use of the Inter- net. For Serbians, on the other hand, cognitive innovativeness was not related to seeking social gratification from use of the Internet.

\section{LIMITATIONS}

This study was the first to investigate the underlying reasons for Internet usage in Central European markets, especially in ones where Internet penetration - compared to oth- 
er European markets - is relatively low, but growing. This study was conducted in two emerging markets: Serbia and Ukraine, and as a result, the generalizability to other emerging markets may be limited. Furthermore, the respondents were pooled from the capital cities in each of these markets since this is where the largest concentration of Internet users are found, yet this again may limit the generalizability of the findings, particularly if Internet usage behavior elsewhere in the country differs markedly from that in the capital cities. However, this is an opportune time for marketers to gain a better understanding of the behavior of online consumers in markets such as these. Understanding online consumer behavior in emerging markets may be the key competitive tool that will enable some firms to develop successful marketing strategies in emerging markets. .

\section{REFERENCES}

Armstrong, C.L. \& McAdams, M. (2009). Blogs of information: How gender cues and individual motivations influence perceptions of credibility. Journal of Computer-Mediated Communication, 14, 435456.

Assael, H. (2005). A demographic and psychographic profile of heavy Internet users by type of Internet usage. Journal of $A d$ vertising Research, 45(1), 93-123.

Bettman, J. R. (1979). An information processing theory of consumer choice. Reading, MA: Addison-Wesley.

Blake, B., Neuendorf, K. and Valdiserri, C. (2003). Innovativeness and variety of Internet shopping. Internet Research, 13(3), 156-169.

Childers, T. L. (1986). Assessment of the psychometric properties of an opinion leadership scale. Journal of Marketing Research, 23(2), 184-188.

Cui, C. C., \& Adams, E.I. (2002). National identity and NATID: An assessment in
Yemen. International Marketing Review, 19(6), 637-662.

Donthu, N. and Gilliland D. (1996). The infomercial shopper. Journal of Advertising Research, 36(2), 69-76.

Eighmey, J. (1997). Adding value in the information age: Uses and gratifications of sites on the WorldWideWeb. Journal of Business Research, 41, 187-194.

Gevorgyan, G. \& Manucharova, N. (2009). Does culturally adapted online communication work? A study of American and Chinese Internet users' attitudes and preferences toward culturally customized web design elements. Journal of Computer-Mediated Communication, 14(2), 393-413.

Hill, C. (2009). International Business: Competing in the Global Marketplace. McGraw-Hill/Irwin Publishers. New York, New York.

Hirschman, E. \& Holbrook, M. (1982). Hedonic consumption: Emerging concepts, methods and propositions. Journal of Marketing, 46(3), 92-102.

Holbrook, M. \& Hirschman, E. (1982). The experiential aspects of consumption: Consumer fantasies, feelings and fun. Journal of Consumer Research, 9(September), 132-140.

Howard, J. A. \& Sheth, J. (1969). The theory of buyer behavior, New York, John Wiley.

James, W.L., Torres-Baumgarten, G., Petkovic, G., \& Havrylenko, T. (2008). Exploring web language orientation in emerging markets: The case of Serbia and Ukraine. Journal of Targeting, Measurement and Analysis for Marketing. London: June, 16(3), 189 -203.

Jarvenpaa, S. L. \& Tractinsky N. (1999). Consumer trust in an Internet store: A cross-cultural validation. Journal of Computer-Mediated Communication, 5(2), (Accessed on-line July 31 2009 at www.jcmc.indiana.com/). 
Jayawardhena, C., Wright, L.T. \& Dennis, C. (2007). Consumers online: intentions, orientations and segmentation. International Journal of Retail and Distribution Management. 35(6), 515-526.

Kekic, Laza. (October 8, 2009). The Global Economic Crisis and FDI Flows to Emerging Markets. Columbia FDI Perspectives, No. 15. Reprinted with permission from the Vale Columbia Center on Sustainable International Investment. (www.vcc.columbia.edu).

Kim, J. \& Haridakis, P. (2009). The role of Internet user characteristics and motives in explaining three dimensions of Internet addiction. Journal of Computer-Mediated Communication, 14, 988-1015.

King, C. W. \& Summers J.O. (1970). Overlap of opinion leadership across consumer product categories. Journal of Marketing Research, 7(1), 43-50.

Ko, H., Cho, C-H. \& Roberts, M.S. (2005). Internet uses and gratifications. Journal of Advertising, 34(2), 57-70.

Kotler P. \& Keller, K. (2006). A Framework for Marketing Management, Prentice Hall: Upper Saddle River, New Jersey, $3^{\text {rd }}$ edition.

Lai, M. K., Wu, W. Y., \& Lin, S. M. (2009). The effects of website design on female's emotional arousal and e-satisfaction. The Business Review, Cambridge. 12(1), 243249.

Leung, L. \& Wei, R. (2000). More than just talk on the move: Uses and gratifications of the cellular phone. Journalism and Mass Communications Quarterly, 77(2), 308- 320.

Lynch, P.D. and Beck, J.C. (2001). Profiles of Internet buyers in 20 countries: Evidence for region-specific strategies. Journal of International Business Studies, 32(4), 725748.
Magazine Publishers of America, Engagement: Understanding Consumers' Relationships with Media. Accessed on January $\quad 31, \quad 2010 \quad$ from http://www.magazine.org/advertising/acco untability/Engagement_Study.aspx

Munnukka Juha (2007). Characteristics of early adopters in mobile communications markets. Market Intelligence Planning, 25(7), 719-731.

Noble, G. (1987). Discriminating between the intrinsic and instrumental domestic telephone user. Australia Journal of Communication, 11, 63-85

Noble, G. (1989). Towards a 'uses and gratifications' of the domestic telephone. Telefon und Gesellschaft. Berlin: Volker Spiess, 198-307.

Novak, T.P., Hoffman, D.L. \& Yung, Y.F. (2000). Measuring the customer experience in online environments: A structural modeling approach. Marketing Science, 19, 22-42.

Press, S. J. (1972). Applied Multivariate Analysis. Holt, Rinehart and Winston: New York.

Roy, S. K. (2009). Internet uses and gratifications: A survey in the Indian context. Computers in Human Behavior. 25, 878-886.

Stafford, T. F., Stafford, M. R. \& Schkade, L. L. (2004). Determining uses and gratifications for the Internet. Decision Sciences. Atlanta: Spring, 35(2), 259- 288.

Strauss,Judy and Raymond Frost (2009). E_Marketing. Prentice-Hall: Upper Saddle River, New Jersey, $5^{\text {th }}$ edition.

Venkatraman, M. P. \& Price L.L. (1990). Differentiating between cognitive and sensory innovativeness: Concepts, measurement, and implications, Journal of Business Research, 20(4), 293-315. 


\section{BOOK REVIEW}

Ted London and Stuart L. Hart. ( 2011). Next generation business strategies for the base of the pyramid: New approaches for building value. Pearson Education Inc., publishing as FT Press, New Jersey, 249 pages.( ISBN 0-13704789-4)

Emerging markets continue to attract significant interest of the marketers and academicians frequently write about the extraordinary market potentials of these enormous markets offer. However, Ted London and Stuart L. Hart's recent insightful co-edited book, Next Generation Business Strategies for the Base of the Pyramid book, offer clarifications on many potential misconceptions about these markets (specifically for BoP markets) and explore the successful business strategies required for these markets. This book consists of a collection of essays written by different authors and sometimes becomes difficult to read. However, it is an eye-opener in terms of gaining insightful information about uniqueness of these markets and the challenges ahead of the marketers who plan to operate in these markets.

In the introduction section, authors set the tone for the book by focusing on the importance of their core message about BoP markets: rather than looking to find a fortune in these markets, marketers should be focused on "creating a fortune with the BoP. They make strong arguments about the opportunities and challenges in these markets and offer different premise for those companies, non- profits, social entrepreneurs, and development agencies to serve the BoP. They explain the key characteristics of BoP markets and passionately argue that the next generation of business strategies in these markets should mainly focus on "co-creation of fortune" rather than seeing them as billions of consumers. Accordingly, the book is organized into three sections: Roadmaps for Success, Strategic Opportunities, and Effective Implementation.

Roadmaps for Success (Part One) consist of two chapters about building better ventures and the "patient capital" approach. They argue that BoP businesses (ventures) should see them as co-creators of wealth. To do so, they must embrace and demonstrate the "enhanced mutual value." Economically viable enterprises will be the ones who explore strategies to enhance consumer demand, reduce costs, and facilitate the development of public good. At the same time, they need to be patient by having a very long term horizon for success. This requires collaboration by business and donor community. Finally, they argue that these ventures should have a longer time horizon for success, willing to forego maximum financial returns in exchange for social impact, radically reducing costs, and have greater tolerance for risk. These criteria sound like very difficult to accept but they become very reasonable when evaluated in light of the size of the future potential returns.

Strategic opportunities (Part Two) consists of two chapters about taking the green leap and to stay on track while building markets 
with the BoP. I think the Chapter 3 is the most interesting chapter in this book. The authors argue that the traditional approach of "no regard" to environment in BoP markets should be replaced with small scale, "small footprint" products and services. They provide a contrast between Green Giant (large-scale, policy change, big footprint, capital intensive) and Green Sprout (small-scale, labor intensive, localized, self-organizing) approaches for green technology. They argue that before a critical mass is created, it is necessary to start focusing on incubating sustainable technology in these markets. Once these processes and technologies are developed, then they can be leapfrogged into other markets. A number of examples (such as LifeSprings, Ecotact, WHI, D. Light) are provided throughout the book.

Finally, Effective Implementation (Part Three) consists of three chapters that mainly focus on presentation of operational challenges for business in BoP markets. Chapter 5 explains the characteristics of consumers and market in a very realistic way. A market is made up with large number of consumers with low income, low literacy, and intensely characterized with human relationships, aspiring to a better life. Studies show that in a market characterized by such minimal resources, both buyers and sellers place significant emphasis on relationships. Authors state that these require localization, concentration, and socialization. They believe that $\mathrm{BoP}$ ventures become successful when local players are collaborate as financial and technological networks and benefit from the management expertise of global players.

In summary, I certainly recommend this extraordinary book to anyone who is interested in learning more about the challenges and opportunities faced by the low-income markets around the world. This book combines the wealth of experiences authors had along with the in-depth understanding of economics and business. The authors not only view the world's poor as billions more consumers but also evaluate them as talented social entrepreneurs, significantly different from what we are used to in the Western countries. For practitioners, this book may help develop sensitivity to the potential challenges and opportunities BoP offers and specific steps for successful operations in these immensely large markets.

Ali Kara

Pennsylvania State University-York Campus 


\section{JOURNAL OF EUROMARKETING}

Enlarged Europe is playing an increasingly more important role in the global economy. The purpose of the Journal of Euromarketing is to meet the needs of academics, practitioners, and public policy makers in the discussion of marketing issues pertaining to Europe and European countries' trading relationship with other nations. The purpose of this exciting journal is to increase our understanding of the strategic planning aspects of marketing management in Europe. As well, marketing and international business aspects of the trading relationship between European and foreign firms are also explored conceptually as well as analytically. The unique position of the region would provide fascinating reading material for practitioners, public policy makers and academicians. The articles submitted to the journal create a forum whereby a conceptual understanding of the European markets and marketing systems be operationalized, analytical insights obtained as well as the past, the present, and the future of European marketing be highlighted.

The manuscripts submitted should report the results of cross-cultural/national and comparative studies conducted among countries of Europe. They can be based upon a single country of the region and/or industry there upon with a concerted effort to contrast the results/findings and managerial implications with those obtained by international marketing scholars/practitioners elsewhere. Both thought provoking and welldeveloped and documented conceptual/theoretical as well as empirical contributions are sought. But every manuscript must have an applied, managerial orientation.

With its 27 full and 5 associate members, $\mathrm{EU}$ is the world's largest internal market possessing nearly $\$ 12$ trillion economy. Its importance is constantly increasing. Currently, there is a vacuum in the marketing literature which needs to be filled by relating the Europe factor to the global marketing scene; emphasiz- ing on an interaction mode - that is, the horizontal dimension as well as the inter and intra trade and marketing activities in Europe. As such, Journal of Euromarketing covers the following areas of inquiry:

a) Functional areas of marketing in Europe and comparison with the practices of those in other regions.

b) The dynamics that account for the linkage of European national markets into markets of the developing world, North and Latin America, the Far East and Africa.

c) Determine the best methods available for marketing goods and services in different socio-economic, demographic, cultural, competitive, and legal-political environments of Europe at national and regional levels.

d) The method by which European marketing institutions are linked together into viable and coherent business systems.

e) The type of environmental factors prevailing in different European countries of the region which force changes in the marketing structure of the area countries and industrial sectors

f) How efficiently does the marketing system perform its universal functions in the countries of Europe and how the weaknesses of the marketing system can be overcome in the region?

g) The various stages of market and marketing system development in Europe as a working device for generalizing and, possibly, predicting likely developments in marketing in individual countries of the region.

Both thought provoking theoretical/ conceptual and insightful empirical contributions containing most current and up-to-date knowledge which offer the greatest managerial insights are considered. Articles submitted must contain practical information for the marketing practitioners, public policy makers, classroom teachers and researchers with a major emphasis on 
European marketing. The Journal tries to appeal to a larger group of readers, so the articles should be written in such a manner that those outside the field can comprehend the expertise and attitudes of those who work within it. Hence, a major criterion is that the language used should be as simple as possible without altering in any way, form, or shape the quality of the information to be communicated. Although not exhaustive, the following topics are illustrative of the subject areas to be covered in the Journal:

- Cross-National Consumer Segments in Europe

- Export behavior of European Firms

- Marketing Strategies of European Multinationals

- Marketing Implications of Strategic Alliances of European Firms

- Markets and Marketing Systems of European Countries

- Marketing Practices of Europe Companies

- Public Sector Marketing in Europe

- Comparative Marketing Systems in Europe

- Diffusion of Innovations Among European Nations

- Transfer of Marketing Technology and Reverse Technology Transfer in Europe

- Buyer-Seller Interactions and Organizational Buyer Behavior Issues in European Markets

- Business Customs and Practices Among European Countries

- Marketing Interaction/Interrelationships Between Europe and Other Trading Blocs

- European Corporate Cultures

- Legal-Political Aspects of Marketing in Europe

- Marketing Issues Pertaining to EU, EFTA, Council of Europe, European Members of OECD, and Associate Members of EU

- Marketing Research in Europe
- Communication/Promotion/Advertising Strategies of European Firms

- Other Topics Directly Related to European Marketing

The Journal is published four times a year. Papers are blind reviewed by at least two members of the Editorial Review Board. Book reviews are special case study materials based on product/service, success and/or failure of European companies in global markets and industries shall also appear as regular items in the Journal of Euromarketing.

Prospective authors are requested to attempt to restrict their submissions to approximately twenty-five double spaced pages including figures, tables, and references. Authors should submit their manuscripts electronically along with a short abstract and a one-page executive summary to either Editor-in-Chief Erdener Kaynak at ek9@comcast.net or Associate Editor Ajay K. Manrai at manraia@udel.edu. The IMDA Press style guidelines should be used in preparing manuscripts. If in doubt, prospective authors should either refer to the inside back cover of any IMDAPress journal or use The American Psychological Association style guidelines. For "Instructions for Authors" and for additional information, please contact either Editor at:

Erdener Kaynak, Ph.D.

Editor-in-Chief

Journal of Euromarketing

The IMDA Press

P.O. Box 216

Hummelstown, Pennsylvania 17036

U.S.A

Telephone: (717) 566-3054 (Journal)

(717) 948-6343

Fax: (717) 566-1191 (Journal)

(717) $948-6495$ 


\section{INSTRUCTIONS FOR AUTHORS}

Aims and Scope. The Journal of Euromarketing aims to meet the needs of academicians, practitioners, and public policymakers in the discussion of marketing issues pertaining to Europe. It helps to increase our understanding of the strategic planning aspects of marketing in Europe and the marketing aspects of the trading relationship between European and foreign firms. Today's Europe is going to play an increasingly more important role in the global economy, so the unique position of the region is certain to provide fascinating reading material. The Journal of Euromarketing fosters a conceptual understanding of the European markets and marketing systems, provides analytical insights, and highlights the past, present, and future of European marketing.

Manuscript Submissions. Authors strongly encouraged to submit manuscripts electronically. If submitting a disk, it should be prepared using MS Word or WordPerfect and should be clearly labeled with the authors' names, file name, and software program. Manuscripts should be submitted in triplicate to Dr. Erdener Kaynak, Editor, Journal of Euromarketing, School of Business Administration, Pennsylvania State University at Harrisburg, 777 West Harrisburg Pike, Middletown, PA 17057 or by e-mail at k9x@psu.edu

Each manuscript must be accompanied by a statement that it has not been published elsewhere and that it has not been submitted simultaneously for publication elsewhere. Authors are responsible for obtaining permission to reproduce copyrighted material from other sources and are required to sign an agreement for the transfer of copyright to the publisher. All accepted manuscripts, artwork, and photographs become the property of the publisher.

All parts of the manuscript should be typewritten, double-spaced, with margins of at least one inch on the all sides. Number manuscript pages consecutively throughout the paper. Authors should also supply a shortened version of the title suitable for the running head, not exceeding 50 character spaces. Each article should be summarized in an abstract of not more than 100 words. Avoid abbreviations, diagrams, and reference to the text in the abstract.

References. References, citations, and general style of manuscripts should be prepared accordance with the APA Publication Manual, $4^{\text {th }}$ ed. Cite in the text by author and date (ex: Smith, 1983) and include an alphabetical list at the end of the article. Examples: Journal: Tsai, M. \& Wagner, N. N. (1978). Therapy groups for women sexually molested as children. Archives of Sexual Behavior, 7(6), 417-427. Book: Millman, M. (1980). Such a pretty face. New York: W. W. Norton. Contribution to a Book: Hartley, J. T., \& Walsh, D. A. (1980). Contemporary issues in adult development of learning. In L. W. Poon (Ed.), Ageing in the 1980s (pp. 239-252). Washington, DC: American Psychological Association.

Illustrations. Illustrations submitted (line drawings, halftones, photos, photomicrographs, etc.) should be clean originals or digital files. Digital files are recommended for highest quality reproduction and should follow these guidelines: 300dpi or higher; sized to fit on journal page; EPS, TIFF, PSD format only; and submitted as separate files, not embedded in text files.

Color Illustrations. Color illustrations will be considered for publication; however the author will be required to bear the full cost involved in color art reproduction. Color art can be purchased for online only reproduction or for print + online reproduction. Color reprints can only be ordered if print + online reproduction costs are paid. Rates for color art reproduction are: Online Only Reproduction: \$225 for the first page of color; \$100 per page for the next three pages of color. A maximum charge of $\$ 525$ applies. Print + Online Reproduction: $\$ 900$ for the first page of color; $\$ 450$ per page for the next three pages of color. A custom quote will be provided for articles with more than four pages of color.

Tables and Figures. Tables and figures (illustrations) should not be embedded in the text, but should be included as separated sheets or files. A short descriptive title should appear above each table with a clear legend and any footnotes suitably identified below. All units must be included. Figures should be completely labeled, taking into account necessary size reduction. Captions should be typed, double-spaced, on a separate sheet.

Proofs. Page proofs are sent to the designated author using IMDA Press's Article Tracking System (ATS). They must be carefully checked and returned within 48 hours of receipt.

Reprints and Issues. Reprints of individual articles are available for order at the time authors review page proofs. A discount on reprint is available to authors who order before print publication. Each corresponding author will receive 3 complete issues in which the article publishes and a complimentary PDF. The file is for personal use only and may not be copied and disseminated in any form without prior written permission from IMDA Press. 